\title{
Estudios dialectales sobre la provincia de Zamora (1879-1995)
}

\section{INTRODUCCIÓN}

La provincia de Zamora está constituida por comarcas pertenecientes al antiguo Reino de León que, como consecuencia de su peculiar situación geográfica, presentan influencias culturales diversas de las regiones limítrofes: Galicia y Portugal, en el caso de las occidentales, Castilla, en el de las orientales. Esta particularidad origina una rica diversidad etnográfica y dialectal que ha atraído, desde siempre, la atención de numerosos investigadores, cuyos trabajos, realizados en diversas épocas, con diferentes metodolologías y con propósitos científicos igualmente distintos, nos ofrecen una visión global, si bien no exhaustiva, de la diversidad antes apuntada.

Un rasgo en común que poseen todos esos trabajos es su dispersión. Se trata de estudios numerosos y que han sido publicados hace ya muchos años, en diversos lugares -incluso fuera de nuestras fronteras-, en revistas muy especializadas, algunas de acceso restringido, o sabemos de su existencia por citas y referencias, pero se encuentran inéditos. Por ello, no resulta fácil su consulta, de manera que, aunque se han llevado a cabo descripciones de la diversidad etnográfica y dialectal de nuestra provincia, su dispersión nos impide disponer de la información de conjunto que todos estos estudios nos proporcionan ${ }^{1}$.

El Proyecto de Investigación de que este trabajo forma parte tiene dos objetivos fundamentales: por un lado, describir la actividad dialectológica desplegada en nuestra provincia a lo largo de este siglo, y por otro, proporcionar una visión de conjunto de la diversidad dialectal de sus hablas actuales mediante la elaboración de una Enciclopedia Dialectal de Zamora a partir de los materiales lingüísticos allegados por estos trabajos. Exclui-

1 Persuadidos de la necesidad e interés de recopilar tanto las investigaciones realizadas, como sus valiosos resultados, solicitamos del Instituto de Estudios Zamoranos "Florián de Ocampo", dependiente de la Diputación de Zamora, en la X Convocatoria de Becas de Investigación, 1995, una ayuda económica para la realización de esta tarea, la cual, una vez concedida, nos ha permitido iniciar ya las primeras labores y lograr los primeros resultados. Dejo constancia aquí de mi gratitud por su concesión. 
mos, por tanto, de nuestra investigación todos aquellos estudios lingüísticos sobre la provincia de Zamora realizados con criterios históricos y tomando como base documentos escritos, y nos centramos en cuantos trabajos han sido llevados a cabo a partir de la observación del habla viva, desde fines del siglo pasado hasta nuestros días (la más antigua de las investigaciones consultadas es de 1879, y la más reciente de 1995). Secundariamente, y como complemento a las obras dialectales, también tenemos en cuenta estudios etnográficos que incluyen descripciones léxicas, sumamente interesantes para nuestros propósitos, y que, en ocasiones, permiten llenar, además, lagunas correspondientes a algunas áreas poco estudiadas desde el punto de vista dialectológico. Por otro lado hay que decir también que no sólo tenemos en cuenta investigaciones específicas sobre las hablas de Zamora, sino también otras generales, o de ámbito más amplio, que contienen observaciones sobre la diversidad dialectal de nuestra provincia.

El propósito de este artículo es dar a conocer parte del trabajo ya realizado, que tiene que ver, en concreto, con el primero de los dos objetivos antes mencionados (describir la actividad dialectológica desplegada en nuestra provincia a lo largo de este siglo). En el momento actual se ha terminado ya la búsqueda bibliográfica y se ha confeccionado, igualmente, el correspondiente fichero (que tenemos en soporte informático), para cuya elaboración hemos recurrido a los fondos bibliográficos de varias bibliotecas ${ }^{2}$, a la pequeña colección de obras sobre las hablas de Zamora que nosotros mismos hemos podido ir reuniendo a lo largo de más de diez años de investigaciones en este campo, y a la adquisición, gracias a la ayuda económica concedida, de diversos trabajos de reciente publicación, aún no descatalogados. También hemos conseguido varios trabajos inéditos, gracias a la amabilidad y buena disposición de sus autores ${ }^{3}$, cuyos materiales enriquecen de manera notable nuestro fichero. Pues bien, vamos a analizar aquí, a partir de la explicación de los objetivos, métodos, contenidos y resultados de estos estudios, cuál ha sido la evolución de la investigación dialectológica en nuestra provincia a lo largo de este período, lo que hacemos con un propósito funda-

2 Biblioteca Municipal de Zamora, Biblioteca de la Facultad de Filología de la Universidad de Salamanca y Biblioteca Pública e Arquivo Distrital de Bragança (mi agradecimiento al Sr. Belarmino Afonso, su director, por su inestimable ayuda).

3 Quiero manifestar aquí mi gratitud a todos ellos, y muy especialmente a nuestro maestro el profesor D. Antonio Llorente Maldonado de Guevara, que nos ha permitido consultar las encuestas inéditas por él realizadas para el Atlas Lingüístico de España y Portugal, el trabajo de conjunto más importante llevado a cabo hasta la fecha sobre las hablas de Zamora. 
mentalmente explicativo y no crítico, aunque sí incluiremos al final del trabajo una valoración prospectiva en la que, tomando como base la descripción efectuada, intentaremos señalar cuáles han de ser las líneas futuras de actuación que a nuestro juicio ha de seguir la investigación dialectal sobre la provincia de Zamora.

\section{PERÍODOS EN LA EVOLUCIÓN DE LA INVESTIGACIÓN DIALECTAL SOBRE LAS

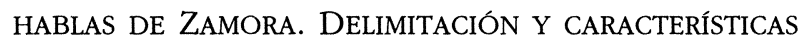

La investigación dialectal sobre las hablas de Zamora realizada a lo largo de los últimos cien años ha seguido la misma trayectoria y evolución que, como parece lógico suponer, ha seguido la investigación dialectal española en su conjunto en el mismo período de tiempo. Así, si esta última ha pasado por una etapa, a finales del siglo pasado y principios de éste, de adopción y aclimatación de los conceptos y métodos de la filología europea a nuestra realidad, también las primeras manifestaciones de aquélla son trabajos en los que se realiza la asimilación de ideas procedentes de fuera y en los que se ponen en práctica métodos aprendidos allende nuestras fronteras. Igualmente, si la investigación lingüística española sufre, después de la Guerra Civil (1936-1939), la pérdida de la labor magisterial y de coordinación de actividades que Pidal ejercía con anterioridad, y se produce la diáspora de investigadores muy activos antes de ella, lo que da lugar a una recesión en las investigaciones y a que las que se llevan a cabo sean fruto de esfuerzos individuales, más que de trabajos de grupo o escuela, también disminuyen los estudios dialectales sobre las hablas de Zamora en este período, y los que se realizan deben atribuirse, de manera similar, a algunas individualidades. Por último, si a partir de los años 60 resurge en nuestro país el interés por la cultura tradicional y por las hablas populares, y tiene lugar una profunda renovación de la dialectología tradicional, mediante la incorporación, sobre todo, del nuevo enfoque sociolingüístico, también aumentan en esta época, en consonancia con el ambiente general, los estudios dialectales sobre las hablas zamoranas, algunos de los cuales se realizan siguiendo los postulados y métodos de la incipiente sociolingüística.

Puede hablarse así, pues, de tres períodos en la evolución de la investigación dialectal sobre las hablas de la provincia de Zamora desde finales del siglo XIx y a lo largo del Xx: un primer período, que abarcaría el último cuarto del siglo xIx y el primer tercio del siglo xx (1879-1936); un segundo período, que comprendería aproximadamente el segundo tercio del siglo xx (1936-1973); y un tercer período, formado por el último tercio del siglo xx (1973-1995). 
Corresponde al primer período (1879-1936) la aparición de los primeros trabajos sobre las hablas de Zamora, obra de eruditos locales, y de los primeros estudios propiamente filológicos, que vienen firmados, además, por autores de gran talla, como es el caso de Leite de Vasconcellos (desde Portugal), que realizó varias investigaciones sobre las hablas de Hermisende y Riodonor, Menéndez Pidal y sus discípulos (Navarro Tomás, Américo Castro y otros), que llevan a cabo diversas encuestas en nuestra provincia, y Fritz Krüger, pionero en la aplicación y desarrollo del método "palabras y cosas", que encuentra en las hablas de Sanabria un apropiado campo de experimentación y trabajo.

El segundo período (1936-1973) es el momento de los esfuerzos individuales de Luis Cortés Vázquez, con sus estudios sobre las hablas sanabresas, y del más ocasional, aunque no por ello menos valioso, de José María Baz y su interesante monografía sobre las hablas alistanas. También se dan en este momento, a pesar de haberse perdido el sentido de escuela y grupo, tan fecundo en muchos aspectos, que Menéndez Pidal había creado en la etapa anterior, loables intentos de continuación de la tarea de exploración y descripción de las hablas leonesas emprendida por el gran maestro de la filología española, intentos que, con referencia a las hablas de Zamora, están representados por diversos trabajos de D. Catalán, A. Galmés y Germán de Granda (trabajos genéricos sobre las hablas leonesas) y de Rodrigo López (sobre las hablas de Aliste y algunas comarcas limítrofes). Por su parte, Fritz Krüger, que vive ahora en Mendoza (Argentina), muy alejado, por tanto, de las tierras sanabresas cuyas hablas habían sido su objeto de estudio, ofrece, en un intento de continuación de la labor iniciada en el período anterior, una serie de trabajos fonéticos, morfológicos y léxicos basados en los datos recogidos en su visita a Sanabria a principios de los años 20, interesantes también, pero que resultan de muy limitado alcance si los comparamos, sobre todo, con los publicados en la etapa precedente. En Portugal, en cambio, el sentido de escuela que en España se ha perdido es mantenido por un investigador, Paiva Boléo, formado en Hamburgo con el profesor Krüger, que ejerce su magisterio desde la Universidad de Coimbra, donde trabajan investigadores interesados en el estudio de las hablas tramontanas del Nordeste portugués y de las zamoranas limítrofes con esta área (M. J. de Moura Santos, sobre todo, y, en menor medida, J. Herculano de Carvalho). Además, trabajos de eruditos locales y otros diferentes tipos de estudios que describiremos más adelante completan, finalmente, el mosaico de investigaciones sobre las hablas de Zamora de este momento (1936-1973).

El tercer período (1973-1995) se caracteriza, como hemos apuntado, por la aparición de un renovado interés por las tradiciones y la cultura 
popular, en general, y por las hablas vivas, en particular, que se traduce, por lo que a nosotros se refiere, en la realización de un importante número de trabajos dialectales sobre nuestra provincia. Estos estudios se ocupan de las hablas de las distintas comarcas zamoranas (también de las orientales, no sólo de las occidentales, las más arcaizantes o conservadoras), y se llevan a cabo desde perspectivas teóricas diferentes y con distintos enfoques metodológicos. Conviene señalar aquí que este auge en los estudios dialectales se produce de manera simultánea a la progresiva desaparición, como consecuencia de las transformaciones sociales que, de manera similar al resto de España, tienen lugar en los pueblos de nuestra provincia, de aquellos factores que favorecen la conservación de las peculiaridades dialectales (aislamiento, analfabetismo, pervivencia de formas de vida tradicionales, etc.). Se origina así una situación paradójica y hasta cierto punto desazonadora para el investigador, en la medida que justo cuando el interés por estudiar los dialectos es mayor y cuando se dispone de mayores medios y facilidades para ello, decrece la peculiaridad de nuestras hablas como resultado de un cada vez más acusado proceso de estandarización. Este hecho influirá, por otro lado, de forma decisiva en el cambio de perspectiva teórica y en la renovación metodológica (enfoque sociolingüístico) que los estudios dialectales experimentarán en este momento.

En relación con este período (1973-1995) hay que destacar también cierta labor de coordinación ejercida por las universidades de Salamanca y Valladolid en el conjunto de estudios dialectales sobre Zamora llevados a cabo en esta etapa como tesinas o tesis doctorales. Ello no significa, no obstante, que en estas universidades se hayan elaborado programas previos de investigación de las hablas de nuestra provincia. Especialmente destacada es, en este sentido, la labor del profesor Llorente Maldonado de Guevara, Catedrático - hoy emérito- de Lengua Española de la Universidad de Salamanca, quien es responsable de gran parte de la investigación dialectal sobre la provincia de Zamora efectuada en este período, y no sólo como director de las tesis y tesinas de sus alumnos, sino también como autor de las encuestas de Zamora para el Atlas Lingüistico de España y Portugal y de diversos estudios elaborados por él a partir de los materiales recogidos en estas encuestas ${ }^{4}$. Dentro de este conjunto de apoyos institucionales a la investigación dialectal sobre las hablas de Zamora hay que mencionar también la interesante labor de mecenazgo efectuada por el Instituto de Estudios Zamoranos "Florián de Ocampo", dependiente de la Diputación de Zamora, bien por medio de su progra-

\footnotetext{
4 De la descripción de todos estos estudios nos ocuparemos más adelante.
} 
ma anual de becas a tesis doctorales y a proyectos de investigación, bien a través de la publicación - ya como libros, ya como artículos en su Anuario- de estudios dialectales realizados con o sin el patrocinio de esta institución.

A modo de resumen de la actividad dialectológica llevada a cabo sobre la provincia de Zamora en este período (1973-1995), podemos decir, finalmente, que las principales líneas de investigación seguidas son tres: (I) trabajos que continúan el enfoque teórico y metodológico tradicional, (II) atlas lingüísticos y diversos trabajos de geografía lingüística y (III) estudios de carácter sociolingüístico. Junto a éstos encontramos también las aportaciones de diversos autores locales, de estudiosos del folclore y de las tradiciones populares, y de otros investigadores que especificaremos más adelante. También hay que reseñar la inexistencia en esta época - hasta donde nosotros sabemos - de estudios sobre las hablas de Zamora realizados por autores portugueses, hecho que sorprende, dada la calidad de los trabajos de los dos períodos anteriores.

\section{PRIMER PERÍODO: FINALES DEL SIGLO XIX Y PRIMER TERCIO DEL SIGLO XX} (1879-1936)

\section{Primeros trabajos de estudiosos locales}

La publicación más antigua sobre las hablas de Zamora que conocemos es una breve relación de vocablos, cuyo autor es el historiador local Cesáreo Fernández Duro, y que lleva por título "Locuciones zamoranas" 5 . La revista en que aparece esta lista de palabras y expresiones, El Averiguador Universal, es una curiosa publicación del último cuarto del siglo XIX, estructurada en forma de preguntas y respuestas, en la que unos lectores formulan preguntas y otros lectores responden. De estas «locuciones" dice Fernández Duro que son palabras y expresiones que no figuran en el Diccionario de la Lengua Castellana, y se pregunta si son o no exclusivas de la provincia de Zamora. Obtiene respuesta de Fernando Belmonte, en artículo igualmente titulado "Locuciones zamoranas" ${ }^{6}$, quien señala la aparición en distintos lugares (Galicia, Andalucía y Asturias, en el ámbito occidental, por tanto) de aquellas formas. Todas las palabras y expresiones que Fernández Duro recoge en aquella relación las incluirá más tarde en las "Locuciones zamoranas" que figuran en sus

5 El Averiguador Universal, Año I, núm. 7 (1879), pp. 89-90.

6 El Averiguador Universal, Año I, núm. 7 (1879), p. 308. 
Memorias históricas de la ciudad de Zamora, su provincia y obispado ${ }^{7}$, trabajo muy citado en los estudios dialectales posteriores, y que ha servido, además, como fuente para la descripción de las hablas zamoranas en manuales de dialectología y en diversos estudios de conjunto sobre el dialecto leonés. A las incluidas en la relación de El Averiguador Universal añade ahora el historiador zamorano una serie de palabras cotidianas que "sorprenden al forastero" y que "desaparecerán al cabo" (p. 468), cuya selección responde, por tanto, a los principios de "rareza" y "desuso". Fernández Duro ofrece generalmente estos vocablos y expresiones sin localizar, y sólo de unos pocos nos dice que son específicos de Sanabria, Aliste o Sayago, o de alguna localidad, como Castrogonzalo (comarca de Los Valles).

Dentro del conjunto de primeros estudios sobre las hablas de Zamora salidos de la mano de eruditos locales hay que mencionar también una serie de Artículos cuyo autor es Ursicino Álvarez Martínez, vinculado a Fernández Duro. Se trata de diversos trabajos de carácter costumbrista y de interés lingüístico-etnográfico, sobre diferentes aspectos de la vida cotidiana en Zamora y su provincia (vendimia, matanza, Navidad, etc.), que aparecieron en la Zamora Ilustrada ${ }^{8}$, una Revista Literaria Semanal, editada en Zamora durante los años 1881 y 1882, bajo la dirección del mencionado Ursicino Álvarez Martínez. Con el título genérico de Artículos hacemos referencia aquí a algunos de esos trabajos, concretamente, a los que resultan más interesantes desde el punto de vista dialectal, y que son: "El bendito Cristo de Morales" (núm. 10), "Blas y Menga" (núm. 15), "La vendimia" (núm. 33), "La matanza" (núm. 40) y "La Navidad en Zamora" (núm. 42). Estos cinco artículos parecen haber sido elaborados más con un propósito lingüístico que etnográfico, de manera que lo que al autor parece realmente interesarle es reunir y dar a conocer una serie de vocablos y expresiones relacionados con una fiesta, costumbre o actividad tradicional determinada, más que describir la fiesta, costumbre o tradición en cuestión. Aunque Álvarez Martínez ofrece normalmente el vocabulario que recoge sin localizar, en algunos casos deja entrever su mayor relación con algunas áreas de la provincia, concretamente, con Tierra del Pan, Tierra del Vino, Sayago y con Zamora ciudad.

7 Madrid, 1882-1883, t. 4, pp. 468-476.

8 Existe edición facsímil a cargo de la Diputación de Zamora (Zamora, Tomo I [núm.s 1-28], Tomo II [núms. 29-50], 1988 [2.]]). 
Estudios desde Portugal. Leite de Vasconcellos, pionero en la investigación filológica de las hablas de Zamora

El primer trabajo en que un filólogo - no un estudioso local- se ocupa de un habla de Zamora no viene firmado por un autor español, sino portugués. Se trata de una circunstancia lógica, sin duda, si consideramos que Portugal se adelantó a España en la incorporación de las nuevas ideas dominantes entonces en Europa en lingüística románica ${ }^{9}$, y si tenemos en cuenta que las estrechas relaciones culturales existentes entre las comarcas fronterizas de Sayago, Aliste y Sanabria (España), por un lado, y Trás-os-Montes (Portugal), por otro, han atraído, desde siempre, el interés por esta zona de los investigadores portugueses. El autor de este trabajo es el gran maestro de la filología portuguesa J. Leite de Vasconcellos, y su título, "Linguas raianas de Trás-os-Montes" ${ }^{10}$. En este artículo se ocupa Leite del habla del pueblo sanabrés, fronterizo, de Riodonor (tanto en su parte portuguesa, como española), de la que nos ofrece unas sucintas notas (fonético-históricas y morfológicas), elaboradas a partir de los datos recogidos en un viaje que realizó en 1884. Estos datos ponen de manifiesto, en opinión del autor, la filiación lingüistica leonesa, no portuguesa, del habla de Riodonor. Leite señala también la existencia de algunas diferencias entre la parte española y la portuguesa, como la presencia, por ejemplo, en la primera del sonido interdental, fricativo, sordo, $[\theta]$, que dice no haber encontrado en la segunda.

Del pueblo de Riodonor volvió a ocuparse Leite en varias ocasiones más. Así, en Estudos de philologia mirandesa, I y II ${ }^{11}$, compara ${ }^{12}$ su habla, y también las de Hermisende y Castromil, con otras próximas (mirandés, portugués y gallego), a fin de averiguar las correspondientes diferencias y semejanzas entre ellas. Leite señala el carácter leonés del habla de Riodonor, el portugués de la de Hermisende y el gallego de la de Castromil. Los materiales que aparecen en este trabajo proceden, en el caso de Hermisende y Riodonor, del mencionado viaje de 1884. En cuanto a los de Castromil, dice Leite que nunca estuvo allí, pero que

9 Cfr. Diego Catalán, Lingüistica Íbero-románica (Madrid: Gredos, 1974), pp. 19-21.

10 Revista de Guimarães, III (1886), pp. 61 y ss. Aparece incluido también en J. Leite DE Vasconcellos, Opúsculos t. IV, Filología, II (Coimbra, 1929/1938), pp. $723-738$.

11 Lisboa: Imprensa Nacional, 1900/1901.

12 Tomo II, pp. 55-58. 
conoció en Trás-os-Montes a gentes de este pueblo. Más tarde, en Esquisse d'une dialectologie portugaise ${ }^{13}$, encontramos de nuevo, dentro de un trabajo más amplio, notas morfológicas y de fonética histórica sobre Riodonor, basadas igualmente en los materiales que recolectó en su visita de 1884. La información que ofrece aquí es prácticamente la misma que publicó en "Linguas raianas de Trás-os-Montes", con algún dato añadido. Como en los otros trabajos, Leite la considera también un habla leonesa. Posteriormente, esta localidad vuelve a ser motivo de su interés en una nota, "Noticia do idioma de Rio de Onor", incluida en Lições de Filologia ${ }^{14}$. En ella comenta y describe el opúsculo de Daniel Rodrigues, "O Rio d'Onorense" ${ }^{15}$, al que elogia, por un lado, por tratarse de uno de los pocos estudios realizados hasta entonces sobre esta habla, y al que censura, por otro, por ser, fundamentalmente, una colección de textos portugueses "da nossa lingua culta" traducidos al riodonorés. Además de la recensión de este estudio, ofrece Leite unas cuantas notas sobre el habla de Riodonor, basadas, al igual que ocurre en los trabajos anteriores, en sus observaciones de 1884 , a las que añade ahora, no obstante, unas informaciones obtenidas en Braganza, en 1902, a partir de entrevistas a personas procedentes de esta población. Con todo, el trabajo más importante de este investigador portugués sobre el habla riodonorés se encuentra en su "Breve estudo dos falares de Riodonor e Guadramil" ${ }^{16}$, en el que por primera vez se nos ofrece una descripción amplia y completa, y no, como en las otras publicaciones, unas sucintas notas fonéticas y morfológicas. En esta ocasión, además, los materiales en que se basa el estudio no son sólo los recogidos en 1884 - ya usados en los trabajos citados-, sino otras informaciones obtenidas en Braganza, en 1915, a partir de entrevistas a hablantes que proceden de esta población. Dice Leite que en 1902, por el mismo procedimiento y en la misma ciudad, recogió también otros materiales que, por desgracia, se le han perdido, aunque, afirma, no aportaban nada nuevo a los otros que sí obraban en su poder. Estos materiales de 1902 fueron utilizados, no obstante, según él mismo indica y tal como acabamos de decir, para elaborar la breve nota titulada "Noticia do idioma de Rio de Onor". La descripción que figura en "Breve estudo dos falares de Riodonor e Guadramil" presenta varias partes: (I) fonología, descripción fonético-his-

\footnotetext{
13 París: Aillaud \& Cie., 1901, pp. 198-199.

14 Lisboa, $1926\left(2^{\mathrm{a}}\right)$, pp. 453-454, posteriormente reeditada en Río de Janeiro, 1959 $\left(3 .{ }^{2}\right)$, pp. 417-418.

15 O Instituto, LV (190).

16 Opúsculos t. IV, Filología, II (Coimbra, 1929/1938), pp. 739-790.
} 
tórica que constituye la parte más amplia del trabajo, muy abundante en aspectos estudiados y en materiales aportados; (II) morfología; sendas secciones dedicadas a (III) las partículas y a (IV) la sintaxis, ambas muy breves; (V) varios textos (el padrenuestro, el avemaría y un relato anecdótico); y (VI) un vocabulario. Al final compara Leite las hablas de Riodonor y Guadramil, que también describe en este artículo, y destaca la común filiación leonesa de ambas y las numerosas coincidencias y semejanzas que se dan entre ellas.

Leite se interesó también, además de por el habla de Riodonor, por las de otros lugares fronterizos, ya mencionados, Hermisende y Castromil. De ambas trata, como ya hemos dicho, en Estudos de philologia mirandesa, obra en la que señala el carácter portugués de la de Hermisende y el gallego de la de Castromil. La modalidad dialectal de aquella localidad fue objeto de otro estudio posterior, de mayor alcance, titulado "Linguagem de Ermisende" ${ }^{17}$. En él encontramos dos cuentos populares, una descripción fonético-histórica, unas observaciones morfológicas, unas notas sobre sintaxis y un repertorio léxico. Toda esta información se basa también, como en el caso de estudios anteriores, en los datos recogidos en 1884. Leite vuelve a afirmar aquí que el habla de Hermisende es una variedad del portugués tramontano, teñida, eso sí, de formas castellanas, como parece lógico en una población situada en territorio español. Finalmente, el último trabajo de que tenemos noticia en que Leite volvió a referirse a estas hablas sanabresas fronterizas, pero sólo de pasada y sin hacer una descripción lingüística pormenorizada, es "Linguagens fronteiriças" ${ }^{18}$.

Antes de concluir este apartado dedicado a los trabajos dialectales sobre Zamora realizados desde Portugal, hay que mencionar el estudio ya citado más arriba de Daniel José Rodrigues, "O Riodonorense (Dialecto Transmontano)" ${ }^{19}$. Contiene este artículo una descripción genérica del habla de Riodonor que no se detiene a enumerar sus rasgos fónicos y morfosintácticos y sus elementos léxicos más interesantes, sino que se conforma con señalar algunas generalidades sobre su vitalidad, filiación dialectal (que erróneamente considera portuguesa y no leonesa), etc., a la que sigue una serie de textos en riodonorés - representados de manera bas-

17 Revista Lusitana, VII (1902), después reproducido en "Linguagens fronteiriças de Hespanha e Portugal", Opúsculos t. IV, Filología, II (Coimbra, 1929/1938), pp. 593-619, por donde lo citamos.

18 Revista Lusitana, XXXIII (1935), pp. 307-309.

19 Publicado por primera vez en O Instituto, LV (1909), pp. 559-576, ha llegado hasta nuestro conocimiento en una reedición posterior, O Riodonorense. Lendas. Folclore (Ediçao da Assembleia Distrital de Bragança, 1981), pp. 11-31. 
tante confusa e imperfecta mediante la ortografía portuguesa - seguidos de su correspondiente versión en portugués. Además, no se nos dice cómo han sido recogidos estos textos y no sabemos, por tanto, si han sido tomados directamente de relatos orales de uno o varios informantes, si son, como afirma J. Leite de Vasconcellos — citado más arriba- textos portugueses "da nossa lingua culta" traducidos al riodonorés — quizás por el autor, quizás por algún informante-, o si proceden de una reelaboración posterior de Rodrigues a partir del argumento de cuentos populares. Tales narraciones constituyen, no obstante, una muestra interesante del habla de Riodonor a principios de siglo, especialmente en lo relativo al léxico y a la morfología (pues la pronunciación sólo la reflejan parcialmente y de manera, como decimos, muy imperfecta, y en cuanto a la sintaxis, parece más "literaria" que "oral"), y en ellos se aprecia de forma clara, en contra de la opinión del autor, la filiación leonesa de esta habla fronteriza hispanoportuguesa.

\section{Menéndez Pidal y sus discípulos. Primeras excursiones dialectales por la provincia de Zamora}

La primera descripción de las hablas de Zamora realizada por un filólogo español se debe a Don Ramón Menéndez Pidal. Se encuentra en su conocido estudio El dialecto leonés ${ }^{20}$. Como es sabido, en esta obra se ocupa el ilustre maestro de la descripción de los rasgos fundamentales de las variedades dialectales asturleonesas, al tiempo que establece los límites geográficos en ese momento del viejo dialecto y de sus modalidades internas, y señala una serie de fenómenos lingüísticos que separan al leonés de las lenguas peninsulares vecinas (gallego, portugués y castellano). Menéndez Pidal elaboró esta descripción con muy escasos datos, la mayor parte indirectos. Sus afirmaciones sobre la provincia de Zamora se basan en distintos trabajos ya citados en apartados anteriores, como el vocabulario zamorano publicado por Fernández Duro ("Locuciones zamoranas" en Memorias históricas de la ciudad de Zamora, su provincia y obispado), varios estudios de Leite de Vasconcellos sobre Hermisende y Riodonor ("Linguas raianas de Trás-os-Montes" y "Linguagem de Ermisende"), y también en un repertorio de vocablos sayagueses, inédito, que le proporcionó nada más ni nada menos que el mismísimo

$20 R A B M, \mathrm{X}$ (1906) [1. [], reeditado más tarde en Oviedo: Instituto de Estudios Asturianos, $1962\left(2 .^{a}\right)$, con prólogo y notas de Carmen Bobes, y después en León: Diputación Provincial de León, $1990\left(33^{a}\right)$, reedición de la primera. 
D. Miguel de Unamuno, al que podemos considerar por este motivo el más antiguo de los recolectores "aficionados" de vocablos zamoranos de este siglo. A partir de las informaciones que encuentra en estos trabajos, señala Pidal el carácter portugués del habla de Hermisende, la presencia del leonés occidental en Sanabria y cómo el viejo dialecto se arrincona en la parte fronteriza de Sayago con Portugal y penetra hacia las tierras de Miranda. Se trata, como vemos, de una caracterización lingüística bastante exacta de la provincia de Zamora que Pidal logra a pesar, como decimos, de que sus afirmaciones se basan en un número muy exiguo de materiales.

Aparte de su propio valor en sí, uno de los mayores méritos de $E l$ dialecto leonés fue el de promover toda una serie de trabajos posteriores sobre las hablas vivas de este complejo dialectal, que dieron lugar, lógicamente, a un mayor y más profundo conocimiento de sus variedades. Precisamente, el primer continuador de la tarea emprendida por $E l$ dialecto leonés fue, como señalan D. Catalán y A. Galmés, "La diptongación en leonés" ${ }^{21}$, el propio Menéndez Pidal, con una serie de encuestas por correspondencia llevadas a cabo al año siguiente, 1907, algunas de las cuales fueron enviadas a pueblos de la provincia de Zamora, concretamente, a Sanabria (San Justo, Requejo, Santa Cruz de Abranes, Trefacio, Galende, Ungilde, Quintana, Cobreros, Pedralba de la Pradería, Robleda) y La Carballeda (Manzanal de Arriba). Los materiales recogidos por medio de esta encuesta por correspondencia han permanecido inéditos hasta la actualidad, si bien han sido consultados para algunos trabajos posteriores, como el que acabamos de citar de D. Catalán y A. Galmés.

Esa labor de investigación directa de las hablas de Zamora iniciada por Pidal fue continuada después por Agustín Blánquez Fraile, "Límites del dialecto leonés occidental en Alcañices, Puebla de Sanabria y La Bañeza" 22. Se trata de una investigación realizada a instancias de la Junta para la Ampliación de Estudios e Investigaciones Científicas, que constituye, además, una de las primeras exploraciones dialectales llevadas a cabo (1907) en la provincia de Zamora. El objetivo último de Blánquez Fraile fue establecer los límites del leonés occidental en nuestra provincia, y para ello recorrió las comarcas de Tierra de Alba, Tierra de Tábara, Aliste, Los Valles, La Carballeda y Sanabria, en los "tiempos heroicos", además, en que los desplazamientos debían hacerse, como cuenta el propio autor en descripciones no exentas de cierto regusto romántico, en diligencia, a caballo, en burro o a pie. La recolección de los materiales -fónicos, morfoló-

${ }^{21}$ Archivum, IV (1954), pp. 87-147.

22 Memoria de la Junta para la Ampliación de Estudios (Madrid, 1907), pp. 67-78. 
gicos y léxicos- se hizo de manera un tanto asistemática, pues si en unos casos dice Blánquez Fraile que se valió de la encuesta (Hermisende), en otros le bastan las observaciones hechas con algunas personas en las posadas o a la entrada de los pueblos, y en otros, los datos suministrados no proceden del conocimiento directo del habla local, sino de informes proporcionados por personajes cultos vinculados a esas localidades, como los párrocos. Los límites que señala Blánquez Fraile son, a grandes rasgos, los apuntados por Menéndez Pidal en El dialecto leonés y los mismos que se han venido repitiendo después en manuales y monografías dialectales, si bien difieren en algunos puntos concretos. Así dice, por ejemplo, que Padornelo es de habla leonesa, con influencia gallega, mientras que suele afirmarse que este lugar es, precisamente, el primer pueblo sanabrés de habla no leonesa, e, igualmente, considera que el habla de Hermisende es gallega, no portuguesa, como se afirma en otros estudios. Por el Este, los límites que señala Blánquez Fraile y los que figuran en otros trabajos posteriores presentan un grado de coincidencia todavía menor: deja fuera del ámbito leonés las comarcas de Tierra de Tábara y Los Valles. Por otro lado, el trabajo contiene también unas curiosas notas de "carácter sociolingüístico" sobre el escaso prestigio que tienen las hablas dialectales que estudia, lo que se manifiesta en el sentimiento de inferioridad lingüística que percibe en los entrevistados.

La exploración dialectal de la provincia de Zamora realizada por iniciativa de Pidal no concluyó, sin embargo, con el estudio de Blánquez Fraile, sino que poco después, en 1910 y en 1912, otros dos discípulos suyos, T. Navarro Tomás y Américo Castro, luego filólogos de gran relieve, recorrerían de nuevo las tierras de nuestra provincia. Navarro Tomás llevó a cabo su excursión en $1910^{23}$, y en su trascurso visitó localidades de las comarcas de Tierra de Alba, Aliste, La Carballeda, Sanabria Leonesa y Trás-os-Montes (Portugal). Los materiales allegados por él no fueron publicados nunca en forma de estudio sistemático independiente, pero han sido consultados por estudiosos posteriores ${ }^{24}$. En cuanto al viaje de

23 No faltan discrepancias en relación con el año en que visitó Navarro Tomás nuestra provincia. Para M. C. RODRIGo LÓPEZ, "Aspectos del dialecto leonés hablado en Aliste (Zamora)" (Trabajos sobre el Dominio Románico Leonés, I [1957], pp. 129142) y para D. CATALÁN y A. Galmés, "La diptongación en leonés" (pp. 87-147) el año es, efectivamente, 1910, mientras que Germán DE GRANDA, "Las vocales finales del dialecto leonés" y Germán DE GRANDA et alii, "Los diptongos descendentes en el dominio románico leonés" (Trabajos sobre el Dominio Románico Leonés, II (1960), pp. 27117 y 119-173, respectivamente) señalan como fecha 1912.

24 Sobre todo por M. C. RODRIGO LÓPEZ, op. cit., que es un estudio basado, fundamentalmente, en estos materiales. También se citan en D. CATALÁN y A. GalmÉs, $o p$. cit., en Germán DE GRANDA, op. cit., y en Germán DE GRANDA et alii, op. cit. 
Américo Castro, en 1912, hay que decir que por esas mismas fechas acababa de terminar su tesis doctoral sobre el leonés medieval de Zamora, Contribución al estudio del dialecto leonés de Zamora ${ }^{25}$, en la que exponía la necesidad de estudiar los restos dialectales leoneses vivos, a lo que respondía, sin duda, esta excursión dialectológica por nuestra provincia. Américo Castro completó la labor de investigación directa con una visita a pueblos de las comarcas de Sanabria, La Carballeda, Los Valles, Aliste, Tierra de Alba y Tierra de Tábara. Los materiales, fundamentalmente léxicos, allegados por Castro no fueron nunca publicados por él en forma de trabajo dialectal independiente, sino que los incluyó en su "Reseña a $F$. Hanssen, Gramática bistórica de la Lengua Castellana, Halle, Max Niemeyer, $1913{ }^{26}$ y en el artículo "Adiciones hispánicas al diccionario etimológico de W. Meyer-Lübke»" ${ }^{27}$.

Continuación de la investigación directa de las hablas de Zamora iniciada por Pidal puede considerarse también el conjunto de encuesta realizadas en nuestra provincia para el ALPI ${ }^{28}$. Como es sabido, el Atlas lingüistico de la Peninsula Ibérica, que sigue los principios establecidos por el Atlas Lingüístico de Francia (1902-1910) de J. Gilliéron, fue una iniciativa de Menéndez Pidal, cuya elaboración se confió a T. Navarro Tomás. Aunque el proyecto ya había tomado forma hacia 1923, las primeras encuestas no se llevaron a cabo hasta 1931, y los primeros datos no se publicaron, además, hasta pasados 30 años. Para su realización, Navarro Tomás contó con varios grupos de exploradores. Las encuestas de Zamora, en concreto, pertenecen a la campaña de 1931 a 1936, y los que las llevaron a término fueron Aurelio M. Espinosa (hijo) y Aníbal Otero. Cubren un total de doce puntos, si nos atenemos a las localidades oficialmente zamoranas, y trece, si incluimos también, como venimos haciendo en este trabajo, el pueblo portugués de Río de Onor, localidad inseparable, a mi juicio, de la española Rihonor de Castilla, ambas de habla vernácula leonesa. Los otros pueblos donde se realizaron encuestas fueron: Hermisende, Padornelo (Sanabria Gallegoportuguesa), San Martín de Castañeda, San Ciprián de Sanabria, Río de Onor (Sanabria Leonesa), Cubo de Benavente, Otero de Bodas (Los Valles), Mahíde, Villarino Tras la Sie-

25 Madrid, 1913, leída un año antes, en 1911.

26 RFE, I (1914), pp. 101-103 y 181-184.

27 RFE, V (1918), pp. 21-42, VI (1919), pp. 337-345. Estos materiales recolectados por Castro fueron aprovechados también por D. CATALÁN y A. GalmÉs, op. cit., por D. CATAláN, "El asturiano occidental" (RomPh, X [1956-1957], pp. 71-158) y por Germán DE GRANDA et alii, op. cit.

28 T. NAVARRo TOMÁs (director), Atlas lingüistico de la Península Ibérica (ALPI), I, Fonética, 1 (Madrid: CSIC, 1962). 
rra (Aliste), Losacio de Alba (Tierra de Alba), Fariza (Sayago Noroccidental), Villafáfila (Tierra de Campos) y El Pego (La Guareña). Como puede observarse, la red es mucho más densa en las comarcas septentrionales y occidentales de la provincia, si bien no hay ninguna localidad de La Carballeda, aunque sí algunas muy próximas, como Cubo de Benavente y Otero de Bodas, cuyos informantes, por otro lado, parecen considerarse de La Carballeda, ya que al ser preguntados por el nombre de los habitantes del lugar responden en ambos casos "carballeses". Los materiales del ALPI publicados a partir de los años 60 recogen las respuestas a unas setenta preguntas de carácter fonético, $\mathrm{y}$, por lo que a nosotros atañe, las formas pertenecientes a la provincia de Zamora así obtenidas constituyen una valiosa, aunque reducida, aportación - no sólo en el plano fónico, sino también en algunos casos en el léxico- al conocimiento de nuestra diversidad dialectal.

Por último, puede decirse también que los trabajos de Fritz Krüger -en cuanto que investigador vinculado a Pidal y a sus colaboradores, con quienes mantuvo estrechas relaciones en sus estancias en España- siguieron ampliando y completando las investigaciones directas sobre las hablas de nuestra provincia promovidas por D. Ramón, pero la mayor entidad de la obra de este gran filólogo alemán, así como sus diferencias teóricas y metodológicas con el gran maestro asturiano -especialmente en sus últimos trabajos, pues en los primeros sí que se nota la impronta de Pidal y de la Escuela de Madrid- hacen preferible considerarlo un investigador independiente y estudiarlo, en consecuencia, por separado.

\section{La obra lingüistico-etnográfica de Fritz Krüger ${ }^{29}$}

La obra lingüístico-etnográfica de Fritz Krüger sobre las hablas y la cultural material de Sanabria no es sólo el conjunto de trabajos más importante realizado sobre nuestra provincia en este período, sino también uno de los mayores llevados a cabo sobre ella en este siglo, y de los realizados en ese

29 Puede encontrarse más información acerca de los estudios sobre Zamora de Fritz Krüger en los siguientes, entre otros, trabajos: Diego CATALÁN, Lingüística Íberorománica, pp. 84-86; J. I. PÉREZ PASCUAL, "La aportación de F. Krüger a los estudios filológicos sobre Zamoran, Studia Zamorensia, 2 (1981), pp. 333-337; L. Calvo Calvo, "Fritz Krüger y los filólogos del Seminario de Lengua y Cultura Románicas de la Universidad de Hamburgo. Sus aportaciones a la etnografía peninsular", RDTP, XIVI (1991), pp. 349-361; Pedro VEGA, "La cultura popular en Sanabria. Una aportación fundamental al estudio etnográfico-lingüista", Anuario 1993 del Instituto de Estudios Zamoranos "Florían de Ocampo" (Zamora, 1995), pp. 357-368. 
momento en toda la Romania. Como señala P. Vega ${ }^{30}$, con Fritz Krüger "Por primera vez, en la historia lingüística románica, España y la Península Ibérica ${ }^{31}$ se convierten en el centro de interés de la investigación científica", de manera que Sanabria, su lengua y su cultura, fueron para él no sólo el objeto material de estudio e investigación, sino también el campo para la experimentación y desarrollo de una —entonces nueva - metodología, consagrada posteriormente con el nombre de "Wörten und Sachen", "palabras y cosas", de la que se considera a Krüger su máximo cultivador.

El interés de Krüger por España, en general, y por nuestras hablas, en particular, no debe considerarse fruto de una preferencia personal o producto de la casualidad, sino que hay que relacionarlo con la presencia en nuestro país de filólogos alemanes desde fines del siglo XIX. Así, el maestro de Krüger en la Universidad de Hamburgo, Bernard Schädel, fundador del "Kolonial-Institut" que más tarde se convertiría en el "Seminario de Lengua y Cultura Románicas" (Seminar für Romanische Sprachen und Kultur"), había contribuido anteriormente (1906), de manera notable, al inicio y desarrollo de la lingüística catalana ${ }^{32}$, y seguramente influiría en su inclinación hacia España. La atracción que los estudiosos alemanes sintieron por nuestro país, así como por otras zonas de la Europa meridional (Italia, Cerdeña, etc.), frente a lo que ocurre con los filólogos franceses y suizos, que se ocupan principalmente de sus propias áreas lingüísticas, se explica, según L. Calvo Calvo ${ }^{33}$, por el importante papel que en la elección del campo de estudio desempeñó el concepto de unbekannte, 'desconocido', que se relacionaba con las ideas de "rústico", "atrasado", etc. En el caso de F. Krüger, parece que su interés por el dialecto leonés pudo haberle surgido, según P. Vega ${ }^{34}$, al realizar una reseña sobre la obra de Santiago Alonso Garrote, El dialecto vulgar leonés hablado en Maragatería y Tierra de Astorga (1909) para la revista Bulletin de Dialectologie Romane ${ }^{35}$. Su primera exploración de nuestra provincia, dentro de una investigación más amplia del complejo dialectal leonés en su área meridional, data precisamente de ese año (primavera de 1912), fruto de la cual fue el libro Studien zur Lautgeschichte westpanischer Mundarten auf Grund von Untersuchungen an Ort un Stelle ${ }^{36}$. Se trata de una obra "valiosa en la que abundan, sin em-

30 Pedro Vega, op. cit., p. 367.

$31 \mathrm{Y}$, en particular, las hablas sanabresas, añadiríamos nosotros.

32 Cfr. L. Calvo Calvo, op. cit., p. 353, n. 16.

33 L. Calvo Calvo, op. cit., p. 354, n. 17.

34 Pedro VEGA, op. cit., p. 360.

35 Tomo IV (1912), p. 69.

36 Hamburgo: Lüchte \& Wulff, 1914, publicada anteriormente en Jabrbuch der hamburgischen Wissenschaftlichen Anstalten, Bd. XXXI, 1913. 
bargo, los datos y observaciones erróneos" ${ }^{37}$, cuya realización sirvió al ilustre dialectólogo alemán para obtener la habilitación como docente en la Facultad de Filosofía y Letras de la Universidad de Hamburgo. A pesar de su antigüedad, de su gran importancia como trabajo pionero en los estudios dialectales en España y del enorme interés que tiene para el conocimiento de las hablas occidentales, ha permanecido sin traducir hasta la fecha, lo que ha dificultado su consulta y ha ocasionado que en muchos trabajos no haya sido tenido en cuenta. En ella se propone Krüger describir la situación lingüística de una serie de hablas fronterizas con Portugal pertenecientes a la provincia de Cáceres, en su zona Norte, y a la de Zamora, en su zona Suroeste, dejando en medio, pues, sin estudiar, la provincia de Salamanca. Parece, no obstante, que en un principio su intención fue el estudio de toda esta área occidental, Salamanca incluida. En nuestra provincia se ocupa de las hablas de veinte localidades situadas en las comarcas de Sayago (la mayor parte), Tierra de Alba y Aliste. Es éste un viaje en el que no llega a estudiar, por tanto, la comarca sanabresa, que más tarde se convertirá en objetivo principal de gran parte de su obra, pero sí se da cuenta en él de la extraordinaria vitalidad de las hablas de Sanabria, lo que hará que a partir de ese momento sus investigaciones se centren casi con exclusividad en esta comarca zamorana. En esas veinte localidades entrevistó - con el auxilio de un cuestionario preparado- a otros tantos sujetos, hombres y mujeres, generalmente de edad (el más joven tiene 45 años, el más viejo, 85, si bien predominan los que tienen alrededor de 70). La investigación se preocupa fundamentalmente por los aspectos fonético-históricos de las hablas estudiadas, de manera que los materiales recogidos en cada punto suelen presentarse a continuación de la palabra latina correspondiente. Estos materiales ilustran diferentes soluciones occidentales de vocales, consonantes, grupos consonánticos, etc. Al final incluye también un capítulo dedicado a la morfología verbal.

La segunda excursión de Fritz Krüger por tierras de Zamora, en este caso ya de Sanabria, tiene lugar a principios de los años 20, concretamente en el invierno de 1921/1922. Se trata de un viaje becado por la Fundación Científica de Hamburgo, para el que cuenta también con el apoyo de Menéndez Pidal y del Centro de Estudios Históricos ${ }^{38}$. Por eso no es de extrañar que

37 Diego CATALÁN, Lingüística Íbero-románica, pp. 84-85.

38 La persona encargada de atender a Krüger a su llegada a España fue Vicente García de Diego, quien después escribiría, a la muerte del gran filólogo alemán, una nota, "Fritz Krüger (1889-1974)" (RDTP, XXX [1974], pp. 559-561), en la que pondera su obra y su persona, y destaca cómo le sorprendieron vivamente la extraordinaria firmeza y determinación con que el joven filólogo estaba dispuesto a afrontar las penurias y dificultades que entonces entrañaba un viaje por Sanabria. 
sus primeras publicaciones respondan más, como ha señalado D. Catalán ${ }^{39}$, a los gustos y preocupaciones de la Escuela de Madrid que a los intereses de la Escuela de Hamburgo. Estos trabajos fueron El dialecto de San Ciprián de Sanabria ${ }^{40}$ y el artículo "Mezcla de dialectos" ${ }^{41}$.

El dialecto de San Ciprián de Sanabria es una obra fundamental que tiene -aparte de la valía e interés en sí de su propio contenido lingüístico- una gran importancia para el desarrollo de la dialectología en nuestro país, pues se trata de la primera monografía dialectal llevada a cabo en España sobre el habla de una localidad, y de un trabajo que ha servido de modelo - tanto en su concepción, como en su método, organización y exposición de los datos recogidos- a otras investigaciones posteriores. Su objetivo fundamental es la exposición de los "rasgos característicos", especialmente fonéticos y morfológicos, y secundariamente léxicos, del habla de este pueblo sanabrés. Los datos en que se basa la investigación fueron recogidos en la visita que Krüger hizo a San Ciprián en noviembre de 1921, y los procedimientos seguidos para su obtención fueron la observación asistemática del habla local y los informes que le proporcionaron el maestro del pueblo y su padre, "que dominan perfectamente el castellano, [y] hablan al mismo tiempo con perfección a la antigua" (p. 16). Desde una perspectiva metodológica conviene señalar también que aunque la investigación se centra en el habla de San Ciprián, se ofrece, en realidad, información dialectal sobre las de gran parte de la comarca sanabresa y de sus zonas limítrofes, ya que el autor compara constantemente los datos recogidos en esta localidad con otros observados en otros puntos de la comarca. En cuanto a su contenido, encontramos en la Introducción una descripción de diferentes aspectos del pueblo (geografía, arcaísmo característico de la comarca de Sanabria, vitalidad del dialecto, etc.) y de la investigación (objetivos, metodología y bibliografía consultada), a la que siguen una parte dedicada a la exposición de los rasgos fonéticos más característicos del habla de San Ciprián, que se realiza —al igual que harán más tarde las monografías dialectales, locales o comarcales, que adoptan la metodología historicista - atendiendo a las diversas soluciones halladas para vocales, consonantes y grupos consonánticos latinos, y otra en la que estudia el autor diferentes aspectos morfológicos relacionados con los pronombres, el artículo y verbo. El trabajo se cierra con la inclusión de siete textos dialectales representados mediante transcripción fonética, y un vocabulario que, según el autor, contiene "palabras cuyo interés no es

39 Diego CATALÁN, Lingüistica Íbero-románica, p. 89, n. 225.

40 Madrid: Anejo IV de la RFE, 1923.

${ }^{41}$ En Homenaje a Menéndez Pidal (Madrid, 1925), II, pp. 121-166. • 
simplemente fonético" (p. 119), constituido, fundamentalmente, por topónimos y otros términos de interés lingüístico-etnográfico.

Por su parte, "Mezcla de dialectos" es, sin duda, uno de los artículos más interesantes y curiosos escritos por Krüger sobre las hablas de Sanabria, y no sólo por la extraordinaria riqueza de materiales que aporta y por la agudeza de las observaciones de su autor, sino también por lo sorprendente y llamativo del hecho lingüístico de que se ocupa: la "mezcla de dialectos". En efecto, Krüger estudia aquí la combinación de fenómenos, formas y tendencias dialectales que se produce en las hablas meridionales sanabresas fronterizas con Portugal, en las que se entremezclan, con diferente proporción e intensidad en cada caso, el gallego, el portugués, el leonés y el castellano. Los pueblos en que centra su atención son, concretamente, Hermisende, La Tejera, Calabor (Sanabria Gallegortuguesa), Santa Cruz de Abranes y Rionor de Castilla (Sanabria Leonesa). Con el fin de realizar las oportunas comparaciones, Krüger recoge también formas y fenómenos de otros pueblos sanabreses (Padornelo, Lubián, Castromil, San Ciprián de Sanabria, etc.), materiales que proceden, como todos los de los demás trabajos sobre Sanabria, de su viaje de 1921-1922. El artículo se compone, en cuanto a su contenido, de varias partes: una primera en que se describen el propósito del trabajo, los rasgos generales de las hablas estudiadas (occidentales, carácter conservador, etc.) y la bibliografía consultada; otra dedicada a la fonética, desde un punto de vista historicista; una tercera en que se describen los aspectos morfológicos de las hablas estudiadas; y la última, en que expone el autor sus conclusiones generales. A lo largo de todo el trabajo Krüger compara continuamente las hablas que estudia y señala la filiación dialectal de los distintos fenómenos que analiza. En sus conclusiones, pone de manifiesto el carácter esencialmente portugués del habla de Hermisende y el leonés de la de Santa Cruz de Abranes, señala que la mayor mezcla - a veces, incluso, en una misma palabra - se produce en Calabor, cuya habla es, en su opinión, fundamentalmente gallega, aunque con abundantes elementos leoneses, portugueses y castellanos, y afirma, por último, que el habla de Rionor es leonesa, teñida de portuguesismos.

El resto de trabajos sobre Sanabria realizados por Krüger en esta época se inscriben ya plenamente dentro de la metodología "palabras y cosas". Se trata de "Vocablos y cosas de Sanabria" ${ }^{42}$, de Die Gegenstandskultur Sanabrias und seiner Nachbargebeite ${ }^{43} \mathrm{y}$, como trabajo más amplio, pero

$42 \quad R F E, \mathrm{X}$ (1923), pp. 153-166.

43 Universidad de Hamburgo, 1925. Traducido por Christiane Blanck-Conrady como La cultura popular en Sanabria (Zamora: Consorcio de Fomento Musical, Instituto de Estudios Zamoranos "Florián de Ocampo" (CSIC-Diputación de Zamora, Caja España, 1991). 
que también incluye referencias a la cultura y hablas sanabresas, de Die nordwest-iberische Volkskultur ${ }^{44}$.

Con "Vocablos y cosas de Sanabria" ofrece Krüger un anticipo de lo que será Die Gegenstandskultur Sanabrias, trabajo con el que comparte tanto los materiales en los que se basa (recogidos en el invierno de 19211922), como la perspectiva metodológica con que se llevó a cabo, bien explícita, además, en el propio título. El hecho de que este trabajo se publicara en 1923, dos años antes, pues, que Die Gegenstandskultur Sanabrias, hace que se le pueda considerar el primer estudio aparecido en España de este tipo, pionero, por tanto, de un método que será después tan utilizado por otros estudios dialectales (monografías, atlas, etc.) hasta la actualidad. La aplicación del método "palabras y cosas" en ambos trabajos se realiza, además, de modo que luego resultará modélico tanto para la dialectología española, en particular, como para la lingüística románica, en general, de manera que a partir de este momento las relaciones entre filología y etnografía se van a ir estrechando, y se van a fijar, gracias, sobre todo, al impulso de Krüger, los principios teóricos y metodológicos de la que será conocida como Escuela de Hamburgo. El contenido de "Vocablos y cosas de Sanabria" es, por otro lado, muy simple. En él se limita el autor a dar cuenta de la etimología y variantes correspondientes a tres términos sanabreses, xixugueiro (donde $x=$ sonido prepalatal fricativo sordo), 'correas que sujetan el timón del arado al yugo', teriwéla, 'palo que sujeta el dental a la cama del arado' y randa, 'traviesa de madera que sirve para sujetar el rodezno en el molino de agua sanabrés'.

Die Gegenstandskultur Sanabrias es, por su parte, una de las obras capitales de Krüger, y también, por supuesto, de la lingüística románica. Se trata, igualmente, de la descripción lingüístico-etnográfico más importante realizada sobre una comarca de nuestra provincia, tanto por su amplitud y exhaustividad, como por el apropiado momento en que su autor llevó a cabo su visita a estas tierras, la cual, a pesar de su importancia, ha permanecido sin traducir casi setenta años, limitada, pues, su consulta a unos cuantos estudiosos y eruditos. Sólo gracias a la insistencia de otro estudioso de nuestra cultura tradicional y gran admirador del erudito alemán, el profesor Luis Cortés Vázquez, y al patrocinio de diversas instituciones zamoranas y de la comunidad, se ha traducido por fin, y se encuentra ya, por tanto, accesible al gran público. El estudio recoge información tanto de la comarca de Sanabria como de sus áreas limítrofes

44 Wörter und Sachen, 1927. Traducido por Emilio de Lorenzo como El léxico rural del Noroeste Ibérico (Madrid: Anejo XXXVI de la RFE, 1947). 
en Orense, León, La Carballeda y Portugal. Tiene dos partes bien diferenciadas: una primera en que se exponen las "bases económicas y espirituales" de Sanabria y de sus zonas colindantes, por tanto, las características geográficas, vías de comunicación, medios de transporte, vida económica, etc. de la región estudiada, y una segunda en que se describen, desde una perspectiva lingüístico-etnográfica, las manifestaciones de su cultura material, organizada esta descripción en diferentes apartados: casa, mobiliario, harina y panificación, ganadería y vida pastoril, agricultura, el lino y los trajes. La exposición se completa con unos buenos materiales gráficos (dibujos y fotografías) y unos bien elaborados índices (léxicos, de topónimos, etc.).

En cuanto a Die nordwest-iberische Volkskultur, se trata de una ampliación de Die Gegenstandskultur Sanabrias. Si en ésta centra Krüger su atención en Sanabria y en sus zonas limítrofes, en aquélla la amplía a una vasta zona que abarca desde Asturias al Miño y Tras-os-Montes, con el propósito de "aclarar el origen y la formación de la cultura popular ibérican. Tras un prólogo en el que se describen los objetivos, método, área de estudio, etc. de la investigación, encontramos veintidós capítulos dedicados a los diferentes elementos de la cultura material (yugo, arado, narria y carro, grada, horca, hoz, trilla y manal, pajares y almiares, graneros, cobertizos, molienda y molinos, cigoñales y norias, vinicultura, apicultura, viviendas, hogar, ajuar, balcón, tejado, tejar, hilado y tejido e indumentaria), a los que siguen unas conclusiones generales, que se completan con unas interesantes fotografías y un índice de palabras. Como ya hemos señalado, sólo una parte de la enorme cantidad de materiales que se recogen en esta obra se refieren a Zamora. Son, fundamentalmente, materiales ya recogidos en Die Gegenstandskultur Sanabrias.

A finales de los años 20, Krüger traslada su esfera de acción desde el Noroeste Peninsular hasta los altos valles pirenaicos, donde llevará a cabo muy importantes y no menos notables investigaciones. Más tarde, su exilio, a partir de 1945, en Mendoza (Argentina), supondrá "la interrupción y, de hecho, el abandono de su línea tradicional de trabajo" ${ }^{45}$. Pero seguirá publicando distintos artículos sobre Sanabria, de los que nos ocuparemos más adelante, elaborados a partir de los materiales recogidos en su visita de 1921/1922. Baste decir ahora como final de esta pequeña descripción de su obra que suscribimos íntegramente lo escrito por P. Vega ${ }^{46}$ a propósito de ella: "Gracias a Fritz Krüger el dialecto y la cultura sanabresa ocupan un lugar destacado entre los estudios de lingüística románica. Su

45 Cfr. L. Calvo Calvo, op. cit., p. 359.

46 Pedro Vega, op. cit., p. 358. 
herencia puede ser guía y estímulo para continuar la urgente tarea de recoger documentalmente lo que está a punto de desaparecern.

\section{SEGUNDO PERÍODO: SEGUNDO TERCIO DEL SIGLO XX (1936-1973)}

\section{Los trabajos lingüistico-etnográficos de Luis Cortés Vázquez}

Después de las investigaciones de Fritz Krüger en la comarca de Sanabria durante la década de los años 20 , no se realizaron, en el período inmediatamente anterior a la Guerra Civil, más estudios dialectales sobre nuestra provincia que las encuestas llevadas a cabo para el ALPI por Aurelio M. Espinosa (hijo) y Aníbal Otero, durante la campaña de 1931 a 1936. Con este trabajo se cierra, pues, una etapa en la evolución de los estudios dialectales sobre la provincia de Zamora, que dará paso, a finales de los años 40, a un nuevo período en el que otros investigadores - una veces con preocupaciones similares, y otras con preocupaciones distintasvan a ser los protagonistas. Durante unos diez años (finales de los años 30 y principios de los 40) no se registra - hasta donde nosotros sabemos- ninguna investigación sobre las hablas de Zamora, y no será hasta $1947^{47}$ cuando un joven y entusiasta filólogo llamado Luis Cortés Vázquez recoja el testigo dejado por su admirado maestro Fritz Krüger, y realice una serie de nuevas exploraciones por tierras de Sanabria. En el trascurso de este viaje ${ }^{48}$, efectuado con el apoyo económico de una beca de 500

47 Conviene aclarar, no obstante, que tres años antes, en 1944, el pueblo de Riodonor recibe la visita del ilustre antropólogo portugués Jorge Dias, quien elaborará, desde su especialidad, una extraordinaria descripción de la localidad, y recogerá también toda una serie de materiales dialectales que le permitirán confeccionar más tarde, en colaboración con J. Herculano de Carvalho, un excelente trabajo sobre el habla de este interesante pueblo hispanoluso. De este estudio nos ocuparemos por extenso más adelante.

48 Paulette Gabaudan, en su Introducción a Luis CORTÉs VÁzQuEz, Obra dispersa de etnografia (Salamanca: Centro de Cultura Tradicional-Diputación de Salamanca, Caja España, 1996), pp. XXXI-XXXIII, recrea con todo lujo de detalles las penurias de este viaje. Reproducimos por su gran interés parte de esa relación, que queremos sirva también como homenaje al esfuerzo abnegado, muchas veces ignorado y pocas reconocido, de tantos dialectólogos: "se iba con el coche de línea hasta Puebla de Sanabria, con la bici en la baca, y, a menudo también, el pasajero; y luego en bici, por los caminos pedregosos. Cuando ya no había camino sino una senda impracticable, pues a pie, con la bici a cuestas. [...]

"La pensión se buscaba en casa de los particulares. Allí, unas casuchas, mal cubiertas de pizarras, donde entraba el agua por el tejado cuando llovía, con piso de 
pesetas concedida por la Diputación de Zamora, anota costumbres, cuentos, romances, topónimos, refranes... que después serán objeto de múltiples publicaciones. Este interés por todo lo popular constituirá siempre una constante de su obra, pues el profesor de Salamanca no parece pretender en sus trabajos como único objetivo la investigación lingüística, ni tampoco con exclusividad la investigación lingüístico-etnográfica, sino que más bien parece concebir su tarea como un estudio de la cultura popular en su conjunto, y en sus múltiples y diversas manifestaciones. De ahí que encontremos entre sus escritos no sólo descripciones dialectales, sino también estudios de toponimia, recopilaciones de textos (cuentos, romances, etc.) de tradición oral, estudios sobre folclore, trabajos de interés fundamentalmente etnográfico en los que se presta gran atención a los aspectos lingüísticos, etc.

Fruto de esa primera excursión por Sanabria fueron diversas publicaciones. Entre otras, su tesis doctoral sobre toponimia, inédita, a partir de la cual elaboró tres artículos (sobre el nombre de Zamora, el de Lubián y sobre diversa toponimia menor) y también la parte dedicada a esta temá-

tierra apisonada, contenían, como únicos muebles, la cama del matrimonio y la cuna del niño más pequeño, y luego arcones para la ropa y los víveres, donde dormían, con una simple manta a guisa de colchón, el resto de la familia y el huésped. [...] comían con una única cuchara, que se pasaban en círculo, muy de prisa, por la gran costumbre que tenían. Cada uno metía la cuchara en la olla, sorbía y la pasaba a su vecino.

„El menú era poco variado. [...] sopas de ajo y huevos fritos con chorizo. Pero las sopas de ajo tenían, para un muchacho de ciudad, un pequeño inconveniente. $\mathrm{Y}$ es que las señoras, que no usaban mortero, machacaban el ajo entre sus dientes y lo escupían luego a la olla. Así que se aficionó a los huevos fritos [...]

"Aparte de las incomodidades, el viaje tenía también sus imprevistos y sus peligros. El lobo andaba suelto por la Sierra, y los muchachitos que a veces le acompañaban para enseñarle el camino, —no había señales de tráfico-, y cuyos ojos estaban bien ejercitados, se lo hacían ver por los matorrales [...]

"Y sin embargo el lobo no era el mayor peligro. En aquellas tierras retiradas y casi incomunicadas, la guerra no había terminado aún: había maquis en la Sierra. El gobernador civil, que le dio un salvoconducto había sido formal: "Puedes ir a donde quieras, menos a Pías y Barjacoba, que están del otro lado de la Sierra; el lugar no es seguro". Dócil, Luis Cortés lo prometió. Pero en una mañana alegre, que invitaba a una caminata montañera, le pareció que la ausencia de Pías y Barjacoba sería un fallo muy grave en su estudio. Y emprendió el camino. Bastante adentrado ya en la Sierra, apercibió un cuerpo tendido entre los matojos. Era un guardia civil muerto. Bajó en seguida al pueblo a señalarlo. Los guardias le dijeron: "Tiene que haber dos. Llévanos al lugar donde lo has encontrado". En efecto, había dos. Cuando volvió otra vez al pueblo con los guardias y los dos muertos, el gobernador civil, alertado, estaba llegando. Bajó del coche, fue en seguida al futuro doctorando y le pegó un par de tortas, diciendo: "Te había prohibido ir; estos muertos podían ser tú" [sic]". 
tica en su libro sobre el habla de Lubián (véase más adelante) ${ }^{49}$. Ciñéndonos al objeto de este trabajo, las publicaciones fruto de este viaje que hay que destacar son los artículos "La leyenda del Lago de Sanabria" "50, "Veinte cuentos populares sanabreses" ${ }^{51}$, "Dos textos dialectales de Rihonor y dos romances portugueses de Hermisende" 52 y el libro El dialecto galaicoportugués bablado en Lubián (Zamora). Toponimia, textos y vocabulario ${ }^{53}$, de los que nos ocuparemos a continuación.

"La leyenda del Lago de Sanabria" es uno de los primeros trabajos del profesor Cortés Vázquez sobre esta fábula popular sanabresa, y la primera vez que se ocupa de ella -en palabras suyas- "amplia y científicamente». En este trabajo pretende fijar, por un lado, el contenido de la leyenda del Lago a partir de varias versiones recogidas en los pueblos de Ribadelago, San Martín de Castañeda (Sanabria Leonesa), Chanos y Calabor (Sanabria Gallegoportuguesa) y, por otro, señalar sus antecedentes franceses. Cortés Vázquez llama la atención también sobre la más bien escasa difusión que esta leyenda ha tenido en España. El artículo lo completa un apéndice en el que figuran los textos dialectales -en transcripción fonética- recogidos por el autor en los pueblos mencionados, acompañados de abundantes notas de carácter lingüístico constituidas esencialmente por comentarios léxicos, de pronunciación o de morfosintaxis.

"Veinte cuentos populares sanabreses" es, por su parte, la primera ocasión en que el profesor Cortés Vázquez publica una colección de cuentos sanabreses, algo que después volverá a realizar —aprovechando, precisamente, en algunos casos, estos materiales, pero también otros dispersos en revistas especializadas o de difícil acceso- en diversas ocasiones. Los cuentos incluidos en esta colección fueron recogidos, en el transcurso de la ya citada excursión, en los pueblos de Ribadelago, Galende, Rihonor (Sanabria Leonesa) y en la localidades de Chanos, Lubián, Hermisende y Calabor (Sanabria Gallegoportuguesa). El artículo se estructura en varias partes: una primera en la que se exponen diversos aspectos (lingüísticos, históricos, folclóricos, etc.) sobre la comarca de Sanabria en general, así como la relación de trabajos bibliográficos consultados; una segunda sobre diversas circunstancias (entre ellas, por supuesto, las

\footnotetext{
49 Ibidem, p. XXXIII.

so RDTP, IV (1948), pp. 94-114.

$51 \quad R D T P, \mathrm{~V}$ (1949), pp. 201-270.

52 Miscelánea de filologia, Literatura e Historia cultural á memoria de Francisco Adolfo Coelho (Lisboa, 1949-1950, t. II), pp. 388-403.

53 Salamanca: Acta Salmanticensia, Universidad de Salamanca, 1954.
} 
lingüísticas) de los pueblos a que pertenecen los cuentos recogidos; una tercera en que figuran los cuentos objeto del artículo, primero representados mediante la ortografía convencional, y después mediante transcripción fonética; una cuarta donde realiza Cortés un estudio folclórico de estos cuentos; y una quinta y última parte en que se ocupa el autor de los aspectos lingüísticos, dialectales, de los textos recogidos, especialmente fonéticos, y, sobre todo, léxicos, con inclusión de un breve glosario de términos gallegos y leoneses -en transcripción fonética-, acerca de los cuales indica su significado y filiación dialectal. El artículo se completa con un apéndice de carácter etnográfico dedicado a la descripción del cortello dos lobos, 'trampa para cazar lobos', de Lubián. Tanto de este lugar, como de otros relacionados con los cuentos incluye el autor diversas fotografías y dibujos de gran valor didáctico.

Por otro lado, el propósito de Cortés Vázquez al elaborar "Dos textos dialectales de Rihonor y dos romances portugueses de Hermisende" es ofrecer sendas muestras del habla leonesa de Rihonor (Sanabria Leonesa) y del habla portuguesa de Hermisende (Sanabria Gallegoportuguesa), respectivamente, con dos cuentos ya publicados en "Veinte cuentos populares sanabreses", en el primer caso, y con dos romances inéditos hasta ese momento, en el segundo. Se trata de unos textos que el autor nos ofrece con doble representación gráfica, en transcripción fonética y mediante la ortografía convencional. La exposición presenta tres partes: una primera en la que se describen diversos aspectos (lingüísticos, históricos, etc.) de las localidades de Rihonor y Hermisende, una segunda en que figuran los textos objeto del artículo y una tercera en que realiza Cortés diversos comentarios sobre ellos. Especialmente interesantes resultan las abundantes notas que encontramos a pie de página, en las cuales analiza el autor, desde un punto de vista lingüístico, los cuentos y romances recogidos. Estos comentarios lingüísticos se refieren, sobre todo, a aspectos léxicos, si bien contienen igualmente información sobre pronunciación y morfosintaxis.

El trabajo más importante sobre Sanabria realizado por Cortés Vázquez en esta época fue, sin duda, El dialecto galaico-portugués bablado en Lubián (Zamora). Toponimia, textos y vocabulario, obra elaborada con los materiales recogidos en esa primera visita de 1947 y en varias visitas posteriores en 1953. Según indica el propio autor, se trata de un trabajo concebido como anticipo de una futura investigación sobre la totalidad de pueblos de la zona zamorana gallegoportuguesa (probablemente estaba pensando en el Atlas Lingüístico y Etnográfico de Sanabria), estudio que, sin embargo, nunca llegó a realizar. El dialecto galaico-portugués bablado en Lubián (Zamora) no es una investigación completa de un 
habla local —fónica, morfológica y léxica—, al estilo de otras monografías, sino que se ocupa, fundamentalmente, de la toponimia de este lugar y también de la de otros pueblos de la zona- y de su vocabulario. Incluye también, no obstante, una serie de notas fonéticas y morfológicas, elaboradas a partir de los textos dialectales que recoge. Es probable, aunque Cortés Vázquez nunca lo dejó escrito de manera expresa, que algunos materiales de este estudio procedan de la encuesta provisional que para el Atlas Lingüístico y Etnográfico de Sanabria realizó en Lubián. Avala esta hipótesis el hecho de que en estas encuestas Cortés pensaba aplicar un cuestionario lexicográfico para obtener vocabulario y estudiar la fonética, recoger algunos relatos para describir la morfología y la sintaxis y anotar topónimos, lo que se corresponde claramente con el subtítulo del trabajo Toponimia, textos y vocabulario. La obra se abre con una minuciosa descripción de la extensión de las variedades gallegoportuguesas en la provincia de Zamora, en la que, además de enumerar los pueblos que hablan estas variedades, se señala cómo, desde el punto de vista geográfico-histórico, no existe relación entre esta área y el resto de las tierras de Zamora, lo que explicaría su diferente filiación lingüística. El capítulo siguiente se centra ya en la localidad de Lubián -aspectos geográficos, históricos, población, economía, etc.-, para pasar después, en el tercero, al estudio de su toponimia, mayor y menor, y de la de sus alrededores. El cuarto capítulo se dedica a los textos, una serie de cuentos recogidos por Cortés Vázquez en Lubián, para cuya representación emplea el autor la transcripción fonética. A los textos siguen las notas fonéticas y morfológicas a que antes hemos hecho referencia y el vocabulario recogido, en relación con el cual se nos ofrecen también formas de otros pueblos sanabreses - Hermisende, Pías, Porto (Sanabria Gallegoportuguesa), San Martín de Castañeda (Sanabria Leonesa), Asturianos (Carballeda sanabresa)-, con el fin de realizar las correspondientes comparaciones. Los materiales de estos otros lugares es probable que procedan igualmente de las encuestas provisionales que Cortés realizó para su infelizmente nunca llevado a término Atlas Lingüístico y Etnográfico de Sanabria. La transcripción fonética sólo se emplea en este repertorio léxico en algunos casos, aquéllos en que a juicio del autor resulta necesario. Cortés Vázquez practica también una suerte de aescritura fonética" que suprime la $b$ y la distinción entre $b$ y $v$. El trabajo se completa con unas interesantísimas láminas, de carácter lingüístico-etnográfico, sobre el arado, telar, carro, lino, etc.

Como ya hemos indicado, el profesor Cortés Vázquez proyectó un malogrado Atlas Lingüístico y Etnográfico de Sanabria, de cuyas características se nos da cuenta en "Sobre el proyecto de realización del Atlas 
Lingüístico y Etnográfico de Sanabria" ${ }^{54}$. Se trata de una investigación que, como decimos, nunca llevó, por desgracia, a cabo, a pesar de tenerlo bastante perfilado, sin que sepamos bien qué razones -económicas, personales o de otra índole- le impidieron su realización. De haber sido elaborado, se trataría, sin duda, del trabajo lingüístico-etnográfico y dialectal más importante llevado a cabo sobre Sanabria, y de uno de los más interesantes realizados en España y en la Romania. Según se nos dice en "Sobre el proyecto de realización del Atlas Lingüístico $y$ Etnográfico de Sanabria,, la entidad patrocinadora del Atlas iba a ser la Universidad de Salamanca, y el objetivo último del proyecto era describir y mostrar la extraordinaria riqueza y variedad lingüísticas y etnográficas de esta región del Noroeste de Zamora. Cortés Vázquez pensaba realizar encuestas en todos los pueblos de Sanabria y también en algunos puntos de las áreas limítrofes, mediante la aplicación de un cuestionario lexicográfico (estructurado en los habituales apartados nocionales de tiempo, terreno, agricultura, animales, plantas, etc.), cuyas respuestas iban a servir también para el estudio fonético. La morfología y la sintaxis iban a ser estudiadas a partir de relatos recogidos en cada punto visitado. Igualmente, se pensaba recolectar en cada lugar la toponimia menor, y también se quería hacer fotografías y grabaciones como complemento de la investigación. En "Sobre el proyecto de realización del Atlas Lingüistico y Etnográfico de Sanabria" Cortés Vázquez ofrece diversos materiales lingüísticos (vocablos y textos) recogidos en unas encuestas provisionales llevadas a cabo en los meses de enero y febrero de 1953 en unas cuantas localidades representativas, a su juicio, de las diversas modalidades lingüísticas habladas en Sanabria. Se trata de San Martín de Castañeda (de habla leonesa), Asturianos (pueblo de habla leonesa, pero muy castellanizado, ya en La Carballeda limítrofe con Sanabria), Lubián (de habla gallega) y Hermisende (de habla portuguesa). Como ya hemos advertido en el apartado anterior, es probable, aunque Cortés no lo indicó nunca de manera expresa, que diversos materiales recogidos en $E l$ dialecto galaico-portugués hablado en Lubián pudieran proceder de las encuestas provisionales realizadas por el autor en estos puntos. Lo que sí parece seguro es que en 1954 volvió otra vez a Hermisende ${ }^{55}$ con el propósito de realizar —o completar - una encuesta que más tarde habría de convertirse en un estudio lingüístico extenso sobre el habla de esta localidad. Este nuevo estudio tampoco llegó a realizarse. Tan sólo

54 Actas y Memorias del VII Congreso Internacional de Lingüística Románica (7-10 de abril de 1953, Tomo II, Barcelona, 1955), pp. 635-645.

55 Paulette Gabaudan, op. cit., p. XLII. 
sabemos al respecto, por el testimonio de su esposa, Paulette Gabaudan ${ }^{56}$, que en 1983, llevó a cabo Cortés, en compañía del profesor José Antonio Pascual, una segunda encuesta en este pueblo sanabrés de habla portuguesa, a fin de verificar la primera. Desconozco la naturaleza de estos materiales, pues a pesar de haber realizado diversas gestiones entre personas próximas a su autor, no me ha sido posible su examen.

El resto de trabajos sobre nuestra provincia realizados por Cortés Vázquez en este período caen más dentro de la esfera de los estudios etnográficos que de los estudios propiamente lingüísticos. Conviene advertir, no obstante, que fiel al propósito misceláneo e interdisciplinar que preside su obra, Cortés no deja nunca de lado los aspectos dialectales, de manera que estos otros estudios resultan también una magnífica fuente para el conocimiento de nuestras hablas, especialmente en lo que al léxico se refiere. Destacamos "La alfarería en Pereruela (Zamora)" ${ }^{57}$, "El pisón de la Salina en Trefacio (Sanabria)" 58 y "Alfarería femenina en Moveros (Zamora)" 59 .

\section{El habla de la Tierra de Aliste de José María Baz, una monografía} comarcal

Por la misma época en que Cortés Vázquez realiza su viaje por Sanabria, y también con el propósito de elaborar una tesis doctoral, visita José María Baz la comarca de Aliste, en su parte más occidental. El resultado de esta exploración será una tesis, leída en Madrid, en 1949, pero que no se publicará, sin embargo, hasta veinte años después, con el título de El habla de la Tierra de Aliste ${ }^{60}$. Se trata del trabajo dialectal más extenso y exhaustivo realizado hasta la fecha sobre esa comarca de Aliste, cuyas hablas han merecido, no obstante, la atención de otros filólogos, pero no como trabajos monográficos comarcales, sino en forma de monografías dialectales locales, breves notas o estudios en el marco de investigaciones más amplias. Pretende, como señala el autor en la Introducción, "registrar la fuerza todavía latente del leonés en el coto de la tierra alistana" (p. 3). Su estudio no abarca, sin embargo, como hemos dicho, toda la comarca de Aliste, sino sólo la parte más occidental, la

\footnotetext{
56 Ibidem.

57 Zephyrus, V (1954), pp. 141-163.

$58 \quad R D T P$, XII (1956), pp. 419-427.

59 Zephyrus, IX (1958), pp. 95-107.

60 Madrid: Anejo LXXXII de la RFE, CSIC, 1967.
} 
situada entre Alcañices y la frontera con Portugal, a la que se le da el nombre de Rincón de Aliste. Busca Baz, sin duda, la parte de Aliste presumiblemente más arcaizante, más conservadora. La recolección de los materiales se realiza a partir de la observación asistemática de las hablas locales, aunque a juzgar por la lista de informantes que cita en las páginas 5-7, parece que el autor debió de llevar a cabo también algún tipo de encuesta. En este sentido dice Baz que la obtención de los materiales lingüísticos objeto de estudio pensaba realizarla en un principio siguiendo las normas del Atlas Lingüistico de la Península Ibérica, pero señala que esta metodología la abandonó pronto por considerarla insuficiente. Los sujetos consultados son todos viejos, como es habitual en las investigaciones de esta época, si bien parece que en su observación del habla espontánea tuvo en cuenta todo tipo de hablantes, incluso niños. El libro presenta tres partes claramente diferenciadas: una primera, en que se describen diferentes aspectos geográficos, históricos y sociales; una segunda, el grueso del trabajo, en que se realiza la exposición de los fenómenos fonéticos (con empleo de signos fonéticos cuando resulta necesario, y siguiendo la estructura de los estudios dialectales historicistas), morfológicos (con un buen estudio - comparado con otros trabajos de la época- de fenómenos morfológicos, especialmente del verbo) y sintácticos; la tercera parte es un estudio lexicográfico, de interés lingüístico-etnográfico, dedicado al arado, carro, aperos de labranza, ganadería, el lino, la casa alistana, etc. En las conclusiones, destaca Baz como hecho más relevante la presencia en el habla de Aliste de elementos leoneses, portugueses y vulgares, que conviven con "una gran fuerza lingüística, cada vez más intensa y absorbente: el castellano" (p. 111). La obra se completa con un vocabulario, un índice de palabras, dibujos de interés etnográfico y unos cuantos mapas al estilo de los atlas lingüísticos, que presentan la distribución geográfica de determinados fenómenos fonéticos o la diversidad léxica de la comarca. A lo largo del trabajo también se estudian, de manera esporádica, algunos topónimos.

\section{Continuadores de los estudios de Pidal y sus discípulos}

Aunque en este período se pierde, como hemos dicho más arriba, el espíritu de escuela creado por Menéndez Pidal en el anterior, y se produce también la diáspora de sus discípulos, no faltan, sin embargo, desde principios de los años 50, continuadores de sus estudios, que lo son tanto porque siguen y amplían la descripción de las hablas leonesas iniciada por D. Ramón, como porque realizan investigaciones basadas en materiales 
dialectales allegados por Pidal y los miembros de su escuela. Dentro de este conjunto de investigadores, debemos distinguir entre aquellos que realizan trabajos específicos sobre las hablas de Zamora, y los que se ocupan de las leonesas en general, y sólo colateralmente de las zamoranas en cuanto que pertenecientes al complejo dialectal leonés.

Al primer grupo pertenece el trabajo, ya citado, de M. C. Rodrigo López, "Aspectos del dialecto leonés hablado en Aliste (Zamora)". Se trata de una obra que tiene por objeto aestudiar las principales características del dialecto leonés hablado en la región de Aliste" (p. 131). Los materiales lingüísticos en que se basa están constituidos por los datos recogidos por el profesor Navarro Tomás en su excursión a Aliste de 1910 y por los obtenidos en una encuesta llevada cabo por la autora en 1954. Se quiere averiguar así, mediante la comparación de materiales recogidos en dos momentos distintos, qué evolución ha experimentado el dialecto entre estas dos fechas, 1910-1954, principios y mediados de nuestro siglo. Las formas lingüísticas estudiadas se ofrecen con su correspondiente localización en el pueblo donde fueron recogidas, que en su mayor parte pertenecen a la comarca de Aliste, si bien, en ocasiones, la investigación va más allá de los límites estrictamente comarcales, y penetra en Tierra de Alba (Pino), La Carballeda (Santa Cruz de los Cuérragos), Sanabria Leonesa (Riodonor) y Portugal (Quintanilla, Guadramil). La exposición adopta la estructura característica de las investigaciones que siguen la línea clásica, tradicional, de la dialectología historicista, de manera que los materiales objeto de estudio se agrupan y clasifican atendiendo al modo como en ellos se presenta la evolución de vocales, consonantes y grupos consonánticos latinos. La información lingüística proporcionada es, pues, fundamentalmente fonética (fonético-léxica en cuanto que todos los fenómenos estudiados se recogen en palabras, representadas, además, con la ortografía convencional), si bien el trabajo ofrece también, como complemento, unas notas finales sobre morfología verbal.

En el segundo grupo estarían los ya mencionados trabajos de D. Catalán y A. Galmés, "La diptongación en leonés", Germán de Granda Gutiérrez, "Las vocales finales del dialecto leonés" y Germán de Granda Gutiérrez et alii, "Los diptongos descendentes en el dominio románico leonés". Se trata de trabajos genéricos sobre las hablas leonesas que, por lo que respecta a las de Zamora, aportan pocas novedades.

En "La diptongación en leonés" se proponen los autores estudiar este fenómeno a partir de los datos recogidos hasta ese momento tanto por trabajos sobre las hablas leonesas ya publicados, como por diversas investigaciones cuyos materiales se encontraban entonces $-\mathrm{y}$ en algunos casos aún hoy- inéditos. La investigación se basa, por lo que respecta a 
la provincia de Zamora, en las publicaciones ya citadas en este artículo de A. Blánquez Fraile, "Límites del dialecto leonés occidental en Alcañices, Puebla de Sanabria y La Bañeza", de J. Leite de Vasconcellos, "Breve estudo dos falares de Riodonor e Guadramil", de A. Castro, "Reseña a F. Hanssen, Gramática bistórica de la Lengua Castellana", de Fritz Krüger, Studien zur Lautgeschichte westpanischer Mundarten auf Grund von Untersuchungen an Ort un Stelle, El dialecto de San Ciprián de Sanabria, "Mezcla de dialectos" y de Luis Cortés Vázquez, "La leyenda del Lago de Sanabria", "Veinte cuentos populares sanabreses", "Dos textos dialectales de Rihonor y dos romances portugueses de Hermisenden. También en los siguientes trabajos inéditos: las encuestas por correspondencia llevadas a cabo en distintos pueblos de Sanabria por Menéndez Pidal en 1907, los materiales recogidos por Navarro Tomás, en 1910, en las comarcas de Aliste y Sanabria, por Américo Castro, en 1912, en las comarcas de Sanabria, La Carballeda, Los Valles, Aliste, Tierra de Alba y Tierra de Tábara, y por los propios Catalán y Galmés en Sanabria, en 1949, a los que habría que añadir la tesis doctoral entonces inédita de José María Baz, El babla de la Tierra de Aliste. Los autores hacen referencia también a un informe sobre Sanabria de 1953. El estudio abarca, pues, un estado de lengua que va desde fines del siglo XIX hasta mediados del Xx. La descripción de la diptongación en el leonés actual se complementa, además, desde una perspectiva histórica, con el análisis de la toponomia y de algunos documentos medievales.

En "Las vocales finales del dialecto leonés" se propone el autor estudiar el origen, desarrollo y modalidades del vocalismo final leonés a partir de los materiales recogidos en distintas monografías publicadas hasta ese momento y a partir también de los datos inéditos recogidos por Menéndez Pidal (1910 y 1932), Rodríguez Castellanos (1932) y Martínez Burgos y Navarro Tomás (1910/1912) en diversos viajes por tierras del antiguo Reino de León. En el caso de la provincia de Zamora, utiliza como obras de consulta los siguientes trabajos: J. Leite de Vasconcellos, Estudos de philologia mirandesa, I y II, R. Menéndez Pidal, El dialecto leonés, Agustín Blánquez Fraile, "Límites del dialecto leonés occidental en Alcañices, Puebla de Sanabria y La Bañeza", Fritz Krüger, Studien zur Lautgeschichte westpanischer Mundarten auf Grund von Untersuchungen an Ort un Stelle, El dialecto de San Ciprián de Sanabria, "El perfecto de los verbos -ar en los dialectos de Sanabria y de sus zonas colindantes" ${ }^{61}$, Luis Cortés Vázquez, "La leyenda del Lago de Sanabria" y la tesis doctoral entonces inédita de José María Baz, El habla de la Tierra de Aliste. También los materiales igualmente inéditos recogidos por Navarro Tomás en 1910.

\footnotetext{
61 RFE, XXXVIII (1954), pp. 45-82.
} 
Abarca, pues, un estado de lengua que va desde fines del siglo XIX hasta mediados del $\mathrm{xx}$.

Por su parte, en "Los diptongos descendentes en el dominio románico leonés" se proponen Granda y sus colaboradores estudiar la vitalidad de los diptongos ou, ei en el viejo dialecto, tomando como corpus de análisis los materiales recogidos en diferentes trabajos - unos publicados, otros inéditos- sobre estas hablas. Los estudios utilizados para la descripción de las hablas de Zamora son prácticamente los mismos que hemos enumerado al hablar de "Las vocales finales del dialecto leonés". Tiene, no obstante, en cuenta algunos otros, como los artículos sobre Riodonor publicados por Leite de Vasconcellos en Opúsculos (véase más arriba), el de Fritz Krüger, "Mezcla de dialectos", y también unas referencias a los datos recogidos por Américo Castro en su excursión por Zamora de 1912. Como en el otro trabajo, abarca también un estado de lengua que va desde fines del siglo XIX hasta mediados del $\mathrm{xx}$.

\section{Nuevas contribuciones de F. Krüger desde Mendoza (Argentina)}

Es también a principios de los años 50 cuando Fritz Krüger reanuda sus publicaciones sobre las hablas de Zamora. Éstas habían ocupado un lugar importante en sus primeras investigaciones, pero las deja de lado, como dijimos, a finales de los años 20 , atraído por las no menos interesantes y arcaicas hablas de los altos valles pirenaicos. Cuando otra vez vuelve a fijar su atención en las hablas de nuestra provincia, Krüger vive ya en Mendoza (Argentina), su nuevo lugar de trabajo desde 1945, el que será su residencia definitiva, hasta su muerte, en 1974. Por esa razón, los estudios de esta época se basan en los materiales recogidos por el profesor de Hamburgo en sus anteriores visitas a Zamora, en 1912 y 1921/1922. Dentro de este conjunto de trabajos, debemos distinguir dos grupos bien diferenciados: por un lado, los genéricos sobre el Noroeste ibérico, en los que encontramos, como es lógico, diversas referencias a las hablas de Zamora; y por otro, los estudios específicos sobre Sanabria que Krüger publica como anticipo de su malogrado proyecto de un Atlas lingüistico comentado de Sanabria y de sus zonas colindantes, otro proyecto, pues, que, como el de Cortés Vázquez, tampoco llegó a concretarse. Pertenecen al primer grupo los artículos "Cosas y palabras del Noroeste Ibérico" ${ }^{62}$, "Contribuciones a la Geografía léxica del NO. de la Península" ${ }^{63}$ y el realizado en colaboración con W. Ebeling,

62 Nueva Revista de Filología Hispánica, IV (1950), pp. 231-253.

63 RDTP, XIII (1957), pp. 3-23. 
"La castaña en el Noroeste de la Península Ibérica" ${ }^{64}$. En el segundo grupo tenemos "El perfecto de los verbos -ar en los dialectos de Sanabria y de sus zonas colindantes" (ya citado), "Aportes a la fonética dialectal de Sanabria y de sus zonas colindantes" ${ }^{65}$ y "Los adverbios lejos y luego en perspectiva dialectal ${ }^{66}$. Se trata de una serie de trabajos realmente interesante, pero de mucho menor relieve que los realizados en el período anterior.

Los estudios sobre el Noroeste ibérico continúan la descripción lingüístico-etnográfica de esta área, iniciada en los años 20 con Die Gegenstandskultur Sanabrias y con Die nordwest-iberische Volkskultur. "Cosas y palabras del Noroeste Ibérico" centra su atención en el vocabulario relacionado con la quema del monte como sistema de cultivo y en los nombres del tronco de la berza, y se basa en los materiales recogidos en su viaje a Sanabria en el invierno de 1921-1922. En "Contribuciones a la Geografía léxica del NO. de la Península" estudia Krüger las variantes dialectales de NUDO, COTOBELO, TOBILLO y CODO, las designaciones de "hoyo", los derivados de COlOSTRUM-" COlOBRA (COlUBRA) y los derivados de MULGERE-"*MUNGERE, JUNGERE, a partir de los materiales recogidos en diferentes localidades de las comarcas de Sanabria, Aliste y Sayago, visitadas en sus viajes de 1912 (Aliste y Sayago) y 1921-1922 (Sanabria). En "La castaña en el Noroeste de la Península Ibérica" Krüger se vale de los materiales sobre la cultura material de la castaña recogidos en Lugo y Pontevedra por W. Ebeling para realizar una descripción de esta actividad tradicional, a la vez que estudia, analiza y compara el vocabulario recogido aquí con el de otras zonas próximas, y también con el que figura en otros estudios peninsulares (como los de Sanabria) y sobre diversos lugares de la Romania. Este vocabulario se organiza en torno a varios núcleos temáticos: la castaña, el castaño, el castañal; la flor, el erizo, la corteza; la formación y los defectos de la castaña; la recolección; el tratamiento de las castañas; y las castañas en la alimentación popular.

Como ya hemos dicho, con los materiales recogidos por Krüger en su viaje a tierras sanabresas en el invierno de 1921-1922, pensaba el ilustre dialectólogo elaborar un trabajo titulado Muestras de un Atlas lingüístico comentado de Sanabria y de sus zonas colindantes, proyecto que nunca realizó y que, en realidad, nunca tuvo el propósito de llevar a cabo du-

\footnotetext{
64 Anales del Instituto de Lingüística, V (1952), Universidad Nacional de Cuyo, Mendoza (Argentina), pp. 155-288.

65 RFE, XIVIII (1965), pp. 251-282.

66 Homenaje dedicado al Dr. Rodolfo Oroz (Santiago de Chile, 1967), pp. 251-282.
} 
rante su excursión a la comarca zamorana. Este hecho se nota en los vacíos que aparecen en los mapas que, como anticipo de este Atlas, incluye en los artículos de que ahora vamos a ocuparnos, lo que se debe a que no tenía información, sobre cada uno los aspectos tratados, para todos los lugares visitados, y ello a pesar de que en aquel viaje utilizó un cuestionario que iba completando sobre la marcha. No sabemos, por otro lado, si estos vacíos pudieron hacer que Krüger abandonara el proyecto definitivamente. En "El perfecto de los verbos -ar en los dialectos de Sanabria y de sus zonas colindantes" realiza el autor un "recorrido lingüístico" por Sanabria y sus áreas limítrofes, en el que nos va describiendo las distintas formas y variantes encontradas para el perfecto simple de los verbos en - ar (cuya representación se realiza, a veces, recurriendo a la transcripción fonética), a la vez que señala su filiación dialectal — gallega, portuguesa, leonesa, castellana-, delimita su área de aparición y, en ocasiones, formula hipótesis de carácter etimológico o se adentra en terrenos más propios de la gramática histórica que de la investigación dialectal. En "Aportes a la fonética dialectal de Sanabria y de sus zonas colindantes" encontramos las diferentes soluciones fonéticas (representadas mediante transcripción) que el autor registró en toda la comarca y en sus áreas limítrofes para las secuencias MI YERNO, LAS (DOS) OREJAS y LA NOCHE, en relación con las cuales estudia los distintos resultados de la evolución de vocales, consonantes y grupos consonánticos, así como determinadas particularidades morfofónicas, y la filiación dialectal de los fenómenos observados. Tres mapas lingüísticos ilustran perfectamente las diferencias y semejanzas geográfico-lingüísticas descritas en la exposición. Por último, en "Los adverbios lejos y luego en perspectiva dialectal" se ocupa el ilustre maestro alemán de las diferentes soluciones fonéticas encontradas para los adverbios LEJOS y LUEGO (representadas mediante transcripción) en las localidades de la comarca sanabresa y de sus áreas limítrofes visitadas, en relación con las cuales estudia igualmente los resultados de la evolución de las vocales, consonantes y grupos consonánticos que los forman, y la filiación dialectal de los fenómenos observados. Incluye también dos mapas lingüísticos.

\section{Nuevos estudios desde Portugal}

Si en el período anterior las hablas de Zamora merecen la atención de un gran filólogo portugués, Leite de Vasconcellos, en éste el interés de Portugal por nuestras hablas se mantiene con trabajos de autores vinculados a la Universidad de Coimbra. Se trata de Jorge Dias y J. Hercula- 
no de Carvalho, "O falar de Rio de Onor" ${ }^{67}$ y de M. J. de Moura Santos, Os falares fronteiriços de Trás-os-Montes ${ }^{68}$.

"O falar de Rio de Onor" es la investigación más extensa y completa publicada hasta la fecha sobre el habla de este pequeño pueblo sanabréstransmontano - dividido a la mitad por la frontera hispano-lusa-, de la cual ya antes se habían ocupado otros estudiosos como Leite de Vasconcellos, Krüger y Cortés Vázquez. Según indican los autores en la Introdução, este trabajo se concibe como una continuación del brillante y monumental estudio etnográfico sobre esta localidad realizado por Jorge Dias, Rio de Onor. Comunitarismo agro-pastoril ${ }^{69}$, en el que también recoge éste, por cierto, un valioso y abundante repertorio léxico constituido por aquellas formas asociadas a las actividades e instrumentos que describe. En "O falar de Rio de Onor" el recolector de los materiales es Jorge Dias - que no es filólogo, sino antropólogo-, mientras que Herculano de Carvalho es responsable de la preparación para su publicación de los materiales recogidos por aquél. El trabajo aparece estructurado en cinco partes: una primera, introductoria, en que se exponen los objetivos y contenidos del estudio; una segunda, en la que describen los autores la presión que sufre el rionorés tanto del español como del portugués, lo que da lugar a la mezcla de los tres en el habla de la localidad, y en la que enumeran también los trabajos realizados anteriormente sobre esta habla; una tercera, dedicada a la fonética desde una perspectiva histórica (no emplean transcripción, sino la ortografía convencional portuguesa), en la que se confirman, en general, las afirmaciones de otros autores; una cuarta, con valiosas observaciones de carácter morfológico sobre el artículo, pronombre, verbo, y sobre sintaxis; y una quinta —que ocupa más de la mitad del artículo, y que es, por tanto, la más extensa-, dedicada al léxico. Se trata, en resumen, de un valioso e interesante estudio que completa y amplia la información sobre el habla de Riodonor proporcionada por investigaciones anteriores.

Por su parte, Os falares fronteiriços de Trás-os-Montes de María José de Moura Santos es una publicación basada en su Dissertaçao de Licenciatura em Filologia Romãnica, realizada bajo la dirección del profesor Paiva Boléo y presentada en la Facultade de Letras da Universidade de Coimbra en octubre de 1960. Constituye una muy seria y rigurosa investigación sobre las hablas transmontanas fronterizas con España (provincias de Orense, Zamora y Salamanca), elaborada, como es natural, desde la pers-

\footnotetext{
${ }^{67}$ Biblos, XXX (1954), pp. 191-244.

68 Coimbra: Facultade de Letras da Universidade de Coimbra, .1967.

69 Lisboa, 1953
} 
pectiva portuguesa, pero que tiene, sin embargo, un gran interés para nosotros, no sólo porque describe la filiación leonesa de distintas hablas situadas en Portugal, o compara éstas y otras con las fronterizas gallegas y del antiguo Reino de León, sino también porque estudia de manera sistemática varios puntos de nuestra provincia -amén de otros gallegos y salmantinos, fuera ya de nuestra área de atención-, que son, concretamente, Riodonor (Sanabria Leonesa), tanto en su parte portuguesa como española, San Martín del Pedroso y Moveros (Aliste) y Torregamones (Sayago Noroccidental). También incluye algunas referencias al habla de Hermisende, cuyos datos proceden del artículo de Krüger, "Mezcla de dialectos" (véase más arriba), y son, por tanto, mucho más antiguos que aquellos otros, y no aportan, en consecuencia, novedad alguna. La exposición se inicia con unos Preliminares que explican los objetivos y metodología de la investigación. En lo que a nosotros atañe hay que decir que las encuestas sobre la provincia de Zamora se llevaron a cabo en los meses de febrero y marzo de 1960, con el auxilio de un cuestionario de 417 preguntas, elaborado por la propia autora a partir del que utilizó Paiva Boléo para su Enquérito Lingüístico por correspondencia en 1942. Los informantes fueron uno solo en cada población, siempre naturales de ella: mujeres de edad en torno a los 65 años en Riodonor y San Martín, y hombres en Moveros ( 45 años) y en Torregamones (65 años). Las respuestas se escribieron empleando la transcripción fonética, modo de representación con el que aparecen también a lo largo de esta publicación, que alterna, sin embargo, en algunos capítulos con el empleo de la ortografía convencional portuguesa. Sigue a esta primera parte la Introdução, en la que reúne la autora gran cantidad de información de carácter geográfico-histórico sobre la región de Tras-os-Montes y donde pone de relieve la estrecha vinculación que esta región ha tenido a lo largo de los siglos con España. El estudio lingüístico se inicia con un interesantísimo capítulo en el que Moura Santos describe las situaciones de contactos de lenguas y de bilingüismo que se dan en esta zona fronteriza. Con respecto a las hablas de nuestra provincia, señala el carácter portugués del habla de Hermisende, con mezcla de elementos leoneses y gallegos y con un avanzado proceso de asimilación del castellano, la mezcla de elementos gallegoportugueses y leoneses en los otros pueblos del Sur de Sanabria (Calabor, Riodonor, etc.) y la pervivencia de restos leoneses junto al castellano en el caso de las hablas fronterizas de Aliste y Sayago. Sigue a continuación la descripción propiamente dicha de las hablas estudiadas, con las correspondientes partes dedicadas a fonética (vocales, consonantes, grupos consonánticos), morfología (artículos, pronombres, etc.), sintaxis (fórmulas de tratamiento, verbo, diferentes construcciones, 
etc.) y léxico (la parte más extensa, en la que además de exponer el vocabulario recogido, se ocupa de la estructura léxica de la región y de las afinidades, interferencias e importaciones léxicas). El estudio lingüístico se completa con una parte dedicada al folclore. En las conclusiones, sintetiza la autora lo expuesto con anterioridad, distinguiendo entre los rasgos generales de la región, los que resultan propios de la zona fronteriza gallegoportuguesa y los que caracterizan a la zona en contacto con las hablas leonesas, y reflexiona, por último, sobre el problema de la influencia española que ha aparecido de manera constante y reiterada a lo largo de todo el libro. Las explicaciones realizadas se ilustran en diferentes ocasiones con interesantes mapas.

Con posterioridad a estos magníficos estudios no se han realizado, que sepamos, otras investigaciones desde Portugal que se interesen también por las hablas limítrofes de Zamora. Sí nos consta, no obstante, la existencia de estudios sobre hablas leonesas en territorio portugués, pero que muestran un claro desinterés por las variedades del otro lado de la frontera, algo que ha sido también bastante frecuente, con respecto a las portuguesas, entre los dialectólogos españoles que han estudiado las hablas fronterizas zamoranas. Queda abierta así para futuros estudiosos una más que atractiva línea de investigación, cuyo principal objetivo ha de ser el descubrimiento de diferencias y semejanzas entre ambos grupos de hablas, separadas en lo político, pero cercanas en lo lingüístico. Esperamos que esta línea de investigación sea desarrollada en el futuro con el adecuado impulso y apoyo de instituciones públicas y privadas.

\section{Otros trabajos}

Vamos a ocuparnos, finalmente, de una serie de trabajos publicados en este período, y que por su diversa naturaleza no encajan en ninguno de los grupos anteriores.

Hablaremos en primer lugar del vocabulario de Manuel Molinero Lozano, "Algunas voces de Zamora" ${ }^{70}$. En un artículo publicado en la revista Servicio (4-II-61) se hizo un llamamiento a los maestros, en nombre de la Revista de Dialectología y Tradiciones Populares, para que contribuyesen a la recopilación del léxico popular hablado en España. Los materiales enviados fueron apareciendo en la RDTP, en la sección Archivo, bajo el título genérico de "Contribución lingüística del Magisterio", y entre ellos figuran tres listas de vocablos pertenecientes a comarcas de la provincia

\footnotetext{
70 RDTP, XVII (1961), pp. 180-184, 548-557, y XVIII (1961), pp. 523-528.
} 
de Zamora, cuya recogida se atribuye a Manuel Molinero Lozano. En cada una de ellas encontramos los vocablos ordenados alfabéticamente, seguidos de su significado y de la comarca (Sayago, Sanabria, La Carballeda) o población (Fuentesaúco, Porto) en que se localizan. En ocasiones, incluye también Molinero, además de las zamoranas, palabras que no pertenecen a Zamora, sino a Salamanca o Reinosa (Santander), cosa que resulta verdaderamente sorprendente, por no decir absurda. En conjunto, se trata de una recopilación de materiales léxicos obra de un estudioso local, no de un especialista, que puede servir, no obstante, como complemento a investigaciones sobre estas mismas comarcas o sobre otras de nuestra provincia.

Muy diferente a este trabajo es la referencia a las variedades dialectales de Zamora que encontramos en Agustín García Calvo, Manifiesto de la comuna antinacionalista zamorana ${ }^{71}$. Dentro de esta obra de carácter político, el profesor García Calvo dedica un capítulo titulado "La cuestión del lenguaje" a tratar la diversidad lingüística de la provincia de Zamora, en general, y las peculiaridades del habla de la que llama "Zamora y su comarca" (y que interpretamos como Zamora ciudad y Tierra del Pan), en particular. En él hace una descripción de una serie de rasgos fonéticos (no emplea transcripción fonética alguna para su representación), morfosintácticos y, sobre todo, léxicos, que el autor considera característicos del "lenguaje zamorano".

Por último, digamos también que en este período aparecen dos manuales de dialectología española, el de Vicente García de Diego, Manual de Dialectología Española ${ }^{72}$ y el de Alonso Zamora Vicente, Dialectología Española ${ }^{73}$, en los que encontramos sendas descripciones de las hablas de Zamora dentro de los capítulos dedicados al dialecto leonés. El primero describe un estado de habla que abarca desde finales del siglo XIX (el trabajo más antiguo consultado es el El dialecto leonés de Menéndez Pidal) hasta principios de los años veinte (estudios de Krüger sobre Sanabria). La descripción del segundo abarca un período de tiempo más amplio, que va desde fines del xIx (obras de Fernández Duro) hasta mediados del xx (Trabajos sobre el Dominio Románico Leonés).

\footnotetext{
71 París, 1970.

72 Madrid: Instituto de cultura Hispánica, 1946.

73 Madrid: Gredos, 1960.
} 


\section{TERCER PERÍODO: ÚlTimo TERCIO DEL SIGLO XX (1973-1995)}

\section{Continuadores de los estudios dialectales tradicionales}

En la evolución de los estudios dialectales sobre la provincia de Zamora, 1973 marca el punto de inflexión entre este tercer período (19731995) y el anterior (1936-1973). Ese año tiene lugar un hecho significativo. Nos referimos a la lectura, en la Facultad de Filología de la Universidad de Salamanca, de una memoria de licenciatura aún hoy inédita, Aproximación sociolingüistica al babla de Sarracín de Aliste, realizada por Luis Santos Río en el Departamento de Lengua Española de dicha Facultad, bajo la dirección del profesor D. Antonio Llorente Maldonado de Guevara. Esta investigación constituye el primer estudio sociolingüístico llevado a cabo sobre el habla de una comunidad zamorana, y uno de los primeros de este tipo elaborados en España. Con ella se inicia en nuestra provincia el proceso de renovación -mediante el enfoque sociolingüístico- de los estudios dialectales, al que ya nos hemos referido.

Con todo, siguen realizándose investigaciones en la línea de los estudios dialectales tradicionales. De estos trabajos vamos a ocuparnos, en primer lugar, en este apartado, y, después, pasaremos ya a describir las investigaciones efectuadas desde las perspectivas geográfico-lingüística y sociolingüística.

Los primeros trabajos en la línea de la dialectología tradicional realizados en este período están también fechados, como el de Santos Río, en 1973. Se trata, además, como en el caso de éste, de dos memorias de licenciatura, ambas igualmente inéditas. Son los trabajos de M. ${ }^{a}$ Rosa Curto López, Nuevas aportaciones dialectales al babla de la Tierra de Aliste ${ }^{74}$ y de Julio Borrego Nieto, Acercamiento al habla de Villadepera de Sayago ${ }^{75}$.

Nuevas aportaciones dialectales al habla de la Tierra de Aliste se centra, fundamentalmente, en el habla de la villa de Alcañices, a pesar de que el título hace referencia a la Tierra de Aliste en su conjunto. Siguiendo el modelo de otras monografías locales y comarcales, el trabajo de Curto López comienza con una exposición sobre diferentes aspectos de la localidad -históricos, geográficos, comunicaciones e industria, etc.-, a los que sigue la lista de informantes (sin indicar, sin embargo, cómo se han obtenido los materiales objeto de estudio), y, a continuación, el repertorio léxico recogido, que constituye el grueso del trabajo y cuya re-

74 Memoria de Licenciatura inédita, Universidad de Valladolid, 1973.

75 Memoria de Licenciatura inédita, Universidad de Salamanca, 1973. 
presentación gráfica sigue las convenciones ortográficas habituales. Este vocabulario aparece bajo el título genérico Palabras y cosas - lo que sugiere que es ésta la orientación teórica y metodológica que sigue, o quiere seguir, la autora-, y está organizado en diferentes apartados nocionales: cuerpo humano, vida pastoril, animales domésticos, campo y cultivos, etc. También se incluyen sendos apartados - menos habituales en otros estudios- sobre topónimos y motes e hipocorísticos. Las unidades léxicas descritas se contrastan, por otro lado, con cinco trabajos de diferente naturaleza: un diccionario de uso (DRAE, 19) , dos diccionarios etimológicos -el de Joan Corominas, Diccionario Crítico Etimológico ${ }^{76}$ y el de V. García de Diego, Diccionario Etimológico Español e Hispánico ${ }^{77}$-, el manual de Alonso Zamora Vicente, Dialectología Española y el estudio dialectal de J. M. Baz, El habla de la Tierra de Aliste. Se cierra el estudio con una serie de notas sobre costumbres locales de carácter religioso, y con la reproducción de algunos textos populares vinculados a tales ritos y celebraciones tradicionales. Al final aparece también un índice léxico que facilita la localización y consulta del vocabulario recogido. En distintos momentos encontramos dibujos que facilitan la comprensión del texto y fotografías que aproximan al lector a la realidad descrita.

Por su parte, la memoria de licenciatura de Julio Borrego Nieto sobre el habla de Villadepera de Sayago es el primer estudio realizado por el autor sobre esta localidad, tan interesante y completo, además, como todos los demás llevados a cabo por él sobre ella con posterioridad. En esta ocasión, Borrego Nieto acomete su investigación siguiendo las pautas teóricas y metodológicas marcadas por muchas monografias dialectales locales anteriores, bien diferentes a los planteamientos de sus acercamientos ulteriores, que tendrán una orientación de carácter sociolingüístico. Su objetivo fundamental es, pues, recoger los rasgos lingüísticos más peculiares del habla de este pueblo sayagués, y, en particular, aquellos que representan la pervivencia del viejo dialecto leonés. En una primera parte introductoria el autor justifica la elección de esta habla por razones "personales" y por tratarse de un área escasamente estudiada, y describe diferentes aspectos históricos, geográficos y sociales de la localidad. A continuación, y dentro de la misma Introducción, expone el contenido de la investigación y los procedimientos empleados para la obtención de los materiales lingüísticos, que consistieron, fundamentalmente, en la observación del habla espontánea y en la aplicación de un cuestionario, particularmente eficaz, según el autor, para la recopilación del léxico. Siguen

\footnotetext{
76 Madrid, 1967.

77 Madrid: SAETA, 1954.
} 
a la Introducción los capítulos dedicados a la fonética, morfología, sintaxis y léxico. Las observaciones fonéticas se refieren tanto a fenómenos históricos, como a otros actuales, y, en general, no se emplea la transcripción para la representación de los vocablos que aparecen como ejemplos. Las partes de morfología y sintaxis constituyen estudios muy amplios y completos de muy diversos fenómenos de esta índole en el habla de la localidad, y son, sin duda, una de las partes más interesantes de esta investigación, no sólo por el propio interés en sí de los fenómenos descritos, sino también por ser uno de los planos de la lengua menos estudiados en las monografías locales tradicionales. La parte dedicada al léxico, por último, no se limita sólo a la mera exposición de palabras y significados, sino que ofrece informaciones complementarias sobre su vitalidad, uso, motivaciones, filiación, localizaciones en otras hablas, etc. El estudio concluye con una serie de afirmaciones sobre la filiación lingüística del habla de Villadepera y sobre las que llama Borrego Nieto -p. 190 - "fuerzas lingüisticas del habla de Villadepera" (fundamentalmente la "analogía" y la "expresividad"). Hay que destacar, por último, que a lo largo de todo el trabajo aparecen diferentes comentarios sobre el alcance sociolingüístico de los distintos fenómenos estudiados, lo que revela el especial interés que este autor siente ya por este aspecto, que será, después, el núcleo central de sus estudios sobre Villadepera.

Dentro de esta misma línea de continuadores de los estudios dialectales tradicionales hay que incluir el artículo de Francisco Ynduráin, "Notas sobre el habla de Benavente (Zamora)" ${ }^{78}$. Se trata de un trabajo escrito con motivo del homenaje a Vicente García de Diego, que quiere ser, en palabras del autor, un "parvo muestrario del habla de un lugar [Benavente]" (p. 567). Contiene una serie de observaciones hechas de manera asistemática entre hablantes naturales de esta localidad, poco viajeros, unos de edad avanzada y otros más jóvenes, de diversas clases y más bien poco cultivados. Un conjunto de frases y dichos, un repertorio léxico, un estudio de los tratamientos y una recopilación de cantares populares constituyen su contenido. Ynduráin comenta los materiales recogidos, y señala, en cada caso, su significado, uso o filiación lingüística. Tiene el mérito de ser la única investigación efectuada hasta la fecha sobre el habla de Benavente.

Ya en la década de los 80 tenemos, por último, para cerrar este apartado, dos trabajos de quien firma este artículo, que pueden clasificarse también dentro de los estudios continuadores de la dialectología tradicional. Se trata de la investigación inédita El habla de Flores de Aliste. Materia-

78 RDTP, XXXII (1976), pp. 567-577. 
les inéditos y del artículo "Vocabulario tradicional de la vid y el vino en el habla de Toro. Su carácter dialectal, ${ }^{79}$.

Con respecto al primero hay que decir que el estudio sociolingüístico sobre el habla de Flores de Aliste a partir del cual elaboré mi memoria de licenciatura Esbozo de un estudio lingüistico de una comunidad alistana (Flores de Aliste) ${ }^{80}$, lo llevé a cabo, tal como explicaré en el apartado correspondiente, mediante la aplicación de diferentes procedimientos sistemáticos de estudio del habla, como las encuestas y las entrevistas grabadas a una muestra representativa de la diversidad sociológica de la localidad. Sin embargo, durante el año que residí en Flores de Aliste recogí también de forma asistemática, en el transcurso de conversaciones con las gentes de este lugar, otros materiales léxicos y distintas observaciones sobre pronunciación y morfosintaxis que no utilicé en los trabajos antes mencionados y que han permanecido inéditos hasta ahora. A ellos me refiero aquí con el título de El habla de Flores de Aliste. Materiales inéditos. Puesto que la Enciclopedia Dialectal de Zamora que queremos elaborar pretende ser una recopilación de todos los materiales dialectales allegados hasta la fecha sobre nuestra provincia, incluiré también en ella estos otros inéditos sobre el habla de Flores de Aliste, sólo en parte coincidentes con los ya publicados.

Por otra parte, en el "Vocabulario tradicional de la vid y el vino en el habla de Toro. Su carácter dialectal" me ocupo de describir la cultura popular de la vid y el vino en la ciudad de Toro. El trabajo presenta dos partes claramente diferenciadas: una, etnográfica, en que se describen las tareas relacionadas con el cultivo de la vid y la elaboración del vino tradicionales, así como las denominaciones que a ellas van asociadas, y otra, lingüístico-dialectal, en que se intenta determinar la filiación geográfica, histórica, etc. de las unidades léxicas recogidas. El estudio se completa con una comparación - apoyada en datos estadísticos- entre el carácter dialectal del vocabulario relativo al cultivo de la vid y el del vocabulario relacionado con la elaboración del vino, y con unas reflexiones acerca de lo interesante que resultaría la realización de una investigación más amplia sobre las actividades vitivinícolas de Toro y la Tierra del Vino, en buena medida realizada ya por Antonio Álvarez Tejedor, Estudio lingüistico del léxico rural de la zona Este de la provincia de Zamora, del que nos ocuparemos más adelante.

79 Anuario 1985 del Instituto de Estudios Zamoranos "Florián de Ocampo" (Zamora, 1986), pp. 265-282.

80 Universidad de Salamanca, 1984. 
Atlas lingüisticos y otros trabajos de geografía lingüistica

Aunque los trabajos de geografía lingüística no constituyen una novedad teórica ni metodológica en este tercer período, y podríamos, por tanto, clasificar a los que se realizan en nuestra provincia a partir de 1973 entre los continuadores de los estudios tradicionales, preferimos, sin embargo, ocuparnos de ellos en capítulo aparte, tanto porque no son dialectología tradicional en el sentido estricto de que la recogida de materiales no la hacen de manera impresionista y asistemática, sino siguiendo procedimientos de encuesta sistemáticos y valiéndose de cuestionarios perfectamente estructurados, como porque la cantidad y relevancia de los trabajos geográfico-lingüísticos realizados en este período (1973-1995) son muy superiores a las de etapas anteriores. Así, por ejemplo, frente a las otras dos épocas (1879-1936 y 1936-1973), en que sólo se llevan a cabo en la provincia de Zamora encuestas para un atlas lingüístico, el ALPI, en este tercer período, encontramos encuestas para tres atlas: el Atlas Lingüístico Galego (ALGa), el Atlas Linguarum Europae (ALE) y el Atlas Lingüistico de España y Portugal (ALEP). De ellos vamos a ocuparnos a continuación.

Los materiales del ALGa publicados hasta la fecha se encuentran recogidos en Constantino García et alii, Atlas Lingüístico Galego (ALGa). I.12. Morfología verbal. II. Morfología no verbal ${ }^{81}$. Este atlas surge, según sus autores, con el propósito de describir del modo más completo posible la realidad lingüística gallega, en un momento - los años 70-, en que tienen lugar dos fenómenos de extraordinaria repercusión en la vitalidad y uso del gallego: la cada vez más intensa castellanización de las tierras gallegas a través de los medios de comunicación, escuela, etc., y también la progresiva desaparición de la sociedad rural tradicional a la que el gallego se encontraba especialmente ligado. Con este atlas se pretende, igualmente, dar a conocer la personalidad de esta lengua dentro de los ámbitos ibérico, románico y europeo, y mostrar así su riqueza y diversidad dialectales. Los autores del proyecto no limitan, además, su investigación al ámbito administrativo de la Galicia actual, sino que realizan también encuestas en puntos lingüísticamente gallegos situados en provincias limítrofes (Asturias, León, Zamora). El ALGa es, de este modo, el segundo atlas, después del ALPI, cuya red incluye pueblos de nuestra provincia. Los puntos estudiados pertenecen, como es lógico, a la Sa-

81 Santiago de Compostela: Instituto da Lingua Galega-Universidade de Santiago de Compostela, Fundación "Pedro Barrié de la Maza, Conde de Fenosa", 1990-1995. 
nabria Gallegoportuguesa, y son, en concreto, como principales, Porto, Lubián y Hermisende (localidad esta última, no obstante, de habla portuguesa y no gallega, según distintos investigadores), y Castromil y San Ciprián de Hermisende, como secundarios, esto es, como puntos cuyos datos se recogen junto a otro principal, que en este caso es Hermisende. Los investigadores que llevaron a cabo las encuestas fueron Francisco Fernández Rei, Manuel González González y Rosario Álvarez Blanco, en los pueblos principales, y Francisco Fernández Rei, por lo que respecta a Castromil, y A. Castro Rodríguez en San Ciprián de Hermisende. En Porto, Lubián y Hermisende entrevistaron a tres informantes en cada uno, hombres y mujeres, mayores de 50 años. Los datos de Castromil proceden de la información suministrada por un hablante de esta localidad que estaba presente durante la realización de la encuesta en Hermisende, y los de San Ciprián, de una grabación realizada para el Archivo Dialectológico del Instituto da Lingua Galega. También se hicieron grabaciones en los otros puntos. El cuestionario aplicado constaba de 2.711 preguntas, de las cuales 527 correspondían a la fonética, morfología y sintaxis, y el resto al léxico, con cuestiones relativas a los apartados nocionales usuales en los atlas lingüísticos (tiempo, terreno, agricultura, animales, plantas, etc.). El cuestionario del ALGa contiene todas las preguntas del cuestionario del ALEP, en el que también se incluye, como es sabido, el del ALE. Siguiendo las pautas habituales en la elaboración de los atlas lingüísticos, los redactores del ALGa anotan las respuestas obtenidas en transcripción fonética. La recolección de estos datos (encuestas y/o grabaciones) se efectuó en junio de 1976 (Porto, Hermisende, Castromil), mayo de 1977 (Lubián) y enero de 1983 (San Ciprián de Hermisende). Hasta ahora sólo han publicado los dos primeros volúmenes del ALGa, correspondientes a la morfología verbal y no verbal. Los próximos en aparecer serán los dedicados a la fonética y al apartado nocional "La tierra y el tiempo".

A partir de los materiales recogidos en el ALGa se han realizado diversos trabajos, entre los que se encuentra un artículo de F. Fernández Rei que hace referencia al gallego hablado en nuestra provincia: "Textos do galego exterior: Piantón (A Veiga-Oviedo), Paradaseca do Bierzo (León) e Lubián (Zamora). Caracterización lingüística" ${ }^{82}$. Con este trabajo se propone el autor ofrecer una muestra del estado actual del que llama "gallego exterior" (gallego hablado en áreas de Asturias, León y Zamora, fuera, por tanto, de los límites administrativos de la Galicia actual), a la vez que

82 Homenaje a Álvaro Galmés de Fuentes, I (Madrid: Universidad de Oviedo/Gredos, 1985), pp. 171-197. 
realiza una caracterización, fonética y morfológica, sobre todo, del gallego oriental, en general, y de las variedades asturiana, leonesa y zamorana, en particular. Tras una explicación de las convenciones gráficas empleadas para la representación tanto de los ejemplos como de los textos (que no aparecen en transcripción fonética, sino siguiendo, en líneas generales, las Normas ortográficas e morfolóxicas do idioma galego del Instituto da Lingua Galega y de la Real Academia Galega), el autor describe las principales características del gallego oriental distinguiendo entre los que llama "rasgos conservadores" y "rasgos innovadores", para pasar, después, a la enumeración de los rasgos más característicos de los gallegos asturiano, leonés y zamorano. En lo que a nosotros respecta, el autor llama la atención sobre lo que son particularidades del gallego de Zamora en su conjunto, sobre lo que son rasgos comunes a Lubián y Hermisende, sobre lo que son fenómenos registrados sólo en un punto del área zamorana (Porto, Lubián o Hermisende) y, finalmente, sobre lo que son fenómenos comunes a las hablas de Zamora, Orense y Pontevedra y, en menor medida, a las coruñesas. El trabajo se completa con la inclusión de las transcripciones de textos recogidos mediante grabación en las localidades mencionadas en el título del artículo.

Por su parte, los materiales del ALE publicados hasta ahora - y hasta donde nosotros sabemos- se hallan recogidos en M. Alinei et alii, Atlas Linguarum Europae $(A L E)^{83}$. Como es sabido, el ALE, un atlas plurilingüe -aún en elaboración - que abarca una vastísima extensión y un gran número de lenguas y dialectos, pertenece al cuarto momento - el de los macrosistemas- en la evolución histórica de la geografía lingüística a lo largo de nuestro siglo ${ }^{84}$. En el ámbito de la Península Ibérica, la realización del ALE se encuentra vinculada a la del ALEP: las localidades que conforman la red de aquél son algunas de las que figuran en éste y el cues-

83 Vol. I.1, I.2, 1. ${ }^{\circ}$ fascicule, (Assen: Van Gorcum, 1983); vol. I, 2. fascicule (Assen: Van Gorcum, 1986).

${ }^{84} \mathrm{Al}$ primer momento pertenecerían los atlas preocupados fundamentalmente por los aspectos fonéticos, como el Atlas Lingüístico de Francia (ALF, 1902-1910) de Gilliéron y el Atlas lingüistico de la Península Ibérica (ALPI, 1962) de Navarro Tomás; un segundo momento estaría representado por la introducción en la geografía lingüística del método "palabras y cosas" con el Atlas Lingüístico-Etnográfico de Italia y la Suiza Meridional (AIS, 1928-1940) de K. Jaberg y J. Jud; y el tercer momento sería el de los atlas regionales, iniciado en Francia por el Nuevo Atlas Lingüistico de Francia por Regiones (NALF, 1942) de A. Dauzat, y continuado, en España, por los atlas regionales realizados por $\mathrm{M}$. Alvar y sus colaboradores, Atlas Lingüístico y Etnográfico de Andalucía (ALEA, 1961-1973), Atlas Lingüistico y Etnográfico de Aragón, Navarra y La Rioja (ALEANR, 1979-1983), etc., de los que será atlas marco el Atlas Lingüistico de España y Portugal (ALEP), en preparación. 
tionario del primero se encuentra integrado igualmente en el del segundo. En nuestra provincia, los puntos del ALEP que se tienen en cuenta en el ALE son Hermisende (Sanabria Gallegoportuguesa), Pozuelo de Tábara (Tierra de Tábara), Fermoselle (Sayago) y Venialbo (Tierra del Vino). Hermisende es, pues, la localidad que aparece en todos los atlas que hasta la fecha contienen referencias a la provincia de Zamora (ALPI, ALGa, ALE y ALEP). En cuanto al cuestionario empleado y a las preguntas que lo componen, unas quinientas, el ALE prescinde, como es natural, de lo específico de cada lugar y busca lo genérico, lo común a territorio tan extenso. Por eso, no debe sorprendernos que las preguntas que lo integran sean todas del tipo ventana, luna, arco iris, nieve, niebla, etc. Esto mismo hace que los materiales procedentes de las hablas de Zamora aparecidos en estos volúmenes sean muy escasos y ofrezcan muy poco interés. Conviene añadir, finalmente, que puesto que los comentarios sobre el ALE aparecidos hasta ahora se han publicado en 1983 y 1986, y las encuestas para el ALEP realizadas por el profesor Llorente Maldonado en la provincia de Zamora se llevaron a cabo, como veremos, en los puntos coincidentes con el ALE, en 1985, los materiales sobre Zamora que se recogen en estas publicaciones tienen que proceder, con toda seguridad, de unas encuestas anteriores, efectuadas quizás alrededor de los años 1976-1977, es decir, justo antes de que Llorente Maldonado llevara a cabo su primera encuesta, en Cubo del Vino, en 1978.

Por otro lado, el trabajo de conjunto más importante llevado a cabo hasta ahora sobre las hablas de Zamora es, sin duda, el constituido por las encuestas de Zamora, inéditas, para el Atlas Lingüístico de España y Portugal (ALEP) ${ }^{85}$, un atlas aún en proceso de realización que será, como atlas general, el marco de todos los regionales emprendidos bajo la dirección del profesor Alvar durante las últimas décadas en nuestro país. Estas encuestas son la primera ocasión en que de forma sistemática y simultánea (en el tiempo y en el espacio) podemos obtener una visión global de la diversidad dialectal de nuestra provincia, ya que han sido realizadas en localidades de la práctica totalidad de comarcas zamoranas (sólo faltan pueblos de una: Tierra de Alba). Una vez publicado el cuestionario del ALEP en 1974, la primera encuesta se llevó a cabo en Villardiegua de la Ribera (Sayago), en 1975, por Julio Borrego Nieto, quien la realizó a la vez que su estudio sociolingüístico, elaborado con el mismo cuestionario, sobre el habla de la vecina localidad de Villadepera de Sayago, trabajo que sirvió de base a su tesis doctoral, dirigida por el profesor Llorente Maldonado. Las demás fueron hechas por este último investigador, con la ayuda en

\footnotetext{
85 Madrid, Departamento de Geografía Lingüística.
} 
un punto (Sarracín de Aliste) de José I. Gómez Asencio (quien hizo la parte de morfología). Todas están fechadas en 1985, con excepción de la de Cubo del Vino, efectuada en 1978, y la de Sarracín de Aliste, en 1987. Así, pues, corresponde atribuir al profesor Llorente Maldonado el mérito de ser responsable, directamente, mediante estas encuestas y diversos trabajos publicados a partir de los datos recogidos en ellas, o indirectamente, mediante la dirección desde su cátedra salmantina de tesis o tesinas sobre las hablas de Zamora, de gran parte de la investigación dialectal sobre nuestra provincia realizada en el último tercio de este siglo. Las localidades encuestadas para el ALEP, veinte en total, fueron, además de las dos mencionadas, las siguientes: Hermisende (Sanabria Gallegoportuguesa), San Martín de Castañeda (Sanabria Leonesa), Espadañedo, Folgoso de la Carballeda (La Carballeda), Brime de Sog, Villabrázaro (Los Valles), San Martín del Pedroso, Ceadea (Aliste), Pozuelo de Tábara (Tierra de Tábara), Fermoselle, Torrefrades (Sayago), Cerecinos de Campos, Belver de los Montes, Matilla la Seca (Tierra de Campos), Andavías (Tierra del Pan), Venialbo, El Cubo del Vino (Tierra del Vino) y Vadillo de la Guareña (La Guareña). El ALEP coincide, pues, con el ALPI en las localidades de Hermisende y San Martín de Castañeda, y con el ALGa, en la de Hermisende. También coincide en dos puntos, El Cubo del Vino y Venialbo, con el trabajo geográfico-lingüístico de Álvarez Tejedor, Estudio lingüistico del léxico rural de la zona Este de la provincia de Zamora (del que nos ocuparemos más adelante), quien utiliza, no obstante, un cuestionario diferente, aunque parecido, como es natural, en lo que es objeto común de ambos trabajos: la agricultura tradicional. Por otro lado debemos señalar también que, además de para la descripción de las hablas de las localidades señaladas, el cuestionario del ALEP se ha empleado igualmente en los estudios sociolingüísticos de otros lugares de nuestra provincia, concretamente, en los de Villadepera de Sayago, Flores de Aliste, Toro y Bóveda de Toro, con lo que el interés de los materiales obtenidos resulta mucho mayor al aumentar así las posibilidades de comparación entre las distintas áreas y comarcas. Los materiales recogidos en estas encuestas están constituidos por las respuestas a cerca de 1.400 preguntas, de carácter fónico (1-131), morfológico (132-218), sintáctico (219-317) y léxico (el resto de cuestiones, organizadas en los habituales apartados nocionales de tiempo, terreno, agricultura, animales, plantas, etc.). Los informantes fueron siempre varones, agricultores y/o ganaderos, a veces también con algún otro oficio añadido a éstos (albañil, alguacil, herrero, comerciante, etc.), de edades entre los 50 y 84 años, pero con predominio de los de más de 60 y menos de 80 , normalmente dos por localidad, a veces tres, en ocasiones uno solo. Como es habitual en este tipo de trabajos, la transcripción fonética 
empleada pretende reflejar los más sutiles aspectos de la pronunciación. Además de las encuestas lingüísticas, también se hicieron, a la vez, grabaciones, fotografías y encuestas etnográficas.

A partir de los materiales recogidos en las encuestas para el ALEP, Llorente Maldonado ha iniciado la publicación de una serie de artículos cuyo objeto es la descripción de las hablas estudiadas ${ }^{86}$.

En "Las hablas vivas de Zamora y Salamanca en la actualidad" ${ }^{87}$ se propone describir, en lo que a nosotros atañe, los principales rasgos de las hablas de Zamora en la actualidad (fónicos, morfosintácticos y léxicos), haciendo especial hincapié en la evolución que han experimentado en los últimos treinta años los rasgos considerados típicamente leoneses. La principal conclusión a que llega es que "el retroceso del leonés ha sido bastante grande y que prácticamente hoy no se puede hablar de la pervivencia del leonés sino de la pervivencia, más o menos intensa según las comarcas, de determinados rasgos leoneses en forma de reliquias que, por lo que respecta a la fonética, encontramos preferentemente en forma lexicalizada y no en forma sistemátican. Otra conclusión muy interesante a que llega este estudio, digna de ser destacada aquí, es la comprobación de una situación de bilingüismo en Hermisende (portugués/castellano con leonesismos) y una situación de diglosía (variedad vernácula leonesa/castellano) en San Martín de Castañeda, sobre todo, y más atenuada en Espadañedo y Folgoso.

Los demás trabajos de Llorente Maldonado elaborados a partir de las encuestas para el ALEP tienen un carácter eminentemente léxico: "Las denominaciones del camino de ganado en las provincias de Zamora, Salamanca y Ávila" ${ }^{8}$, "Las denominaciones de la losa o lancha en las provincias de Zamora, Salamanca y Ávila" ${ }^{89}$, "Las denominaciones correspondientes a las lexías de la lengua estándar arroyo, torrentera, manantial y terreno pantanoso en Zamora, Salamanca y Ávila" "0, "Algunas denominaciones de las formas y de las orientaciones del terreno en Zamora, Salamanca y Ávila" ${ }^{11}$. En estos artículos Llorente expone las distintas de-

86 Estos artículos se refieren, normalmente, a las hablas de Ávila, Salamanca y Zamora, que son las provincias encuestadas para el ALEP por nuestro maestro.

87 En M. Alvar, Lenguas peninsulares y proyección bispánica (Madrid: Fundación Friedrich Ebert, Instituto de Cooperación Iberoamericana, 1986), pp. 107-131.

88 En Homenaje al Profesor Luis Rubio. II, Estudios Románicos, Vol. 5 (Murcia: Universidad de Murcia, 1987/88/89), pp. 797-805.

89 RDTP, XLIII (1988), pp. 365-377.

90 I, RFE, LXIX (1989), pp. 253-275; II, RFE, LXX (1990), pp. 71-89.

91 En Scripta Pbilologica in Honorem Juan M. Lope Blanch, II (Méjico: Universidad Nacional Autónoma de Méjico, 1992), pp. 145-162. 
nominaciones halladas en cada encuesta, con indicación de la localidad, y describe las áreas en que se localizan dentro de las tres provincias estudiadas. También señala si son generales o no, y si cuentan, por tanto, o no, con restricciones de uso. Igualmente, estudia la filiación histórica y la distribución geográfica de las denominaciones no estándar, para lo que recurre a la consulta de diferentes atlas, diccionarios etimológicos, repertorios léxicos, monografías dialectales, etc. A partir de los datos reunidos formula sugestivas hipótesis o llega a interesantes conclusiones en relación con el origen, filiación lingüística, distribución geográfica, etc. de estas unidades léxicas.

Además de los atlas lingüísticos y de los trabajos realizados tomando como base los materiales reunidos en ellos, también se han llevado a cabo en este período otros estudios de geografía lingüistica sobre las hablas de Zamora, de los que vamos a ocuparnos a continuación.

Antonio Álvarez Tejedor es autor de dos publicaciones de este tipo: "Aproximación al estudio del léxico rural de la provincia de Zamora" ${ }^{92}$ y Estudio lingüístico del léxico rural de la zona Este de la provincia de Zamora ${ }^{93}$, ambas basadas en su tesis doctoral, Estudio lingüístico del léxico rural en la provincia de Zamora, realizada bajo la dirección del profesor César Hernández en el Departamento de Lengua Española de la Facultad de Filología de la Universidad de Valladolid, y presentada en esta universidad durante el curso 85/86.

En "Aproximación al estudio del léxico rural de la provincia de Zamora" quiere el autor hacer un avance de su otro trabajo, entonces inédito, y también "verificar que los principios metodológicos de la Geografía Lingüística ofrecen múltiples posibilidades para estudios tanto sincrónicos como diacrónicos en todos los niveles del análisis lingüístico: fonético-fonológico, morfosintáctico, léxico y semánticom. La exposición se organiza en dos partes: una, primera, en que se explican los objetivos y metodología de la investigación antes mencionada (propósito, cuestionario, localidades encuestadas, criterios para la selección de informantes, etc.), y otra, segunda, en que a partir de algunos mapas realizados con los materiales obtenidos mediante las encuestas (mapas correspondientes a las cuestiones "tipos de vino" y "Sembrar sobre rastrojos") se realizan diversos análisis que ponen de manifiesto las enormes posibilidades que la cartografía lingüística ofrece al estudio de las variedades dialectales.

Por otro lado, el propósito de Estudio lingüistico del léxico rural de la zona Este de la provincia de Zamora es, en palabras de Álvarez Tejedor,

92 Anuario 1986 del Instituto de Estudios Zamoranos "Florián de Ocampo" (Zamora, 1986), pp. 251-263.

93 Salamanca: Eds. Universidad de Salamanca-Colegio Universitario de Zamora, 1989. 
recoger "los materiales lingüísticos vivos en un territorio, poco o parcialmente conocido por los lingüistas" (p. 9), siguiendo los planteamientos metodológicos de la tradición dialectológica española, en general, y los de la geografía lingüística, en particular. La publicación aparece dividida en dos partes bien diferenciadas: en la primera se exponen los objetivos y metodología del trabajo, así como las características del territorio estudiado (Presentación y capítulos I-III), y en la segunda (el resto, excluido el capítulo Conclusiones) encontramos los mapas, con los materiales lingüísticos obtenidos, y los comentarios lingüístico-etnográficos que suscitan estos materiales. En la primera parte, Álvarez Tejedor señala que la selección del territorio objeto de estudio (a cuya descripción se dedica todo un capítulo) estuvo motivada, fundamentalmente, por la falta de una investigación de este tipo sobre la región de la Cuenca del Duero, y dice que si eligió una zona comprendida por las comarcas zamoranas de Tierra de Campos, Tierra del Pan, Tierra del Vino y La Guareña, fue, primero, por razones personales, y después, porque estas comarcas guardan similitudes paisajísticas, agronómicas y culturales con las de las provincias limítrofes, amén de que, desde el punto de vista dialectal, presentan hablas mucho menos estudiadas que las de las áreas occidentales de la provincia (Sanabria, Aliste, Sayago). En total se estudiaron 27 localidades de estas cuatro comarcas. Con respecto al cuestionario, dice el autor que uno de la extensión de los empleados habitualmente para la elaboración de los atlas lingüísticos sería poco menos que imposible de llevar a cabo por un solo encuestador, y, por ello, limita su investigación al léxico relacionado con la que llama la "cultura de los cereales y del viñedo" (p. 10). Este cuestionario se aplicó a una serie de informantes seleccionados de acuerdo con los criterios usuales en los estudios de geografía lingüística, de modo que las personas elegidas lo fueron porque resultan más adecuadas que otras para responder a las preguntas de la encuesta, no en función de su representatividad sociológica. Se eligieron, así, hombres, de edad (el más joven tiene 57 años), con estudios primarios y de ocupación agricultores, a veces, también ganaderos. Las respuestas obtenidas se clasificaron, por otro lado, en distintos grupos (normalizadas, leonesismos, arcaísmos, etc.). En la segunda parte, aparecen, como hemos dicho, cartografiados, los materiales lingüísticos obtenidos (representados mediante transcripción fonética en los mapas, y con la ortografía convencional en los comentarios que los acompañan), seguidos de diferentes observaciones de carácter dialectal o etnográfico relacionadas con la pregunta y respuestas en cuestión. En ocasiones, el autor aprovecha determinados materiales para hacer también análisis de tipo semántico. Un índice de palabras al final del libro facilita la labor de búsqueda de todas 
las respuestas obtenidas. Las conclusiones ponen de relieve las peculiaridades lingüísticas encontradas para la zona Este de Zamora, y señalan diferencias y semejanzas entre las comarcas estudiadas, bien en relación con el tipo de léxico que resulta más frecuente en cada una (voces generales, leonesismos, etc.), bien en función de determinadas estructuras semánticas halladas. A lo largo de todo el libro, por otro lado, aparecen dibujos y fotografías que completan perfectamente las explicaciones dadas ${ }^{94}$.

Dentro de los trabajos de geografía lingüística realizados en este período hay que incluir también una serie de materiales que yo recogí, durante los años 1986 y 1987, en el transcurso de varias excursiones por algunas comarcas de nuestra provincia. Se trata de un trabajo inédito, Nombres del arado en la provincia de Zamora, en el que me ocupo de los nombres que se dan al arado y a sus partes en diferentes localidades. La obtención de estas denominaciones se realizó de manera asistemática, en conversaciones informales con los lugareños, y los pueblos en que se recogió información fueron Manzanal del Barco, Carbajales de Alba (Tierra de Alba), Bermillo de Sayago (Sayago Suroriental), Aspariegos (Tierra del Pan), Cubo del Vino (Tierra del Vino) y Cañizal (La Guareña).

También hay que incluir dentro de los trabajos de geografía lingüística el estudio de Inés Fernández-Ordóñez, "Isoglosas internas del castellano. El sistema referencial del pronombre átono de tercera persona" ${ }^{95}$. Se trata de un estudio genérico, no específico, por tanto, sobre la provincia de Zamora, pero en el que se habla de nuestras variedades dialectales. La investigación tiene por objeto la descripción de los diferentes sistemas correspondientes a los pronombres átonos de tercera persona $l e, l a, l o \mathrm{y}$ sus plurales en el castellano actual del Centro y Norte peninsulares, y pretende, en consecuencia, delimitar las áreas de extensión, hoy, en estas hablas propiamente "castellanas", de los fenómenos conocidos como leísmo, laísmo y loísmo. Esta descripción se lleva a cabo a partir de entrevistas grabadas con hablantes "de zona rural y del estrato sociocultural más bajo, a los que se les supone la fijación de su ideal lingüístico en la conservación del sistema propio del lugar», p. 82, y a partir también de los datos suministrados por trabajos anteriores. En relación con las hablas de nuestra provincia se concluye que el sistema etimológico (sin leísmo, ni laísmo) predomina en toda ella, con excepción de los rincones nororiental y suroriental (Tierra de Campos y La Guareña, respectivamente), en los que penetra el que llama sistema referencial tipo A (leísmo, laísmo, lo acusativo

94 Para otros pormenores sobre este trabajo, puede verse la reseña que de él hace J. BorREgo NIETO en Studia Zamorensia, XI (1990), pp. 343-345.

95 RFE, LXXIV, 1994 (pp. 71-125). 
para no contables y loísmo alternando con le dativo para no contables), característico de Palencia, Valladolid y el área occidental de Burgos.

Digamos, para finalizar este apartado, que a caballo entre la geografía lingüística y la sociolingüística se encuentra el muy reciente trabajo, inédito, de María Hernández García, Estudio sociolingüístico. El babla de la comarca de Toro en su zona Norte, del que nos ocuparemos con más detalle al hablar de los estudios sociolingüísticos.

\section{Renovación de los estudios dialectales mediante el enfoque} sociolingüistico

Como ya hemos dicho en apartados anteriores, los estudios sobre las hablas de Zamora realizados desde una perspectiva sociolingüística representan una profunda renovación de las investigaciones dialectales hasta ese momento en nuestra provincia. Esta renovación afecta a muy diversos aspectos teóricos y metodológicos. Por ejemplo, frente a estudios anteriores, en los que lo fundamental era la descripción de los rasgos diferenciales del habla objeto de estudio, los nuevos trabajos sociolingüísticos se ocupan de la descripción de toda el habla, en su conjunto, introduciendo conceptos como los de norma y variación dialectal, y estableciendo correlaciones entre la diversidad lingüística observada y la estructura sociolingüística de la comunidad de habla que se estudia. También, frente a la característica obtención, de manera impresionista y asistemática, de los materiales objeto de estudio que efectúa la dialectología tradicional, se introducen ahora nuevos procedimientos sistemáticos de investigación tanto para la recogida y análisis de los materiales, como para la selección de informantes y para la comparación de los distintos grupos sociolingüísticos. Todo este proceso se ve favorecido, por otro lado, como ya dejamos dicho, por la progresiva desaparición de los factores que favorecen la conservación de las peculiaridades dialectales, lo que hará que el investigador se fije también en la parte normalizada, no sólo en lo dialectal, de las hablas que estudia, y en cómo se dan diferentes grados de variación dialectal según diferentes variables sociológicas (edad, estudios, etc) que estratifican internamente la comunidad.

El primer estudio sociolingüístico sobre el habla de una comunidad de la provincia de Zamora, y uno de los primeros de este tipo elaborados en España, es, según dijimos, la memoria de licenciatura, inédita, de Luis Santos Río, Aproximación sociolingüistica al babla de Sarracín de Aliste. Se trata de una investigación pionera, a la que le faltan, por 
ello, las referencias y apoyos de otras investigaciones anteriores, lo que explica el que la "metodología sociolingüística" que en ella encontramos resulte hoy, a nuestros ojos, en muchos aspectos, "deficiente". Así, por ejemplo, la obtención de los materiales lingüísticos no se realiza de forma ordenada y estructurada, sino a partir de la observación asistemática del habla local, y lo mismo puede decirse de la fijación de los distintos grupos de hablantes, que es una división de la comunidad no arbitraria, pero sí subjetiva, elaborada a partir de las impresiones del autor sobre la estratificación sociolingüística del habla de Sarracín. La adscripción de aquellos materiales a estos grupos se realiza, también, por supuesto, de manera impresionista. Su objetivo general es la descripción del habla de esta comunidad alistana (fundamentalmente, de sus aspectos léxicos y morfosintácticos, y en menor medida de los fonéticos), añadiendo a esta descripción, a diferencia de otras monografías dialectales tradicionales, información sobre la vitalidad y uso de los elementos lingüísticos descritos. Para ello, Santos Río distingue en la comunidad cuatro grupos de emisores: A (arcaizantes), C (innovadores), B (a caballo entre ambos grupos) y D (estudiantes que viven fuera de Sarracín, pero pasan temporadas en el pueblo, y son conocedores del habla local). Al describir los fenómenos estudiados, Santos Río señala cuáles de estos grupos emplean y cuáles no las formas en cuestión. Desde el punto de vista estrictamente dialectal, esta investigación constituye una importante aportación al conocimiento de las hablas alistanas, en general, y de Sarracín, en particular. En ella se recoge un amplísimo repertorio léxico - para cuya representación no emplea la transcripción fonética, aunque sí encontramos una suerte de "escritura fonética" (no usa la $h$, ni la $v$, por ejemplo)_, y también se estudia una gran cantidad de fenómenos morfosintácticos, mucho más numerosos que los de otras monografías tradicionales, y, en especial, que los de otras realizadas sobre la comarca de Aliste.

Los primeros trabajos propiamente sociolingüísticos sobre las hablas de Zamora son, sin embargo, los del profesor Borrego Nieto, quien no sólo realiza la descripción sociolingüística de un habla sayaguesa, la de Villadepera de Sayago, sino que también forja un nuevo método de aproximación y estudio de comunidades lingüísticas de carácter rural, en el que se funden y entremezclan antiguos y sólidos principios y procedimientos de la tradición dialectológica europea con otros nuevos procedentes de la sociolingüística desarrollada en Norteamérica. Puede decirse, así, que en la renovación de la investigación dialectológica mediante el enfoque sociolingüístico que tiene lugar en España en los años 70 y 80, las hablas de Zamora tienen un papel importante, como lo tuvieron, años atrás, 
cuando Krüger ensaya y desarrolla, a partir de investigaciones sobre las hablas sanabresas, el método "palabras y cosas".

Las publicaciones de carácter sociolingüístico de Julio Borrego Nieto sobre el habla de Villadepera se basan en su tesis doctoral, La situación sociolingüistica de una comunidad rural (Villadepera de Sayago), realizada bajo la dirección de D. Antonio Llorente en la Facultad de Filología de la Universidad de Salamanca, Departamento de Lengua Española, y presentada en esta misma universidad durante el curso 78/79 ${ }^{96}$. Estas publicaciones son dos: Sociolingüística rural. Investigación en Villadepera de Sayago ${ }^{97}$ y Norma y dialecto en el sayagués actual ${ }^{98}$.

Sociolingüistica rural. Investigación en Villadepera de Sayago recoge la parte más amplia e importante de la tesis doctoral de Borrego Nieto, constituida, fundamentalmente, por el estudio de la estratificación sociolingüistica de la comunidad de Villadepera tal como se refleja en el plano léxico. Se abre con una parte introductoria en la que se hace, en primer lugar, una amplia y detallada exposición de la sociolingüística como forma de aproximación a la realidad lingüística —antecedentes, nacimiento y concepciones-, y se describen los principios teóricos y los planteamientos metodológicos de este - entonces- nuevo - y prácticamente inédito en España- enfoque lingüístico. Siguen a esta exposición la enumeración de los objetivos del trabajo y la explicación de los procedimientos empleados. El objetivo fundamental es el estudio sociolingüístico de esta comunidad sayaguesa a partir de la descripción de la penetración de la lengua estándar en el sector léxico, en distintos grupos de hablantes y en diferentes sectores del vocabulario. Igualmente es objetivo capital de la investigación el estudio de las creencias lingüísticas de los hablantes, que se cotejan con los hechos lingüísticos para obtener, así, las actitudes. En cuanto a los instrumentos empleados para la obtención de los materiales, Borrego Nieto se vale de cuatro cuestionarios: uno onomasiológico, el del ALEP (sólo la parte léxica, con algunas supresiones y adiciones), durante cuya aplicación también formuló preguntas de carácter semasiológico; un segundo para el estudio de la diversidad semasiológica del vocabulario; y otros dos para determinar las actitudes lingüísticas de la comunidad. Estos cuestionarios se aplicaron a una serie de informantes escogidos en función de las variables edad, sexo

96 Recordemos a este respecto que la memoria de licenciatura del profesor Borrego Nieto había sido también un estudio dialectal, de corte tradicional, sobre el habla de Villadepera: Acercamiento al babla de Villadepera de Sayago.

97 Salamanca: Eds. Universidad de Salamanca, 1981.

98 Salamanca: Eds. Universidad de Salamanca, 1983. 
y la que llama Borrego Nieto contacto con la norma (amplia, restringida o minima, en función de ciertos rasgos de los hablantes, como el grado de instrucción, viajes realizados, influencia en su habla de los medios de comunicación, etc.). A esta parte sigue otra en la que se exponen los resultados de orden lingüístico y sociolingüístico del estudio. En el capítulo 1 se recogen los materiales léxicos - sin empleo de la transcripción fonética-, ordenados según las preguntas y apartados nocionales del cuestionario, y con indicación de su carácter estándar o no y de los informantes que los ofrecen. Se cierra este capítulo con una lista de los vocablos no estándar obtenidos, lista que facilita su búsqueda y localización. En el capítulo 2 se analiza la penetración - global y por apartados nocionales- del vocabulario estándar en el léxico de Villadepera, y se demuestra cómo se ofrece una imagen falsa del habla de una comunidad cuando se recoge sólo el léxico diferencial y cómo existen diferentes grados de resistencia a la penetración del léxico estándar según los distintos sectores léxicos (más resistentes resultan la agricultura, vida pastoril, plantas, animales, etc.). Los capítulos 3 y 4 comparan las diferentes conductas observadas según los distintos grupos de hablantes, y se concluye que el factor realmente determinante de la diversidad de conductas sociolingüísticas es el que llama contacto con la norma. Los demás capítulos, 5, 6 y 7, se ocupan, respectivamente, de la diversidad semasiológica del léxico, de las manifestaciones metalingüísticas de los informantes (indicaciones y apreciaciones ofrecidas de manera espontánea por los sujetos encuestados en relación con sus respuestas) y de las actitudes sociolingüisticas de los hablantes ${ }^{99}$.

Los aspectos fónicos y morfosintácticos del habla de Villadepera, y la distribución sociolingüística que en relación con ellos presenta esta comunidad, fueron objeto de la otra publicación, Norma y dialecto en el sayagués actual. Su objetivo fundamental es la descripción de una serie de fenómenos fónicos — para cuya representación gráfica no emplea la transcripción fonética-, morfológicos y sintácticos del habla de Villadepera, algunos de los cuales son fenómenos históricos, pervivencias, por tanto, del viejo dialecto leonés hablado en estas tierras. En relación con estos fenómenos describe Borrego Nieto lo que llama su amplitud (mayor o menor extensión lingüística del fenómeno) y vitalidad (mayor o menor uso de sus manifestaciones lingüísticas). La obtención de los materiales objeto de estudio se realizó mediante la aplicación de un cuestionario - con diferentes tipos de preguntas según los distintos fenómenos estu-

99 Para otros pormenores sobre este trabajo, puede verse la reseña que de él hace Inmaculada MAS ÁlVAREZ, RFE, LXVII (1987), pp. 181-184. 
diados- a la misma muestra de informantes seleccionados en función de las variables - ya citadas- edad, sexo y contacto con la norma. El resultado es una imagen de la variación lingüística del habla de Villadepera en los planos fónico y morfosintáctico mucho más rica y completa que la ofrecida habitualmente por las monografías dialectales al uso, al incorporar a la descripción del fenómeno estudiado apreciaciones sobre su uso, vigencia, contextos en que aparece, etc. El trabajo se cierra con unas interesantes conclusiones, de orden lingüístico - dialectal- y sociolingüístico, y también metodológico, y con un apéndice en que se comparan dos momentos históricos del habla de Villadepera: la situación actual, descrita por Borrego Nieto, y la de principios de siglo (1912) descrita por Krüger en Studien zur Lautgeschichte westpanischer Mundarten. Un índice de palabras al final del libro permite una rápida y fácil localización de los fenómenos estudiados.

La línea de investigación sociolingüística de comunidades rurales iniciada por Borrego Nieto será seguida después, dentro del ámbito de nuestra provincia, por Juan Carlos González Ferrero, Sociolingüistica y variación dialectal. Estudio del habla de Flores de Aliste ${ }^{100}$. Se trata de un resumen de la memoria de licenciatura del autor, Esbozo de un estudio lingüistico de una comunidad alistana (Flores de Aliste), un trabajo realizado en la Facultad de Filología de la Universidad de Salamanca, Departamento de Lengua Española, bajo la dirección del profesor Antonio Llorente, durante los cursos $82 / 83$ y 83/84, y que se presentó en esta universidad en octubre de este último año. El objetivo general de esta investigación es determinar la peculiaridad lingüística (i.e., dialectal) del habla de Flores de Aliste, y averiguar la variación sociolingüística que en la comunidad corresponde a esta peculiaridad. El procedimiento para la obtención de los materiales lingüísticos fue distinto según cada uno de los planos de la lengua estudiados: para la recogida de los materiales léxicos se empleó el cuestionario del ALEP (pero sólo aquellos apartados nocionales en que la probabilidad de aparición de términos diferenciales es mayor, es decir, accidentes topográficos, agricultura, ganadería, plantas, animales, etc.); también mediante el procedimiento de encuesta y cuestionario se obtuvieron los datos que sirven de base al estudio morfológico; el estudio fonético, en cambio, se efectuó a partir de la observación del habla conversacional recogida en entrevistas grabadas. Estos procedimientos se aplicaron a una muestra de once informantes, representativa de la diversidad sociológica de la comunidad, seleccionados en función de las variables edad, sexo y

100 Zamora: Instituto de Estudios Zamoranos "Florián Ocampo" (CSIC)-Diputación de Zamora, 1986. 
experiencia de la lengua (combinación de los factores "grado de cultura", "acceso a los medios de comunicación" y "viajes", los cuales determinan los contactos de los hablantes con otras variedades de habla distintas a la suya propia e influyen, por tanto, en la configuración definitiva de su propio idiolecto). Desde el punto de vista dialectal, la conclusión más significativa que se desprende de este estudio es que, a pesar de estar situada en un área tradicionalmente considerada leonesa por la dialectología tradicional, el habla de Flores de Aliste es un habla castellana -o castellanizada-, que conserva, no obstante, una serie de rasgos fonéticos, morfológicos y, sobre todo, léxicos, de indudable filiación leonesa. Desde el punto de vista sociolingüístico, la conclusión más destacada es que el factor determinante de las diferentes conductas lingüísticas de los hablantes es la experiencia de la lengua, de manera que cuanto más restringida o local es la experiencia de la lengua del hablante, mayor es el carácter diferencial de su habla, y a la inversa, cuanto más amplia es, menos diferencial resulta.

En esta misma línea de investigación se están llevando a cabo en la actualidad trabajos sociolingüísticos, aún no concluidos, como el de M. ${ }^{a}$ Victoria García Malmierca, La comunidad de Bóveda de Toro: su situación lingüistica actual, tesis doctoral que bajo la dirección del profesor Borrego Nieto se realiza en el Departamento de Lengua Española de la Facultad de Filología de la Universidad de Salamanca. Los materiales en que se basa este estudio fueron recogidos entre 1989-1992, y se obtuvieron mediante la aplicación de un cuestionario (el del ALEP, con adiciones y supresiones) a una muestra de 24 informantes seleccionados en función de las variables edad, sexo y contacto con la norma. García Malmierca ha terminado ya el estudio léxico, mientras que en proceso de realización se encuentran los estudios fonético y morfosintáctico.

Un paso adelante en la investigación sociolingüística de las hablas de Zamora representa la tesis doctoral de Juan Carlos González Ferrero, Estudio sociolingüistico del habla de Toro (Zamora), realizada en la Facultad de Filología de la Universidad de Salamanca, Departamento de Lengua Española, bajo la dirección del Dr. D. Antonio Llorente, y presentada en esta misma universidad durante el curso 89/90. Esta investigación intenta forjar una metodología de aproximación a otro tipo de comunidades de habla, las constituidas por núcleos de población semiurbanos, caso de Toro, muy poco o casi nada estudiados hasta entonces. Se quiere, así, averiguar, fundamentalmente, cuáles son las características que tanto desde una perspectiva estrictamente lingüística, como desde una posición sociolingüística, definen una comunidad de habla semiurbana como la de Toro, frente a otras comunidades de habla rurales y urbanas. Son, por tanto, objetivos 
de esta investigación: (I) describir la variación lingüística que se produce en el habla de Toro, determinando lo que en ella se encuentra normalizado y no normalizado en relación con la norma lingüística estándar; (II) clasificar el conjunto de usos no estándar detectado; (III) determinar qué parte de la variación lingüística descrita constituye la norma lingüistica local; (IV) analizar la correlación existente entre la diversidad social y la diversidad lingüística de la comunidad; y (V) describir el grado de conciencia que los miembros de esta comunidad tienen de sus propios usos lingüísticos. Aunque en este trabajo se estudia el habla de Toro en todos sus aspectos, fónicos, morfosintácticos y léxicos, es, sin embargo, este último plano de la lengua el que recibe una mayor atención. Para determinar lo que en esta habla se encuentra normalizado y no normalizado se toma como patrones de referencia de la norma lingüística estándar el Diccionario de Uso del Español de María Moliner y el Diccionario de la Lengua Española, de la Real Academia. El vocabulario no normalizado se clasifica, a su vez, en leonesismos, arcaísmos, coloquialismos, etc. Junto al estudio léxico, y con el fin de incluir en esta investigación algunas observaciones sobre aspectos semánticos del habla de Toro, se describen también diferentes estructuras del campo semántico "edad». El material que sirve de base al análisis fonético es el mismo sobre el que se realiza el estudio léxico, y en cuanto al estudio morfosintáctico, se analizan unos cuantos fenómenos de carácter dialectal, vulgar, etc., sobre los que se pretende averiguar la vitalidad que presentan sus diferentes variantes en el habla de Toro y la estratificación sociolingüística que les corresponde. Las variables sociológicas que se contemplan en este estudio son cinco: ocupación, edad, sexo, estudios y nivel socioeconómico.

En cuanto a la obtención de los materiales, se emplearon cuatro cuestionarios: uno para el estudio léxico, con dieciocho apartados nocionales y 1.240 preguntas, y basado en el del ALEP, que es un cuestionario diseñado expresamente para el estudio de hablas rurales sin adscripción geográfica concreta, y también en el del Programa Interamericano de Lingüística y Enseñanza de Idiomas, elaborado para estudiar las hablas urbanas, y que se ha empleado en las investigaciones de la norma lingüística culta de las principales ciudades de la Península Ibérica y de Iberoamérica; otro para el estudio del campo semántico "edad", que es un cuestionario de carácter semasiológico, en el que se presentan unidades léxicas referentes a los distintos momentos de la vida (infancia, adolescencia, etc.) para obtener el significado particular, expresado en años, que los distintos informantes les atribuyen; otro para el estudio morfosintáctico, que contiene una serie de preguntas sobre diversos fenómenos dialectales, vulgares, etc., que tienen que ver con distintas categorías gramaticales (el nombre, 
el adjetivo, el verbo, etc.); y otro para el estudio de las actitudes lingüísticas de los miembros de la comunidad (veintinueve preguntas que se refieren a las creencias que tienen los hablantes en relación con la existencia de una "norma lingüística estándar", a su conciencia de la estratificación sociolingüística de la comunidad, a sus actitudes en relación con las hablas urbanas y rurales en general, y también en relación con las limítrofes, etc.). No existe un cuestionario específico para la parte de este trabajo dedicada a la fonética, ya que, según se ha dicho, se toma como corpus de análisis el vocabulario obtenido por medio del cuestionario léxico. El análisis de los materiales se realiza, por otro lado, aplicando procedimientos estadísticos que permiten determinar el grado de significación de las diferencias halladas al comparar apartados nocionales, grupos sociolingüisticos, etc. En líneas generales se concluye en este trabajo, desde una perspectiva estrictamente dialectal, que el habla de Toro presenta un índice de normalización alto y que las formas diferenciales observadas representan una proporción reducida en el habla de la comunidad. No obstante, el léxico vernáculo occidental y otros fenómenos occidentales registran importantes frecuencias, lo que viene a destacar la vinculación con el dominio lingüístico astur-leonés de esta habla situada en el área de nuestra provincia tradicionalmente considerada como castellanizada. En relación con el carácter semiurbano de la comunidad lingüística toresana se afirma que la naturaleza de su variación lingüística es significativamente diferente tanto en comparación con la que corresponde a comunidades típicamente rurales, como en relación con la que se ha descrito para comunidades propiamente urbanas, pero comparte con unas y con otras aspectos lingüísticos comunes que son resultado de su carácter sociológico intermedio entre unas y otras. En este sentido se dice que las comunidades rurales presentan vocablos diferenciales en mayor medida que las urbanas y que son más conservadoras de las peculiaridades dialectales, mientras que las urbanas aparecen como hablas altamente normalizadas, que tienden a eliminar los arcaísmos, dialectalismos, vulgarismos, etc., y que no son conservadoras, sino innovadoras, pues son fuente de neologismos, ya de acuñación propia, ya tomados como préstamos de otras lenguas extranjeras. Las hablas semiurbanas se diferencian de las rurales en que presentan un índice mayor de normalización y menor proporción de dialectalismos, y de las urbanas en que su índice de no normalización es mayor. Por último, desde una perspectiva sociolingüística, se concluye que en una comunidad lingüística semiurbana del tipo de la Toro se da una importante estratificación sociolingüistica según la ocupación, edad, los estudios y el nivel socioeconómico de los hablantes, y también, aunque en menor medida que en los casos anteriores, según el sexo. En ge- 
neral, los usos normalizados predominan en los sectores de ocupación de carácter urbano, en los sujetos jóvenes y en los hablantes con mayor nivel cultural y social, mientras que los usos no normalizados aparecen con mayor frecuencia en los grupos de ocupación no urbanos, y su presencia aumenta conforme se incrementa la edad y conforme disminuyen el nivel cultural y social.

A partir de la tesis doctoral cuyo contenido hemos resumido en el apartado anterior, González Ferrero ha realizado varias publicaciones, que pasamos a describir brevemente, siguiendo el orden cronológico en que han aparecido.

La primera publicación registrada es Palabras y expresiones en el babla de Toro (Zamora) ${ }^{101}$. En ella se resume y reelabora parte de las páginas 192-743 de la tesis doctoral, de las que se toma el vocabulario no normalizado obtenido y su significado, su adscripción dialectal y los datos que justifican esta adscripción. Se abre con una presentación en la que se señala que el contenido del libro está constituido por el vocabulario básico no normalizado que puede observarse en el habla actual de Toro, se explica la metodología empleada y se describen las distintas clases de unidades léxicas encontradas (leonesismos, arcaísmos, vulgarismos, etc.), con indicación del porcentaje que corresponde a cada clase dentro del conjunto del vocabulario estudiado. El resto del trabajo está formado por los diferentes apartados nocionales del cuestionario (agricultura, plantas, ganadería, cuerpo humano, etc.), en cada uno de los cuales se expone el vocabulario no normalizado recogido, ordenado alfabéticamente, y con su significado, adscripción dialectal y datos en que se basa esta adscripción. Para la representación gráfica de estos vocablos se utiliza la ortografía habitual. Un índice final permite la localización y consulta inmediatas de cualquier unidad registrada.

En "Las actitudes sociolingüísticas de una comunidad castellanoleonesa de carácter semiurbano: Toro (Zamora)" ${ }^{102}$ se describen las actitudes lingüísticas subjetivas de los miembros de la comunidad, aspecto al que se dedica el capítulo 7 de la tesis doctoral de autor, y del que este artículo constituye un resumen. Se estudian, pues, las creencias que tienen los hablantes en relación con la existencia de una norma lingüística estándar, sus opiniones sobre las hablas limítrofes, su conciencia de la estratificación sociolingüística de la comunidad, etc. Las actitudes de los hablantes se establecen a partir de la comparación entre los hechos lingüísticos y las creencias y opiniones lingüísticas que éstos manifiestan.

101 Toro: Colectivo Cultural "Bardales", 1990.

102 Anuario 1989 del Instituto de Estudios Zamoranos "Florián de Ocampo" (Zamora, 1991), pp. 663-706. 
En otro artículo, "Rasgos occidentales del habla de Toro (Zamora)" 103, se recogen los rasgos fónicos, morfosintácticos y léxicos de carácter occidental observados en el habla de Toro, con indicación de su vitalidad y de las diferencias sociolingüísticas encontradas en relación con la aparición de tales fenómenos según las variables sociológicas contempladas: ocupación, edad, sexo, estudios y nivel socioeconómico. Aunque se indica que la presencia de elementos occidentales en el habla de Toro es muy reducida y que su aparición se encuentra restringida a ciertos sectores del vocabulario y a ciertos grupos de hablantes, bien delimitados, además, desde el punto de vista sociolingüístico, el artículo hace especial hincapié en destacar cómo la presencia de tales elementos, aunque reducida, deja bien clara la existencia efectiva de relaciones histórico-lingüísticas entre el habla de Toro, situada en el área castellana -o castellanizada- de nuestra provincia, y el conjunto de hablas occidentales, en general, y el complejo dialectal asturleonés, en particular.

En el libro La estratificación sociolingüistica de una comunidad semiurbana: Toro (Zamora) ${ }^{104}$ se resumen los capítulos 1-4 de la tesis doctoral del autor, dedicados a la descripción de la variación lingüística del habla de Toro correspondiente al plano léxico y de la estratificación sociolingüística de esta comunidad, entendida como semiurbana, tal como se refleja en el vocabulario. En él se recogen los aspectos sociolingüísticos más interesantes de esta investigación, de los que ya nos hemos ocupado por extenso ${ }^{105}$.

Próximamente aparecerá, pues en el momento de redactar este artículo se encuentra en prensa, otro libro basado en la misma tesis doctoral, Variables sociolingüisticas en el habla de Toro (Zamora) ${ }^{106}$ libro que resume los capítulos 5 y 6 de esta tesis y parte de su Introducción. En él se recogen fundamentalmente las variables lingüísticas de orden fónico, morfosintáctico y semántico estudiadas en el habla de Toro, con indicación de la estratificación sociolingüística que en función de las mismas corresponde a esta localidad. Como hemos dicho, en este trabajo se atiende tanto a fenómenos fónicos y morfosintácticos de carácter histórico o dialectal, como a otros no específicos del área estudiada, sino generales, que tienen gran interés para el estudio de las variedades lingüísticas del español actual.

103 Studia Zamorensia, XI (1990), pp. 57-84.

104 Salamanca, Eds. Universidad de Salamanca, 1991.

105 De este libro hay reseña de J. FERnández VALLEJo en RFE, LXXIII (1993), pp. 451-452.

106 Zamora: Instituto de Estudios Zamoranos "Florián de Ocampo" (CSIC)-Diputación de Zamora. 
La más reciente investigación sociolingüística realizada en nuestra provincia de que tenemos noticia es el trabajo de María Hernández García, Estudio sociolingüístico. El habla de la comarca de Toro en su zona Norte, trabajo de clase inédito al que hemos tenido acceso gracias a la amabilidad de su autora, cuya dirección ha corrido a cargo del profesor César Hernández, y que ha sido realizado en el Departamento de Lengua Española de la Facultad de Filología de la Universidad de Valladolid, durante el año académico 1994/1995. Se trata de un estudio sociolingüístico sobre distintos aspectos morfosintácticos del habla de varios pueblos del área Norte de la comarca de Toro, en el que se combinan, pues, como ya hemos dicho, la perspectiva geográfico-lingüistica y la sociolingüistica. Los fenómenos morfosintácticos de que se ocupa son muy variados, y van desde la descripción del género y número de determinados sustantivos hasta el análisis de distintos casos de leísmo o laísmo, pasando por el estudio de las formas verbales, formación de palabras y otros. Los procedimientos utilizados para la obtención de los materiales en que se basa el estudio son la encuesta directa y la grabación de una conversación más o menos dirigida a un serie de informantes seleccionados en función de tres variables sociológicas: sexo, edad (tres generaciones: 15-30, 31-50, +51) y estudios (con tres grupos: superiores, medios y primarios o sin estudios). Los pueblos en que se han recogido materiales, y cuya habla, por tanto, se estudia, son Morales de Toro, Pozoantiguo, Villavendimio, Vezdemarbán, Villardondiego, Abezames, Pinilla de Toro, Malva y Fuentesecas. El trabajo no entra, sin embargo, en el análisis de las diferencias existentes entre estas localidades, sino que sólo nos ofrece los resultados globales obtenidos para el conjunto de hablas estudiadas. Se trata, pues, de una valiosa investigación, muy interesante, además, por centrarse en un área poco conocida hasta ahora, y mucho menos todavía en los aspectos morfosintácticos que son su objeto de interés, pero que la autora deberá, ciertamente, ampliar y completar en el futuro mediante un análisis exhaustivo de los materiales reunidos.

\section{Otros estudios}

Los trabajos dialectales descritos en los párrafos anteriores constituyen el conjunto de investigaciones sobre las hablas de Zamora más importante realizado en este tercer período (1973-1995). Además de ellos, también encontramos en este momento toda otra serie de publicaciones, de diversa índole y menor relieve que los anteriores, que contienen, igualmente, información lingüística interesante sobre nuestra provincia. Sus 
autores son, en la mayor parte de los casos, estudiosos locales o especialistas de otras disciplinas, y su aparición es consecuencia, fundamentalmente, del renovado interés que se da en estos años por las tradiciones y cultura popular, en general, y por el de las hablas vivas, en particular.

Comenzaremos la descripción destacando, en primer lugar, la existencia de varios trabajos de carácter estrictamente dialectal. Así, el de Carlos Cabañas, "Aproximación al dialecto leonés de Zamora ciudad" ${ }^{107}$, que tiene el mérito de ocuparse de manera expresa del habla de la capital de la provincia, hasta la fecha muy poco, por no decir nada, estudiada. Su propósito es mostrar su filiación leonesa, para lo que toma una serie de vocablos que según él se emplean habitualmente en Zamora capital y los compara con otros parecidos o completamente diferentes recogidos en obras sobre hablas de la provincia (Aliste, Sanabria, Sayago) o del dominio lingüístico leonés (Bierzo, Cepeda, Arribes, Béjar, etc.). De este modo determina las diferencias y semejanzas entre las denominaciones observadas en el habla de Zamora ciudad y las atribuidas a otras hablas leonesas. Otro trabajo interesante es el de Nicolás Rodríguez Peláez, "Palabras y modismos de la Tierra de Alba" ${ }^{108}$. Contiene un repertorio léxico constituido por unas doscientas palabras y expresiones usuales en la comarca de Tierra de Alba, e interesantes, a juicio del autor, desde el punto de vista dialectal, a cuya forma añade el significado, y, en ocasiones, alguna observación sobre su uso. En general, las formas se presen$\tan$ sin localizar, salvo en una ocasión, en que la expresión recogida se atribuye expresamente a Carbajales. Otro estudio, de mayor entidad que los anteriores, pues se trata de un libro, no de un artículo, es el vocabulario de A. García Caballero, Localismos ${ }^{109}$, trabajo de un erudito local, cuyo propósito es elaborar un diccionario de vocablos populares pertenecientes a las hablas de una serie de pueblos del rincón nororiental de la provincia de Zamora, en el "Confín más occidental de la Tierra de Campos" (p. 9), enmarcados "dentro de un rombo imaginario cuyos vértices estarían en Benavente, Castroverde de Campos, Valderas y Villalpando" (p. 10). Todos los pueblos en que García Caballero recoge vocablos son de Zamora, excepto dos (Quintanilla del Molar y Roales de Campos), que pertenecen ya a Valladolid, pero que por razones de proximidad, historia, etc. resultan afines a aquéllos. García Caballero no

107 Anuario 1985 del Instituto de Estudios Zamoranos "Florián de Ocampo" (Zamora, 1986), pp. 283-292.

108 El Correo de Zamora, I (3-X-91), II (10-X-91).

109 Valladolid: Castilla Ediciones, 1992. 
tiene otra pretensión que la de dejar constancia del uso —cada vez más en declive- de los términos que recoge, de manera que junto a las distintas formas ordenadas alfabéticamente no encontramos más información que su significado. Al final del libro el autor incluye también un repertorio de dichos y adagios populares, con exposición de su significado e intento de explicación de su origen. Por último, dentro de este conjunto de trabajos estrictamente dialectales realizados por autores no filólogos debemos mencionar varios artículos divulgativos, normalmente sobre vocablos o expresiones de Aliste, Alba y Tábara, publicados en la prensa provincial por el profesor y antropólogo Francisco Rodríguez Pascual. Estos artículos suelen tratar del significado, etimología, extensión geográfica, uso, filiación dialectal, etc. de las distintas unidades léxicas a que se refieren. Son ejemplos de estos trabajos "A ti la jaquetona" ${ }^{110} \mathrm{y}$ "No seas cuzo!" "11.

Además de estos escritos estrictamente dialectales, también nos ofrecen información sobre las hablas de nuestra provincia otras obras misceláneas, realizadas normalmente por estudiosos locales, en las que junto a los aspectos geográficos e históricos, y junto a las costumbres, tradiciones y folclore de la localidad o comarca en cuestión, se nos describen igualmente, con mayor o menor amplitud, diferentes rasgos diferenciales de su habla. Pertenecen a este grupo algunas obras de Ramón Manuel Carnero Felipe, como Historia, leyendas y costumbres de Pereruela de Sayago ${ }^{112}$ y Pereruela de Sayago. La parroquia, la desamortización y los Docampo ${ }^{113}$. En la primera aparece información dialectal, fundamentalmente léxica, en los capítulos dedicados a las tradiciones y costumbres del pueblo y a su actividad alfarera (muy bien descrita e ilustrada con dibujos y fotografías), y en el repertorio léxico que el propio autor recoge al final del libro. En la segunda, Carnero Felipe incluye un nuevo vocabulario de términos locales como complemento al que figura en aquel otro estudio. Asimismo, en el libro de Manuel Rivera Lozano, Fermoselle ${ }^{114}$ encontramos un glosario de términos usados en Fermoselle y no recogidos en el DRAE $\left(19^{\mathrm{a}}\right)$, algunos de los cuales han sido tomados, según indica el autor, del libro de L. Cortés Vázquez, Donde Sayago termina... Fermoselle ${ }^{115}$. Por otro lado, en el estudio de

\footnotetext{
110 La Opinión-El Correo de Zamora, 19-VI-95.

111 La Opinión-El Correo de Zamora, 5-X-95.

112 Zamora: Edición del Autor, 1980.

113 Salamanca: Edición del Autor, 1984.

114 Zamora: Edición del Autor, 1982.

115 Salamanca: Librería Cervantes, 1981.
} 
José Rivas Blanco, Aliste visto desde Rabanales ${ }^{116}$ encontramos una descripción de las hablas de Aliste. Esta descripción está constituida tanto por las denominaciones locales que aparecen en los capítulos de carácter etnográfico dedicados a la matanza, juegos, etc., como por las que recoge el autor en el capítulo titulado "Contribución para un vocabulario alistano-leonés", que ésta formado por unas 2000 entradas. Además de información léxica, también encontramos en esta obra alguna referencia esporádica de carácter morfosintáctico sobre el artículo, pronombre, verbo, etc. En la misma línea, el libro de Ángel Turiño Mínguez, Tradiciones $y$ añoranzas de un pueblo de Zamora: Pajares de la Lampreana ${ }^{117}$ presenta una descripción etnográfica de las formas de vida tradicionales (sementera, matanza, fiestas, costumbres, coplas y canciones populares, etc.) de este pueblo, que contiene, por tanto, como es habitual en este tipo de trabajos, una recopilación de las denominaciones locales que aparecen asociadas a estas formas de vida cada vez más en desuso, de las que el autor nos da, como natural del pueblo, el testimonio personal de su existencia. Turiño Mínguez recoge, además, al final del libro, un vocabulario con aquellas palabras y expresiones empleadas en Pajares de la Lampreana que a su juicio resultan más llamativas. Por último, el más importante de los trabajos de este tipo que conocemos es seguramente el de Gregorio Rodríguez Fernández, Paisaje y alma de Aliste ${ }^{118}$, obra que se ocupa de la comarca de Aliste, en general, y del pueblo de Riofrío de Aliste, del que es natural el autor, en particular. Los aspectos de que trata son los habituales en este tipo de estudios: geografía, historia, vida tradicional, costumbres, celebraciones religiosas, folclore, peculiaridades lingüísticas, etc. El libro está escrito con un profundo deseo de exhaustividad, lo que hace que las descripciones que incluye resulten, en todos los aspectos, a pesar del carácter de no especialista del autor, completísimas, mucho más que las que encontramos en libros de índole parecida sobre otras comarcas. Desde el punto de vista lingüístico, lo más destacable de esta obra son el abundante vocabulario que presentan las descripciones de carácter etnográfico y las de costumbres y vida tradicional que encontramos, el capítulo dedicado a las peculiaridades lingüísticas de la comarca, que contiene, además de una enumeración de rasgos fonéticos y morfológicos, una serie de diálogos en "habla alistana", a la manera de las obras

116 Zamora: Ayuntamiento de Rabanales, Diputación de Zamora, Caja de Zamora, Caja Rural de Zamora, 1986.

117 Madrid: Edición del Autor, 1988.

118 León: Edición del Autor, $1991\left(1 .^{\mathrm{a}}\right), 1992\left(2 .^{\mathrm{a}}\right)$. 
literarias costumbristas o regionalistas que intentan reproducir el habla popular, y, por último, un diccionario de localismos, al final del libro, que recoge términos usados en Riofrío de Aliste.

Otro conjunto de trabajos que no son dialectales en sentido estricto, pero que contienen información dialectal sobre la hablas de nuestra provincia son aquellos que se ocupan de la cultura popular en sus diferentes aspectos, y, en especial, los de carácter etnográfico. Dentro de este grupo de estudios hay que destacar diversas publicaciones de Cortés Vázquez, algunas de las cuales constituyen reediciones o reelaboraciones de materiales publicados en el período anterior. Es el caso de Leyendas, cuentos y romances de Sanabria. Textos leoneses y gallegos ${ }^{119}$, en la que recoge Cortés leyendas, cuentos y romances sanabreses recolectados por él a finales de los años cuarenta y principios de los cincuenta, y que ya había publicado con anterioridad en diversos trabajos. En la edición de 1981, aparecen, no obstante, varios textos recogidos en una rápida excursión del autor a Sanabria en febrero de 1979. Estos textos leoneses y gallegoportugueses constituyen, además de una valiosísima aportación al conocimiento del folclore y de la literatura popular sanabreses, magníficos documentos para estudiar las hablas de esta comarca zamorana. Junto a los textos encontramos unas notas, de carácter folclórico, que explican el posible origen y difusión de las leyendas, cuentos y romances recopilados, y un vocabulario, cuyo principal objetivo es facilitar la lectura del libro, en el que se recogen diferentes términos -leoneses, gallegos o portugueses- que aparecen en los textos. Otro trabajo no lingüístico de Cortés Vázquez en el que igualmente encontramos información dialectal es el ya citado Donde Sayago termina... Fermoselle. Se trata de una obra literaria en la que el autor rememora la vida (tipos, costumbres, sucesos, familias) a lo largo de la primera mitad de este siglo en el pueblo de Fermoselle, donde han vivido sus antepasados, y él mismo, de niño, y en el que encontramos vocablos de carácter dialectal o diferencial que aparecen utilizados por el autor en descripciones más o menos etnográficas o costumbristas, y también en un glosario que incluye al final del libro. Finalmente, otras obras etnográficas de Cortés Vázquez publicadas en este período tienen también interés dialectal. Citemos los artículos "Los últimos batanes de Sayago (Zamora)" ${ }^{120}$ y "Las alfarerías femeninas" ${ }^{121}$, y el libro

119 Salamanca: Librería Cervantes, $1976\left(1 .^{\mathrm{a}}\right), 1981\left(2 .^{\mathrm{a}}\right), 1992\left(3 .^{\mathrm{a}}\right)$.

120 In Memoriam António Jorge Dias (Lisboa: Instituto de Alta Cultura, Junta de Investigações do Ultramar, III, 1974), pp. 375-392.

121 Narria, 20 (1980), pp. 10-13. 
Alfarería popular del Reino de León ${ }^{122}$. Además de los trabajos de Cortés, encontramos también descripciones de nuestras hablas en obras no dialectales de otros autores. Es el caso de Paule Aliste, Survivances de la tradition orale dans la région d'Aliste ${ }^{123}$, investigación de carácter folclórico que sólo de manera secundaria se interesa por los aspectos dialectales de los textos que recoge y cuyo principal objetivo es la recolección, clasificación y estudio de una serie de cuentos, romances y canciones, restos de una tradición oral aún hoy viva en un pequeño pueblo de Aliste, Tola, del que desciende la autora. Desde el punto de vista dialectal, lo más interesante de este trabajo se encuentra en el capítulo 4 de la Primera Parte, dedicado a la exposición de los rasgos lingüísticos, dialectales, que presentan los textos recogidos, y el Glosario que aparece al final del libro. Otra publicación digna de mención es la de Angélica Fernández Ramos, Estudio y textos del Romancero de Peleagonzalo ${ }^{124}$, estudio folclórico, literario, métrico, musical, etc. del romancero tradicional hoy vivo en la memoria de las gentes de este pueblo zamorano de la Tierra del Vino, en el que aparecen vocablos y expresiones diferenciales asociados a las costumbres y tradiciones locales, y también un breve estudio de diferentes aspectos (fonéticos, morfosintácticos y léxicos) del habla local, tal como se reflejan en los romances estudiados (pp. 119-120). Igualmente debemos incluir en este grupo el trabajo de Miguel Ángel Martín Carbajo, "El arado y el carro en un pueblo del NW zamorano, Brandilanes de Aliste" ${ }^{125}$, en el que encontramos una descripción etnográfica, con auxilio de fotografías y dibujos, del carro y del arado usados en el pueblo alistano de Brandilanes, descripción en la que aparecen los diferentes nombres de sus partes y piezas. Y por último, gran interés ofrece el "Vocabulario de Terroso y San Martín del Terroso (Sanabria)" incluido por J. M. Rodríguez Iglesias en su tesis doctoral inédita Los lenguajes culturales de un municipio sanabrés (Terroso y San Martín del Terroso), pp. 682-704. Se trata de una tesis dirigida por el profesor Francisco Rodríguez Pascual y presentada en 1991 en la Facultad de Filosofía de la Universidad Pontificia de Salamanca, en la que incluye el autor un repertorio léxico formado por palabras y expresiones referentes a los más diversos aspectos de la vida de estos lugares, y que pueden tener, en su opinión, dificultades de comprensión para el lector, o sobre las que resulta interesante, a su juicio, llamar la atención.

\footnotetext{
122 Salamanca: Librería Cervantes, 1987.

123 Perpiñán: CRILAUP, 1988.

124 Zamora: Instituto de Estudios Zamoranos "Florián de Ocampo"-Diputación de Zamora, 1990.

125 Revista de Folklore, núm. 118 (1990), pp. 111-119.
} 
Otro conjunto de trabajos que tienen un claro interés dialectal, aunque no han sido realizados por dialectólogos, son los estudios onomasiológicos sobre animales y plantas llevados a cabo por especialistas del mundo natural. Dentro de este grupo debemos distinguir claramente dos clases de investigaciones: (I) los estudios onomasiológicos específicos sobre nuestra provincia y (II) los generales en los que se incluyen referencias a las denominaciones que en Zamora se dan a plantas y animales. Al primer grupo pertenece el artículo de Ignacio Regueras, "Denominaciones locales de diferentes especies zoológicas en la provincia de Zamora" ${ }^{126}$. Se recogen en él los nombres hallados por el autor en distintas comarcas y pueblos de Zamora para 56 especies y/o géneros de aves y 6 especies de mamíferos. El trabajo contiene información referida a la mayor parte de comarcas zamoranas, pero donde la búsqueda se ha realizado con mayor intensidad ha sido, según el autor, en el área de Montamarta (este pueblo y San Cebrián de Castro, Piedrahita de Castro, Santa Eufemia del Barco, San Pedro de las Cuevas), en Sanabria (al Norte de la carretera Benavente-Orense) y en la zona de Villafáfila (entre el río Esla y el Valderaduey, y desde San Esteban del Molar hasta Villalba de la Lampreana). La exposición adopta la forma de una tabla en la que aparecen, en la parte izquierda, el nombre científico y el vulgar de cada especie, y a continuación, y formando una fila hacia la derecha, los nombres localizados en cada una de las zonas antes mencionadas (Montamarta, Sanabria y Villafáfila) y en otras localidades de la provincia. Se trata de una distribución que permite hacer interesantes comparaciones entre las diferentes denominaciones encontradas para la misma especie según las distintas localidades y comarcas. Al segundo grupo - estudios generales-, pertenecen dos diccionarios: el de Andrés Ceballos Jiménez, Diccionario ilustrado de los nombres vernáculos de las plantas en España ${ }^{127}$ y el de Francisco Bernis, Diccionario de nombres vernáculos de aves ${ }^{128}$. El propósito de Ceballos es recopilar, con la mayor exhaustividad posible, las denominaciones populares empleadas para designar a las plantas en las diferentes lenguas y modalidades dialectales y regionales de la Península Ibérica. Por lo que respecta a Zamora, las fuentes consultadas han sido T. M. Losa España, Contribución al estudio de la flora y vegetación de la provincia de Zamora ${ }^{129}$ y C. Alonso y M. Morey, "La vegetación en

126 Anuario 1985 del Instituto de Estudios Zamoranos "Florián de Ocampo" (Zamora, 1986), pp. 107-113.

127 Madrid: ICONA, 1986.

128 Madrid: Ed. Gredos, 1995.

129 Madrid: CSIC, Instituto A. J. Cavanilles. 
relación con gradientes de encharcamiento y salinidad en las lagunas salobres de Villafáfila (Zamora)" ${ }^{130}$. En cuanto al Diccionario de nombres vernáculos de aves, se trata de una recopilación de los nombres vulgares de las aves de España, para cuya realización el autor ha empleado distintos procedimientos: entrevistas directas, realizadas entre 1934 y 1970 , en diferentes localidades; encuestas postales, mediante cartas dirigidas a personas de diferentes lugares, y que, por tanto, no constituyen un procedimiento directo de recogida de denominaciones; testimonios de ornitólogos y colaboradores residentes en diversas regiones de España; consulta de muy variadas fuentes bibliográficas: vocabularios medievales y dialectales, diccionarios antiguos y modernos, obras científicas, etc. Por lo que se refiere a la provincia de Zamora, Bernis recoge directamente nombres de aves en localidades situadas en la Sanabria Leonesa, Sayago y Tierra de Campos, y mediante encuestas postales en Tierra de Tábara, Tierra de Campos, Sayago Suroriental y Tierra del Vino. Lamentablemente, el autor no suele indicar de qué localidades se trata, ni en los mapas que incluye, ni al describir las denominaciones correspondientes.

Para finalizar esta descripción de los estudios lingüísticos sobre las hablas de Zamora llevados a cabo en este tercer período (1973-1995), vamos a ocuparnos de dos estudios no específicos sobre las hablas de Zamora, sino genéricos sobre las hablas de la comunidad castellanoleonesa, en los que figuran, como es lógico, referencias a nuestra provincia. Se trata de la descripción dialectal de conjunto de Eugenio de Bustos Gisbert, "Las variedades dialectales y regionales en Castilla y León " ${ }^{131}$ y de la recopilación léxica de Eugenio Miguélez Rodríguez, Diccionario de las hablas leonesas (León, Salamanca, Zamora) ${ }^{132}$. El primero tiene por objeto la descripción de las distintas variedades dialectales y regionales de Castilla y León. Dentro de la descripción general del complejo dialectal leonés, el autor señala los rasgos más relevantes de las variedades lingüísticas de Zamora, y su mayor o menor vinculación - semejanzas y diferencias - con otras de este dominio lingüístico. Bustos Gisbert ilustra sus afirmaciones con abundantes ejemplos, y hace especial hincapié en el alto grado de castellanización de las comarcas orientales zamoranas. Al mismo tiempo, llama la atención sobre la conservación de restos leoneses en hablas tan castellanizadas como las de Sayago. Por su parte, el Diccionario de las hablas leonesas de Miguélez Rodríguez presenta una recopilación de términos leoneses, cuyo propósito

130 Boletín de la Estación Central de Ecología, vol. 7, núm. 14 (1978), pp. 21-37.

131 En VV.AA. [coord. de la Junta de Castilla y León], Castilla y León (Madrid: Eds. Anaya, 1987), pp. 338-353).

132 León: Edición del Autor, 1993. 
es refundir "en uno solo los principales vocabularios parciales [sobre las hablas leonesas], pretendiendo que resulte un diccionario, más que leonés, de las hablas leonesas" (p. VII). Se trata, por tanto, de un diccionario de términos leoneses realizado a partir de los materiales léxicos recogidos en diferentes artículos, monografías locales, estudios comarcales, etc. sobre las hablas de las que llama el autor "provincias históricas leonesas: León, Zamora y Salamancaw. En el caso concreto de Zamora, este diccionario se ha elaborado a partir de las investigaciones de José María Baz, El babla de la Tierra de Aliste, Fritz Krüger, El dialecto de San Ciprián de Sanabria y Francisco Ynduráin, "Notas sobre el habla de Benavente (Zamora)". Es, como vemos, una representación un tanto exigua, que podría, sin duda, haberse completado con otros estudios ${ }^{133}$.

133 Estando ya redactado y preparado para su impresión este artículo, hemos tenido conocimiento de la existencia de algunos trabajos no descritos a lo largo de los párrafos anteriores, cuya referencia bibliográfica, al menos, no queremos omitir. Se trata de los siguientes estudios: M. Carmen Rodríguez LAGo, Léxico dialectal y costumbres de Porto (Santiago de Compostela: Facultade de Filosofía e Letras da Universidade de Santiago de Compostela, 1974 [Memoria de Licenciatura inédita]); M. A. FERRERO Domínguez, Palabras, frases $y$ "dichos" de la Tierra de Aliste (Zamora, Instituto Geográfico Catastral, 1992, 2. ${ }^{a}$ ed.); Adolfo ElizAINCín, Dialectos en contacto (español y portugués en España y América) (Montevideo: Ed. Arca, 1992); Luciano LÓPEZ y Araceli GodiNo, "Notas y testimonios sobre un manojo de términos vigentes en el habla de Villalpando", Anuario 1994 (Zamora: Instituto de Estudios Zamoranos "Florián de Ocampo", 1995), pp. 533-556; Fred Boller, "Somos castelans, pero falamos galego", Tranvía-Revue der Iberischen Halbinsel, 27 (Berlín, 1992), pp. 7-11; Fred Boller, "Mundarstudien zum Problem de galicisch-portugiesisch-spanischen Kontaktzone", Sprache, Literatur und Kultur Galiciens, Akten des 2. gemeinsamen Kolloquiums der deutschsprachigen Lusitanistik (Berlin, 10-12 Septembre 1992); Beihefte zu Lusorama, 1. Reihe, Studien zur portugiesischen Sprachwissenschaft, 4. Band, lusitanitischer Teil, Band 1, hrsg. von Johannes Kabatek und axel Schönberger, (TFM/Domus Editoria Europaea, Frankfurt am Main 1993), pp. 27-36; Fred Boller, Die Isoglossenstaffelung in der galicisch-portugiesisch-spanischen Kontaktzone und im Lombada-AlisteGrenzgebiet, t. 1: Kommentar zum Regionalsprachatlas: Die diatopische Variation im Dialektraum, t. 2: Regionalsprachatlas mit synoptischem Kartenteil (Kiel: WestenseeVerlag, 1995); David GARCía LóPEz, Estudio sobre el habla de Porto (Zamora) (Salamanca: Departamento de Lengua Española de la Facultad de Filología de la Universidad de Salamanca, año académico 1994/1995 [trabajo de clase inédito dirigido por el profesor Alexandre Rodríguez en la asignatura de Galaicoportugués); Francisco Rodríguez PASCUAL, "Por riles", La Opinión-El Correo de Zamora (1-III-96); Francisco RODRÍGUEZ PASCUAL, "Morgado", La Opinión-El Correo de Zamora (18-III-96); Francisco RODRÍGUez PASCUAL, "LLuciérnaga o cagaluz?", La Opinión-El Correo de Zamora (12-IV-96); David GARCía LóPEZ, «Buena jera!, La Opinión-El Correo de Zamora (12-IV-96); Francisco RodríGUeZ PASCUAL, "El cibiaco", La Opinión-El Correo de Zamora (11-VI-96); Ramón Manuel CARNERO FELIPE, Viriato, el druida guerrero (Zamora: Duero Ediciones, 1996); Joaquín BLANCO MAJADO et alii, "Diccionario zamorano-leonés-caste- 


\section{VALORACIÓN PROSPECTIVA}

En los apartados anteriores hemos intentado describir la actividad dialectológica desarrollada en nuestra provincia a lo largo de los últimos cien años. Esta descripción, realizada fundamentalmente con un propósito explicativo, supone también, de manera implícita, una valoración retrospectiva de este quehacer lingüístico. En los párrafos que siguen queremos señalar cuáles son, a la vista de la descripción efectuada, las líneas de actuación futura que a nuestro juicio deben seguir los nuevos estudios dialectales sobre $\mathrm{Za}$ mora. Se trata, así, de realizar otro tipo de valoración, una valoración prospectiva, de los trabajos descritos, con el fin de que quienes a partir de ahora se inicien en la investigación dialectal de nuestra provincia puedan disponer de algún tipo de orientación, y puedan conocer qué aspectos son los que - siempre en nuestra opinión- ofrecen un mayor interés.

Un primer aspecto de la cuestión que debe considerarse es qué áreas de la provincia de Zamora tienen mayor interés, a la vista de los trabajos realizados, para estas futuras investigaciones. Puede decirse que las hablas orientales, en cuanto que menos estudiadas, resultan en principio mucho más atractivas e interesantes. Sin embargo, no debe pasársenos por alto que la mayor parte de los estudios sobre las occidentales - sobre Sanabria, por ejemplo- son, en líneas generales, bastante antiguos, lo que hace que la realización de nuevos trabajos sobre estas otras hablas no sólo sea importante porque nos permite conocer su estado actual, sino también porque haría posible averiguar, mediante las correspondientes comparaciones, cuál ha sido su evolución a lo largo de este siglo. En este sentido hay que señalar que ahora mismo disponemos ya de materiales sobre algunas de estas hablas, como la de Hermisende, por ejemplo, recogidos en distintos momentos a lo largo de los últimos cien años, con los que se podrían efectuar ya - sin necesidad de realizar, por tanto, nuevas investigaciones- estudios de gran interés sobre su evolución.

Por su parte, los estudios sobre comarcas y las monografías locales siguen siendo, en general, trabajos de interés, mayor o menor en función

llano", La Opinión-El Correo de Zamora (8-XII-96); David GARCíA LÓPEZ, "Difusión del yeísmo asturleonés en La Carballeda (Zamora)", Lletres Asutrianes 61 (1996), pp. 33-40; David GARCía LÓPEZ, Estudio sobre el habla de La Carballeda y La Requejada (Zamora). Monografía leonesa (Salamanca: Universidad de Salamanca, 1996 [Memoria de Licenciatura inédita]); Julio BorREgo NiETo, "Leonés", en Manuel ALVAR (director), Manual de dialectología bispánica. El español de España (Barcelona: Ed. Ariel, 1996), pp. 139-158; César HERNÁNDEZ ALONSO, "Castilla la Vieja", en Manuel Alvar (director), op. cit., pp. 197-212; Gregorio RODRÍGUEZ FERNÁNDEZ, Imagen y memoria de Aliste (León: Edición del Autor, 1997). 
del área dialectal en que se encuentren las hablas estudiadas, y también en función de los aspectos lingüísticos que se investiguen. En relación con los primeros, los comarcales, además de los estudios dialectales de conjunto referidos a los distintos planos del análisis lingüístico, también pueden resultar interesantes los trabajos intensivos sobre aspectos destacados y específicos de algunas comarcas, como, por ejemplo, el estudio léxico de la cultura material de la vid y el vino en las comarcas vitivinícolas de la provincia. Las monografías locales, por su lado, deben realizarse siguiendo el enfoque sociolingüístico, también válido, pero más laborioso de efectuar en los estudios comarcales. Dos comunidades de habla sobre las que urge, a mi juicio, llevar a cabo estudios de carácter sociolingüístico son los dos núcleos urbanos de mayor entidad de nuestra provincia, Zamora y Benavente, sobre cuyas hablas prácticamente nada se ha trabajado. No nos cabe la menor duda de que la descripción sociolingüística resultante ha de tener gran interés. Además, en todos estos estudios - ya sean sobre comarcas o sobre localidades- debe prestarse, sin duda, a los aspectos morfosintácticos una atención mayor que la que tradicionalmente se ha venido prestando (con frecuencia sólo tratados de manera secundaria).

Otros estudios de carácter sociolingüístico sobre nuestra provincia que aún están por hacer, y que bien merecen, en mi opinión, la dedicación y el esfuerzo de los futuros investigadores, son los relacionados con las situaciones de bilingüismo y diglosía que se dan, sobre todo, en las comunidades lingüísticas sanabresas. Llorente Maldonado ha señalado en diversos trabajos la existencia de estas situaciones, pero hasta la fecha nadie, que sepamos, se ha ocupado de estudiarlas a fondo. Dentro del mismo ámbito de contactos de lenguas y variedades lingüísticas hay que señalar también la necesidad de investigar de manera intensiva los contactos que se producen entre las hablas fronterizas a ambos lados de la raya hispanoportuguesa, poniendo especial énfasis en destacar aquellos elementos que constituyen el trasfondo lingüístico común a las hablas de Zamora y a las de la vecina región portuguesa de Tras-os-Montes.

Y finalmente digamos que a partir de los materiales aportados por los diferentes estudios dialectales sobre la provincia de Zamora realizados hasta la fecha pueden elaborarse también descripciones de conjunto de su diversidad dialectal, ya generales, ya sobre aspectos específicos, algo que nosotros mismos intentaremos hacer, a partir de la recopilación llevada a cabo, dentro del proyecto de elaboración de una Enciclopedia Dialectal de Zamora a que nos hemos referido al principio de este artículo. 


\section{BiBLIOGRAFÍA}

ALINEI, M. et alii, Atlas Linguarum Europae (ALE), vol. I.1, I.2, 1. ${ }^{\circ}$ fascicule, (Assen: Van Gorcum, 1983); vol. I, 2. ${ }^{\circ}$ fascicule, (Assen: Van Gorcum, 1986).

Aliste, PAUle, Survivances de la tradition orale dans la région d'Aliste (Perpiñán: CRILAUP, 1988).

ALONSO, C. Y MOREY, M., "La vegetación en relación con gradientes de encharcamiento y salinidad en las lagunas salobres de Villafáfila (Zamora)", Boletín de la Estación Central de Ecología, vol. 7, núm. 14 (1978), pp. 21-37).

Álvarez Martínez, U., Artículos, en Zamora Ilustrada, núms. 10, 15, 33, 40, 42 (18811882), edición facsímil a cargo de la Diputación de Zamora, Tomo I (núms. 1-28) y Tomo II (núms. 29-50) (Zamora, 1988 [2.ㄹ).

Álvarez Tejedor, ANTONio, "Aproximación al estudio del léxico rural de la provincia de Zamora", Anuario 1986 del Instituto de Estudios Zamoranos "Florián de Ocampo" (Zamora, 1986), pp. 251-263.

- Estudio lingüístico del léxico rural de la zona Este de la provincia de Zamora (Salamanca: Eds. Universidad de Salamanca-Colegio Universitario de Zamora, 1989).

BAZ, JosÉ MARÍA, El habla de la Tierra de Aliste (Madrid: Anejo LXXXII de la RFE, 1967).

Belmonte, Fernando, "Locuciones zamoranas", El Averiguador Universal, Año I, núm. 7 (1879), p. 308.

BERNIS, FRANCISCO, Diccionario de nombres vernáculos de aves (Madrid: Ed. Gredos, 1995).

Blanco Majado, JOAQuín et alii, "Diccionario zamorano-leonés-castellano", La OpiniónEl Correo de Zamora (8-XII-96).

BLÁNQuez Fraile, Agustín, "Límites del dialecto leonés occidental en Alcañices, Puebla de Sanabria y La Bañeza", Memoria de la Junta para la Ampliación de Estudios (Madrid, 1907), pp. 67-78.

BOLLER, FRED, "Mundartstudien zum Problem de galicisch-portugiesisch-spanischen Kontaktzone", en Sprache, Literatur und Kultur Galiciens, Akten des 2. gemeinsamen Kolloquiums der deutschsprachigen Lusitanistik (Berlin, 10-12 Septembre 1992); Beihefte zu Lusorama, 1. Reihe, Studien zur portugiesischen Sprachwissenschaft, 4. Band, lusitanistischer Teil, Band 1, hrsg. von Johannes Kabatek und Axel Schönberger, (Frankfurt am Main: TFM/Domus Editoria Europaea, 1993), pp. 27-36.

- "Somos castelans, pero falamos galego", Tranvia-Reviue der Iberischen Halbinsel 27 (1992), pp. 7-11.

- Die Isoglossenstaffelung in der galicisch-portugiesisch-spanischen Kontaktzone und im Lombada-Aliste-Grenzgebiet, T. 1: Kommentar zum Regionalsprachatlas: Die diatopische Variation im Dialektraum, T. 2: Regionalsprachatlas mit synoptischem Kartenteil (Kiel: Westensee-Verlag, 1995).

BorRego Nieto, Julio, "Leonés", en Manuel Alvar (director), Manual de dialectología bispánica. El español de España (Barcelona: Ed. Ariel, 1996), pp. 139-158.

- Acercamiento al babla de Villadepera de Sayago (Salamanca: Universidad de Salamanca, 1973, [Memoria de Licenciatura inédita]).

- Encuesta en Villardiegua de la Ribera (Zamora) para el Atlas Lingüístico de España y Portugal (Madrid: Departamento de Geografía Lingüística, 1975 [inédita]). 
- La situación sociolingüistica de una comunidad rural (Villadepera de Sayago) (Salamanca: Universidad de Salamanca, 1978 [Tesis Doctoral]), pp. 377-515 inéditas.

- Norma y dialecto en el sayagués actual (Salamanca: Eds. Universidad de Salamanca, 1983).

- Sociolingüistica rural. Investigación en Villadepera de Sayago (Salamanca: Eds. Universidad de Salamanca, 1981).

BUSTOS GISBERT, EUGENIO DE, "Las variedades dialectales y regionales en Castilla y León", en VVAA (coord. de la Junta de Castilla y León), Castilla y León (Madrid: Eds. Anaya, 1987), pp. 338-353.

CABAÑAS, CARLOS, "Aproximación al dialecto leonés de Zamora ciudad", Anuario 1985 del Instituto de Estudios Zamoranos "Florián de Ocampo" (Zamora, 1986), pp. 663-706.

Calvo Calvo, L., "Fritz Krüger y los filólogos del Seminario de Lengua y Cultura Románicas de la Universidad de Hamburgo. Sus aportaciones a la etnografía peninsular", RDTP, XLVI (1991), pp. 349-361.

Carnero felipe, Ramón Manuel, Historia, leyendas y costumbres de Pereruela de Sayago, (Zamora: Edición del Autor, 1980).

- Pereruela de Sayago. La parroquia, la desamortización y los Docampo (Salamanca: Edición del Autor, 1984).

- Viriato, el druida guerrero (Zamora: Duero Ediciones, 1996).

CASTRO, AMÉRICO, "Adiciones hispánicas al diccionario etimológico de W. Meyer-Lübke", RFE, V (1918), pp. 21-42, VI (1919), pp. 337-345.

- "Reseña a F. Hanssen, Gramática bistórica de la Lengua Castellana, Halle, Max Niemeyer, 1913", RFE, I (1914), pp. 101-103 y 181-184.

- Contribución al dialecto leonés de Zamora (Madrid, 1913).

Catalán, D. y Galmés, A., "La diptongación en leonés”, Archivum, IV (1954), pp. 87-147.

CATALÁN, Diego, Lingüística Íbero-románica (Madrid: Gredos, 1974).

CEBALlos JimÉnEZ, ANDRÉs, Diccionario ilustrado de los nombres vernáculos de las plantas en España (Madrid: ICONA, 1986).

CORTÉs VÁZQUEZ, LUIS, "Alfarería femenina en Moveros (Zamora)", Zephyrus, IX (1958), pp. $95-107$.

- "Dos textos dialectales de Rihonor y dos romances portugueses de Hermisende", Miscelánea de Filologia, Literatura e Historia cultural á memoria de Francisco Adolfo Coelho (Lisboa, 1949-1950), t. II, pp. 388-403.

- "El pisón de la Salina en Trefacio (Sanabria)", RDTP, XII (1956), pp. 419-427.

- "La alfarería en Pereruela (Zamora)", Zephyrus, V (1954), pp. 141-163.

- "La leyenda del Lago de Sanabria", RDTP, IV (1948), pp. 94-114.

- "Las alfarerías femeninas", Narria, 20 (1980), pp. 10-13.

- "Los últimos batanes de Sayago (Zamora)", In Memoriam António Jorge Dias (Lisboa: Instituto de Alta Cultura, Junta de Investigações do Ultramar, 1974 [III]), pp. 375-392.

- "Sobre el proyecto de realización del Atlas Lingüistico y Etnográfico de Sanabria", Actas y Memorias del VII Congreso Internacional de Lingüistica Románica, 7-10 de abril de 1953, (Barcelona, 1955), Tomo II, pp. 635-645.

- "Veinte cuentos populares sanabreses", RDTP, V (1949), pp. 201-270.

- Alfarería popular del Reino de León (Salamanca: Librería Cervantes, 1987).

- Donde Sayago termina... Fermoselle (Salamanca: Librería Cervantes, 1995 [2.]; Librería Cervantes, $\left.1981\left[{ }^{2}{ }^{a}\right]\right)$.

- El dialecto galaico-portugués hablado en Lubián (Zamora). Toponimia, textos y vocabulario (Salamanca: Acta Salmanticensia, Universidad de Salamanca, 1954). 
- Leyendas, cuentos y romances de Sanabria. Textos leoneses y gallegos (Salamanca: Librería Cervantes, 1992 [3.․]; Salamanca: Librería Cervantes, 1976 [1.a], 1981 [2.a]).

- Obra dispersa de etnografía (Salamanca: Centro de Cultura Tradicional-Diputación de Salamanca, Caja España, 1996).

CuRTo LóPEZ, M. ${ }^{a}$ RosA, Nuevas aportaciones dialectales al habla de la Tierra de Aliste (Valladolid: Universidad de Valladolid, 1973 [Memoria de Licenciatura inédita]).

Dias, Jorge y De Carvalho, J. Herculano, “O falar de Rio de Onor", Biblos, XXX (1954), pp. 191-244.

DiAS, JoRge, Rio de Onor. Comunitarismo agro-pastoril, (Lisboa: Ed. Presença, 1984 [3.']; Lisboa, 1953 [1. $\left.{ }^{\mathrm{a}}\right]$ ).

ElizAincín, AdOLFO, Dialectos en contacto (español y portugués en España y América) (Montevideo: Ed. Arca, 1992).

FERNÁNDEZ DURO, CESÁREO, "Locuciones zamoranas", El Averiguador Universal, Año I, núm. 7 (1879), pp. 89-90.

- "Locuciones zamoranas", Memorias bistóricas de la ciudad de Zamora, su provincia y obispado (Madrid, 1882-1883), t. 4, pp. 468-476.

FERNÁNDEZ RAmOS, ANGÉliCA, Estudio y textos del Romancero de Peleagonzalo (Zamora: Instituto de Estudios Zamoranos "Florián de Ocampo"-Diputación de Zamora, 1990).

FERNÁNDeZ ReI, F., "Textos do galego exterior: Piantón (A Veiga-Oviedo), Paradaseca do Bierzo (León) e Lubián (Zamora). Caracterización lingüística", Homenaje a Álvaro Galmés de Fuentes, I, (Madrid: Universidad de Oviedo/Gredos, 1985), pp. 171-197.

FERNÁNDEZ-ORDOÑEZ, INÉs, "Isoglosas internas del castellano. El sistema referencial del pronombre átono de tercera persona", RFE, LXXIV (1994), pp. 71-125.

Ferrero Domínguez, M. A., Palabras, frases $y$ "dichos" de la Tierra de Aliste (Zamora: Instituto Geográfico Catastral, 1992, [2..$\left.^{\mathrm{a}}\right]$ ).

GABAUdAN, PAULETTE, "Introducción", en LuIS CORTÉS VÁzQUEZ, Obra dispersa de etnografía, pp. XIII-LVI.

García CABAllero, A., Localismos (Valladolid: Castilla Ediciones, 1992).

GarCía CALVO, AguSTín, Manifiesto de la comuna antinacionalista zamorana (Madrid: Editorial Lucina, 1987 [5. a]; París, 1970 [1.]]; Madrid: La Banda de Moebius, 1976 [2.] $] 1977$ [3.a], 1978 [4. []).

GARCía DE Diego, ViCENTE, "Fritz Krüger (1889-1974)", RDTP, XXX (1974), pp. 559-561.

- Manual de Dialectología Española (Madrid: Ediciones Cultura Hispánica del Centro Iberoamericano de Cooperación, 1946/78 [3.a]).

GarCía LóPEZ, DAvid, "Difusión del yeísmo asturleonés en La Carballeda (Zamora)", Lletres Asturianes 61 (1996), pp. 33-40.

- "Buena jera!", La Opinión-El Correo de Zamora (12-IV-96).

- Estudio sobre el habla de La Carballeda y La Requejada (Zamora). Monografía leonesa, (Salamanca: Universidad de Salamanca, 1996 [Memoria de Licenciatura inédita]).

- Estudio sobre el habla de Porto (Zamora) (Salamanca: Departamento de Lengua Española de la Facultad de Filología de la Universidad de Salamanca, año académico 1994/1995 [trabajo de clase inédito dirigido por el profesor Alexandre Rodríguez en la asignatura Galaicoportugués]).

García MAlmierca, M. ${ }^{a}$ VICTORIA, La comunidad de Bóveda de Toro: su situación lingüistica actual (Salamanca:, Universidad de Salamanca [Tesis Doctoral inédita en proceso de elaboración]).

GaRCía, CONSTANTINo et alii, Atlas Lingüístico Galego (ALGa). I.1-2. Morfología verbal. II. Morfología no verbal (Santiago de Compostela: Instituto da Lingua Galega- 
Universidade de Santiago de Compostela, Fundación "Pedro Barrié de la Maza, Conde de Fenosa", 1990-1996).

GONZÁlez FERrero, JuAN CARLOS, "Las actitudes sociolingüísticas de una comunidad castellanoleonesa de carácter semiurbano: Toro (Zamora)», Anuario 1989 del Instituto de Estudios Zamoranos "Florián de Ocampo" (Zamora, 1991), pp. 663-706.

- "Rasgos occidentales del habla de Toro (Zamora)", Studia Zamorensia, XI (1990), pp. $57-84$.

- "Vocabulario tradicional de la vid y el vino en el habla de Toro. Su carácter dialectal", Anuario 1985 del Instituto de Estudios Zamoranos "Florián de Ocampo" (Zamora, 1986), pp. 265-282.

- El habla de Flores de Aliste. Materiales inéditos, Inédito.

- Esbozo de un estudio lingüistico de una comunidad alistana (Flores de Aliste) (Salamanca: Universidad de Salamanca, 1984 [Memoria de Licenciatura]).

- Estudio sociolingüistico del habla de Toro (Zamora) (Salamanca: 'Universidad de Salamanca, 1989 [Tesis Doctoral]), pp. 192-743 parcialmente inéditis.

- La estratificación sociolingüística de una comunidad semiurbana: Toro (Zamora) (Salamanca: Eds. Universidad de Salamanca, 1991).

- Nombres del arado en la provincia de Zamora, inédito.

- Palabras y expresiones en el habla de Toro (Zamora) (Toro: Colectivo Cultural "Bardales", 1990).

- Sociolingüística y variación dialectal. Estudio del habla de Flores de Aliste (Zamora: Instituto de Estudios Zamoranos "Florián de Ocampo" (CSIC), Diputación de Zamora, 1986).

- Variables sociolingüísticas en el habla de Toro (Zamora) (Zamora: Instituto de Estudios Zamoranos "Florián de Ocampo" (CSIC)-Diputación de Zamora, 1997).

GRANDA GUTIÉRREZ, GERMÁN DE et alii, "Los diptongos descendentes en el dominio románico leonés", Trabajos sobre el Dominio Románico Leonés, II (1960), pp. 119-173.

GRANDA GuTIÉRREZ, GERMÁN DE, "Las vocales finales del dialecto leonés", Trabajos sobre el Dominio Románico Leonés, II (1960), pp. 27-117.

HERnÁNDEZ ALONSO, CÉSAR, "Castilla la Vieja”, en Manuel Alvar (director), Manual de dialectología hispánica. El español de España (Barcelona: Ed. Ariel, 1996), pp. 197-212.

HERNÁNDEZ GARCía, MARÍA, Estudio sociolingüístico. El babla de la comarca de Toro en su zona Norte (Valladolid, Universidad de Valladolid, año académico 1994/1995, [trabajo de clase inédito dirigido por el Dr. D. César Hernández]).

KrÜGer, FritZ y Ebeling, W., "La castaña en el Noroeste de la Península Ibérica", Anales del Instituto de Lingüistica, V (Mendoza [Argentina]: Universidad Nacional de Cuyo, 1952), pp. 155-288.

KRÜGER, FRITZ, "Aportes a la fonética dialectal de Sanabria y de sus zonas colindantes", RFE, XIVIII (1965), pp. 251-282.

- "Contribuciones a la Geografía léxica del NO. de la Península", RDTP, XIII (1957), pp. 3-23.

- "Cosas y palabras del Noroeste Ibérico", Nueva Revista de Filología Hispánica, IV (1950), pp. 231-253.

- "El perfecto de los verbos -ar en los dialectos de Sanabria y de sus zonas colindantes", RFE, XXXVIII (1954), pp. 45-82.

- "Los adverbios lejos y luego en perspectiva dialectal", Homenaje dedicado al Dr. Rodolfo Oroz (Santiago de Chile, 1967), pp. 251-282.

- "Mezcla de dialectos", Homenaje a Menéndez Pidal (Madrid, 1925), II, pp. 121-166. 
- "Vocablos y cosas de Sanabria", RFE, X (1923), pp. 153-166.

- El dialecto de San Ciprián de Sanabria (Madrid: Anejo IV de la RFE, 1923).

- El léxico rural del Noroeste Ibérico (Madrid: Anejo XXXVI de la RFE, 1947). Traducción a cargo de Emilio de Lorenzo del original "Die nordwest-iberische Volkskultur", en Wörter und Sachen, 1927.

- La cultura popular en Sanabria (Zamora: Consorcio de Fomento Musical, Instituto de Estudios Zamoranos "Florián de Ocampo" (CSIC)-Diputación de Zamora, Caja España, 1991). Traducción de Christiane Blanck-Conrady del original alemán Die Gegenstandskultur Sanabrias und seiner Nachbargebeite (Universidad de Hamburgo, 1925).

- Studien zur Lautgeschichte westpanischer Mundarten auf Grund von Untersuchungen an Ort un Stelle (Hamburgo: Lüchte \& Wulff, 1914; Jabrbuch der Hamburgischen Wissenschaftlichen Anstalten, Bd. XXXI [1913]).

LEITE DE VASCONCELLOS, J., "Breve estudo dos falares de Riodonor e Guadramil", Opúsculos t. IV, Filología, II, (Coimbra, 1929/1938), pp. 739-790.

- "Linguagem de Ermisende", Revista Lusitana, VII (1902). Cito este artículo por "Linguagens fronteiriças de Hespanha e Portugal", Opúsculos t. IV, Filología, II (Coimbra, 1929/1938), pp. 593-619.

- "Linguagens Fronteiriças", Revista Lusitana, XXXIII (1935), pp. 307-309.

- "Linguas raianas de Trás-os-Montes", Revista de Guimarães, III (1886), pp. 61 y ss. Cito este artículo por Opúsculos t. IV, Filología, II (Coimbra, 1929/1938), pp. 723-738.

- "Noticia do idioma de Rio de Onor", Lições de Filologia (Rio de Janeiro, 1959 [3. ${ }^{a]}$ ), pp. 417-418. Anteriormente en Lições de Filologia (Lisboa, 1926 (2. ${ }^{\mathrm{a}}$ ), pp. 453-454.

- Esquisse d'une dialectologie portugaise (París: Aillaud \& Cie., 1901).

- Estudos de philologia mirandesa, I y II (Lisboa: Imprensa Nacional, 1900/1901).

LlORENTE MALDONADO DE GueVARA, ANTONIO, "Algunas denominaciones de las formas y de las orientaciones del terreno en Zamora, Salamanca y Ávilan, Scripta Pbilologica in Honorem Juan M. Lope Blanch. II (Méjico: Universidad Nacional Autónoma de Méjico, 1992), pp. 145-162.

- "Las denominaciones correspondientes a las lexías de la lengua estándar arroyo, torrentera, manantial y terreno pantanoso en Zamora, Salamanca y Ávilan, I, RFE, LXIX (1989), pp. 253-275; II, RFE, LXX (1990), pp. 71-89.

- "Las denominaciones de la losa o lancha en las provincias de Zamora, Salamanca y Ávila", RDTP, XLIII (1988), pp. 365-377.

- "Las denominaciones del camino de ganado en las provincias de Zamora, Salamanca y Ávilan, Homenaje al Profesor Luis Rubio. II, Estudios Románicos, Vol. 5 (Murcia: Universidad de Murcia, 1987/88/89), pp. 797-805.

- "Las hablas vivas de Zamora y Salamanca en la actualidad", en M. Alvar, Lenguas peninsulares y proyección bispánica (Madrid: Fundación Friedrich Ebert, Instituto de Cooperación Iberoamericana, 1986), pp. 107-131.

- Encuestas sobre Zamora para el Atlas Lingüistico de España y Portugal (Madrid: Departamento de Geografía Lingüística, inéditas).

LÓPEZ, L. y GODINO, A., "Notas y testimonios sobre un manojo de términos vigentes en el habla de Villalpando", Anuario 1994 (Zamora: Instituto de Estudios Zamoranos "Florián de Ocampo", 1995), pp. 533-556.

LOSA ESPAÑA, T. M., Contribución al estudio de la flora y vegetación de la provincia de Zamora (Madrid: CSIC, Instituto A. J. Cavanilles).

MARTín CARBAJO, Miguel ÁNGEL, “El arado y el carro en un pueblo del NW zamorano, Brandilanes de Aliste», Revista de Folklore, núm. 118 (1990), pp. 111-119. 
MENÉNDEZ PIDAL, R., El dialecto leonés (Oviedo: Instituto de Estudios Asturianos, 1906/62 [2. ${ }^{a}$; $R A B M, \mathrm{X}\left[1906,1{ }^{\mathrm{a}}\right.$ ]; León: Diputación Provincial de León, 1990 [3:a]).

Miguélez Rodríguez, Eugenio, Diccionario de las hablas leonesas (León, Salamanca, Zamora) (León: Edición del Autor, 1993).

MOLINERO LOZANO, MANUEL, "Algunas voces de Zamora", RDTP, XVII (1961), pp. 180-184, 548-557, y XVIII (1961), pp. 523-528.

Moura SANTOS, M. J., Os falares fronteiriços de Trás-os-Montes (Coimbra: Facultade de Letras da Universidade de Coimbra, 1967).

Navarro Tomás, T. (director), Atlas lingüistico de la Peninsula Ibérica (ALPI), I, Fonética, 1 (Madrid: CSIC, 1962).

PÉREZ PASCUAL, J. I., "La aportación de F. Krüger a los estudios filológicos sobre Zamora", Studia Zamorensia, 2 (1981), pp. 333-337.

REGUERAS, IGNACIO, "Denominaciones locales de diferentes especies zoológicas en la provincia de Zamora", Anuario 1985 del Instituto de Estudios Zamoranos "Florián de Ocampo" (Zamora, 1986), pp. 107-113.

Rivas Blanco, José, Aliste visto desde Rabanales (Zamora: Ayuntamiento de Rabanales, Diputación de Zamora, Caja de Zamora, Caja Rural de Zamora, 1986).

Rivera LozANo, MANuel, Fermoselle (Zamora: Edición del Autor, 1982).

Rodríguez Lago, M. ${ }^{a}$ CARMen, Léxico dialectal y costumbres de Porto (Santiago de Compostela: Facultade de Filosofía e Letras da Universidade de Santiago de Compostela, 1974, [Memoria de Licenciatura inédita]).

RODRIGO LÓPEZ, M. C., "Aspectos del dialecto leonés hablado en Aliste (Zamora)", Trabajos sobre el Dominio Románico Leonés, I (1957), pp. 129-142.

RODRIGUES, DANIEL JOSÉ, "O Riodonorense (Dialecto Transmontano)", en O Riodonorense. Lendas. Folclore (Ediçao da Assembleia Distrital de Bragança, 1981 [2. ${ }^{\text {a] }}$ ), pp. 11-31. Publicado anteriormente en O Instituto, LV (Coimbra, 1909), pp. 559-576.

Rodríguez FERnÁNDEZ, GREGorio, Imagen y memoria de Aliste (León: Edición del Autor, 1997).

- Paisaje y alma de Aliste, (León: Edición del Autor, 1992 [2.]; León: Edición del Autor, $\left.1991\left[1 .{ }^{\mathrm{a}}\right]\right)$.

RodríGUEZ IGLESIAS, J. M., "Vocabulario de Terroso y San Martín del Terroso (Sanabria)", en Los lenguajes culturales de un municipio sanabrés (Terroso y San Martín del Terroso) (Salamanca: Facultad de Filosofía de la Universidad Pontificia de Salamanca, 1991 [Tesis Doctoral inédita]), pp. 682-704.

Rodríguez Pascual, Francisco, "A ti la jaquetona", La Opinión-El Correo de Zamora (19-VI-95).

- "No seas cuzo!n, La Opinión-El Correo de Zamora (5-X-95).

- "El cibiaco", La Opinión-El Correo de Zamora (11-VI-96).

- "Morgado", La Opinión-El Correo de Zamora (18-III-96).

- "Por riles", La Opinión-El Correo de Zamora (1-III-96).

- "LLuciérnaga o cagaluz?, La Opinión-El Correo de Zamora (12-IV-96).

Rodríguez Peláez, Nicolás, "Palabras y modismos de la Tierra de Alba", El Correo de Zamora, I (3-X-91), II (10-X-91).

SANTOS Río, LuIs, Aproximación sociolingüística al babla de Sarracín de Aliste (Salamanca: Universidad de Salamanca, 1973 [Memoria de Licenciatura inédita]).

TURIÑo MínguEZ, ÁNGEL, Tradiciones y añoranzas de un pueblo de Zamora: Pajares de la Lampreana (Madrid: Edición del Autor, 1988). 
VEGA, PEDRO, "La cultura popular en Sanabria. Una aportación fundamental al estudio etnográfico-lingüista", Anuario 1993 del Instituto de Estudios Zamoranos "Florián de Ocampo" (Zamora, 1995), pp. 357-368.

YNDURÁIN, FRANCISCO, "Notas sobre el habla de Benavente (Zamora)", RDTP, XXXII (1976), pp. 567-577.

ZAMORA VICENTE, Alonso, Dialectología Española (Madrid: Gredos, 1967/79 [2..]; Madrid: Gredos, $\left.1960\left[10^{\mathrm{a}}\right]\right)$.

\section{JuAN CARLOS GonZÁLEZ FerRero}

Este artículo tiene por objeto la descripción de la actividad dialectológica desplegada en la provincia de Zamora a lo largo de los últimos cien años. Distinguimos tres períodos en la evolución de esta investigación dialectal, desde finales del siglo XIX y a lo largo del xx: un primer período, que abarcaría el último cuarto del siglo xIX y el primer tercio del xx (1879-1936); un segundo período, que comprendería aproximadamente el segundo tercio del siglo xx (1936-1973); y un tercer período, formado por el último tercio del siglo xx (1973-1995). En cada una de estas etapas nos ocupamos de los distintos trabajos realizados, en relación con los cuales exponemos sus objetivos, métodos, contenidos y resultados. Al final del artículo llevamos a cabo una valoración prospectiva de esta actividad dialectológica, de manera que, tomando como base la descripción efectuada, intentamos señalar las líneas de actuación que a nuestro juicio han de seguir los futuros estudios dialectales sobre la provincia de Zamora.

This article aims to describe the dialectological studies carried out in the province of Zamora, Spain, over the past hundred years. We distinguish three periods in the evolution of these studies from the late 19th century to the present: (1) from 1879 through 1936, (2) from 1936 through 1973 and (3) from 1973 through 1995. For each of these periods we discuss the different research projects undertaken, their objectives, methods, materials and results. In the last part of the article we make a prospective evaluation of this dialectological endeavor; in addition, on the basis of our discussion, we suggest the lines of research that these studies should follow in the future. 